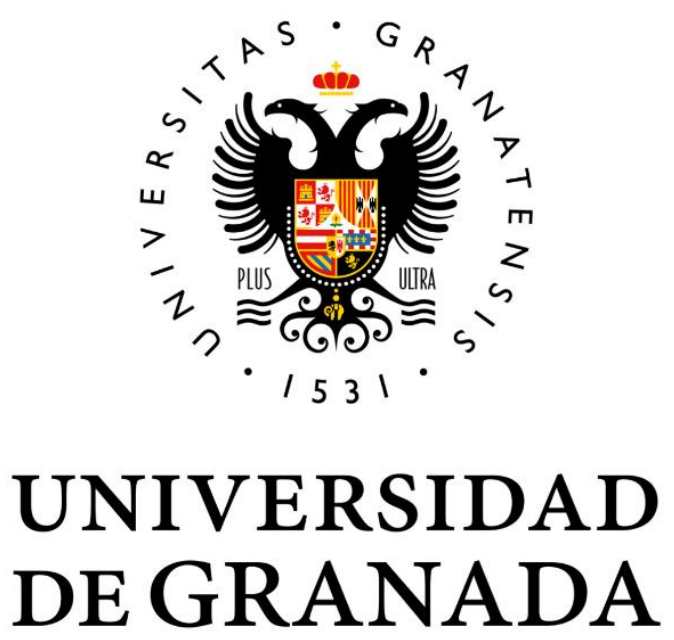

Máster en Didáctica de la Matemática

Departamento de Didáctica de la Matemática

Curso 2020/2021

Trabajo Fin de Máster

\title{
SENTIDO ESPACIAL EN LAS EVALUACIONES ESCRITAS EN SECUNDARIA
}

María Isabel Elvas Fernández

Granada, 2021 


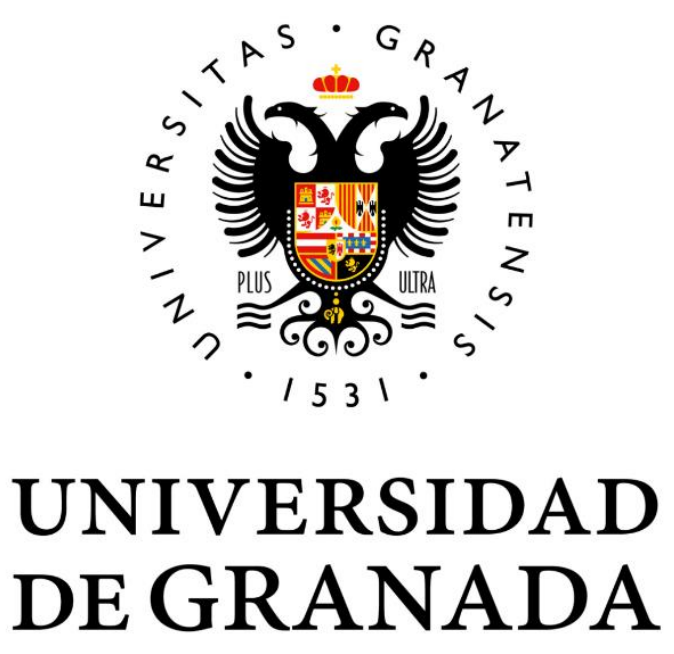

\author{
Máster en Didáctica de la Matemática
}

Departamento de Didáctica de la Matemática

Curso 2020/2021

Trabajo Fin de Máster

Sentido espacial en las evaluaciones escritas en secundaria

Presentado por
D. ${ }^{\text {a }}$ María Isabel Elvas Fernández

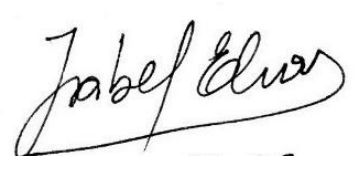

Fdo.: D. ${ }^{a}$ María Isabel Elvas Fernández

\author{
Dirigido por \\ Dr. D. Pablo Flores Martínez
}

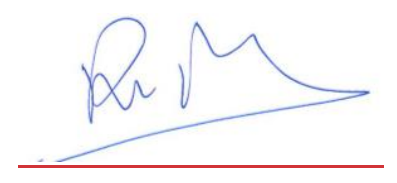




\section{ÍNDICE}

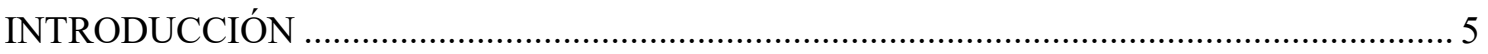

CAPÍTULO 1. JUSTIFICACIÓN Y DETERMINACIÓN DEL PROBLEMA DE

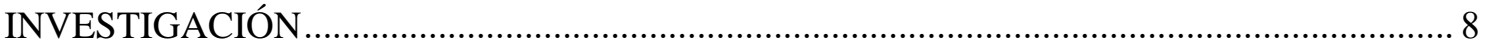

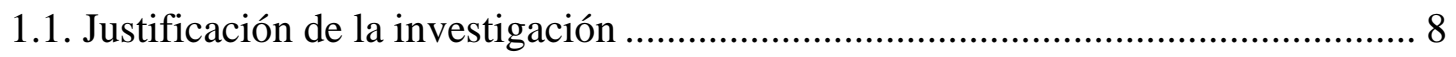

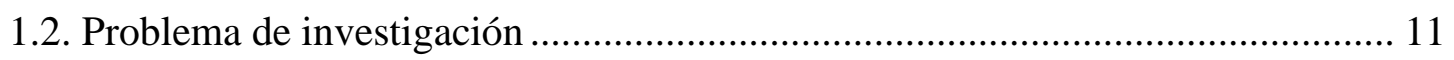

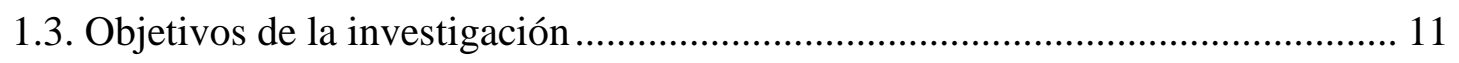

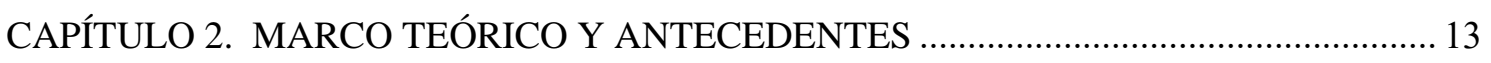

2.1. Evaluación en educación matemática ..................................................................... 13

2.1.1. Evaluación y pruebas en educación matemática ........................................... 14

2.1.2. Objetivos de la evaluación matemática ......................................................... 16

2.1.3. Componentes de la evaluación ................................................................ 17

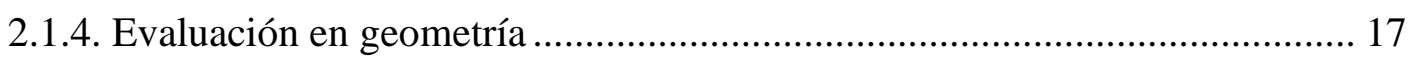

2.1.5. El contexto y el enunciado en las actividades de evaluación ........................ 18

2.1.6. Tipologías de las actividades de evaluación .............................................. 18

2.1.7. La demanda cognitiva en las actividades de evaluación ............................. 19

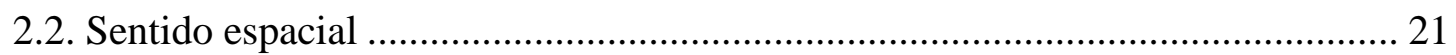

2.2.1. Antecedentes del sentido espacial .......................................................... 21

2.2.2. Componentes y habilidades del sentido espacial ........................................ 25

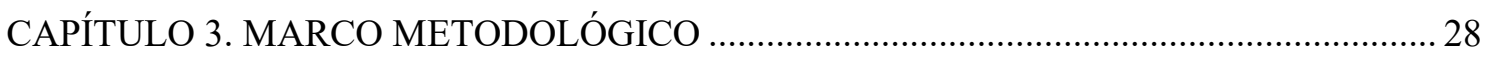

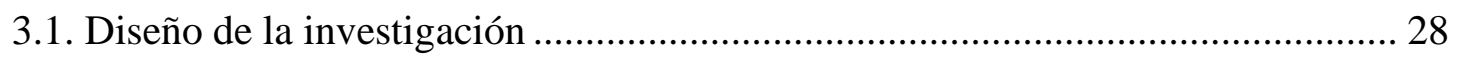

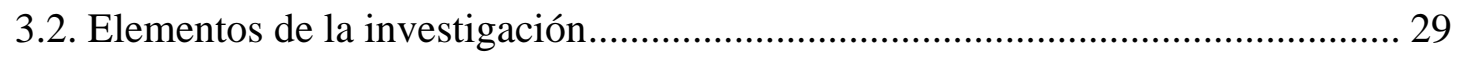

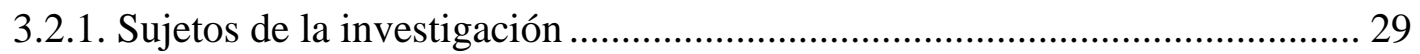

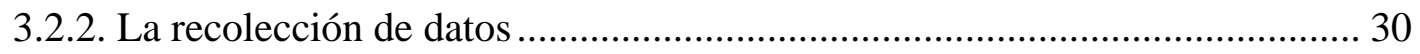

3.2.3. Determinación de las categorías de análisis .............................................. 31

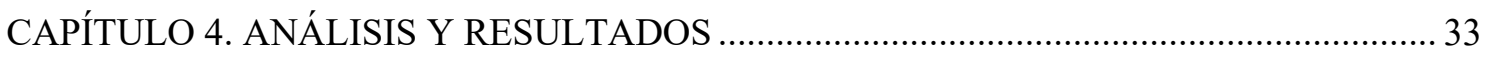

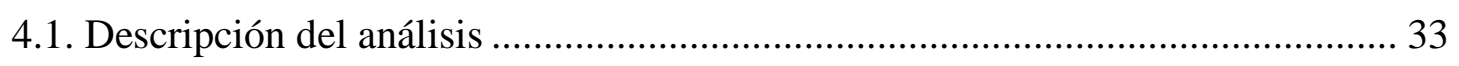

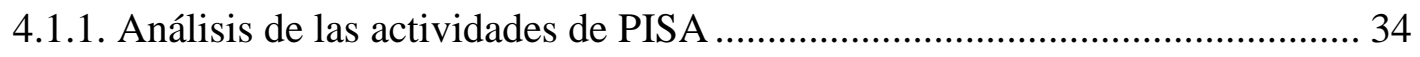

4.1.2. Análisis de las actividades de aula ............................................................... 37

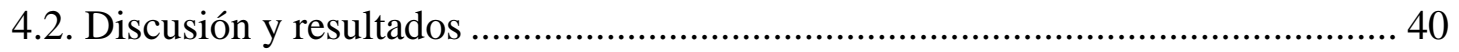

4.2.1. Resultados de las actividades de PISA....................................................... 41

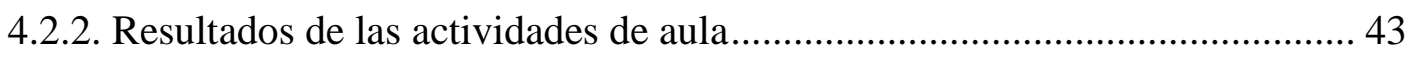


4.2.3. Resultados de las actividades de evaluación en geometría ........................... 46

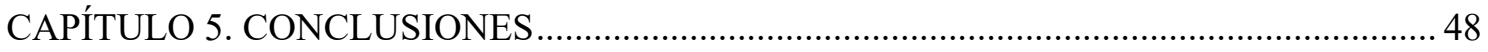

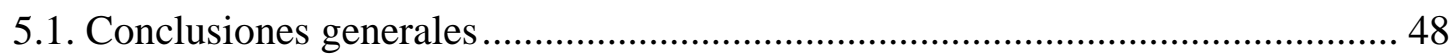

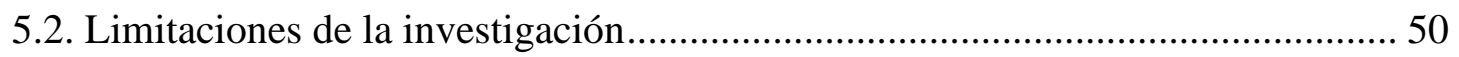

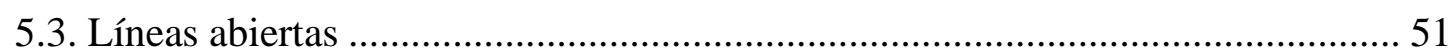

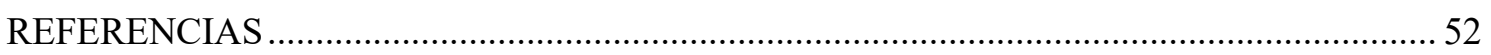

ANEXO A. ACTIVIDADES SELECCIONADAS ….......................................................... 1

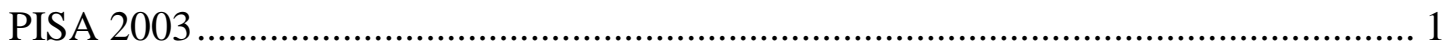

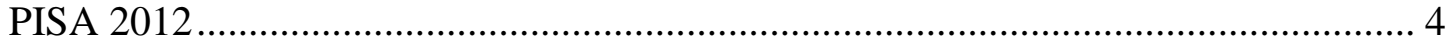

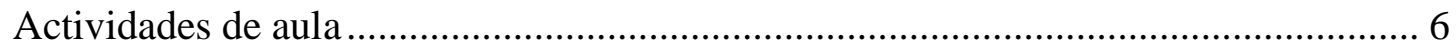

ANEXO B. RESOLUCIÓN DE ACTIVIDADES SELECCIONADAS …................................. 9

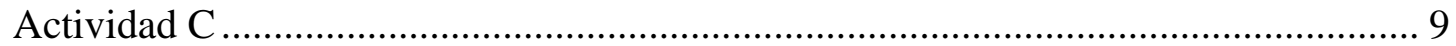

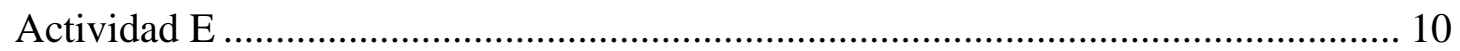

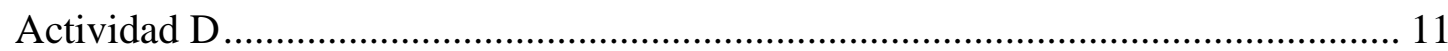

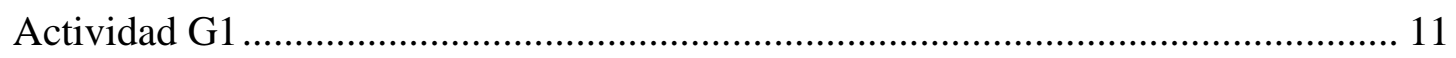

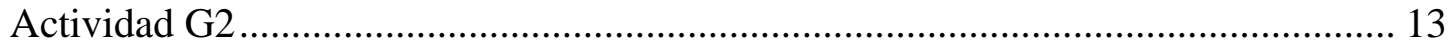

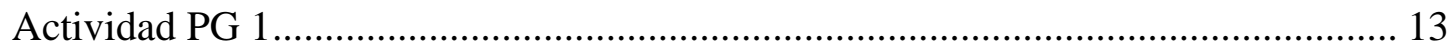

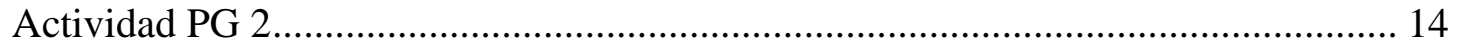

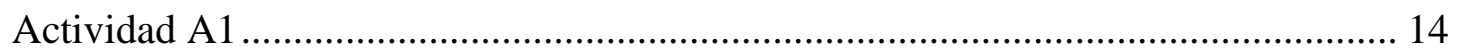

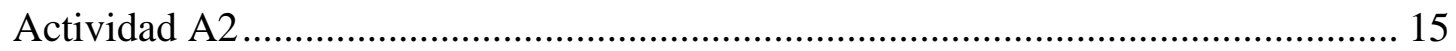

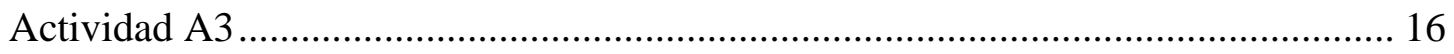

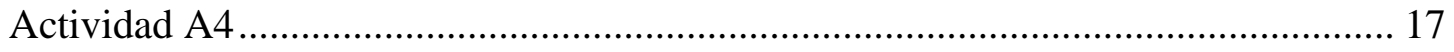

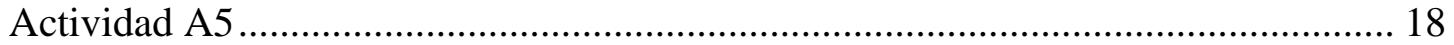

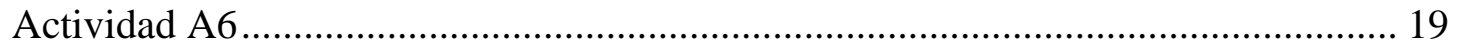

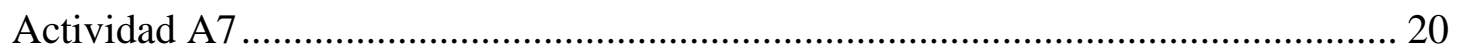

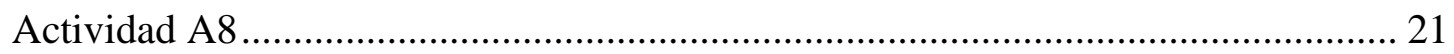

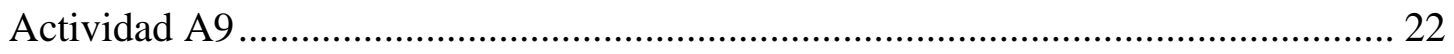

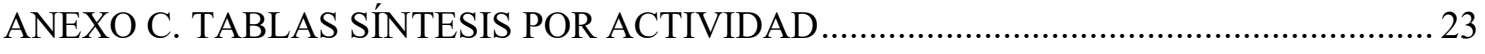

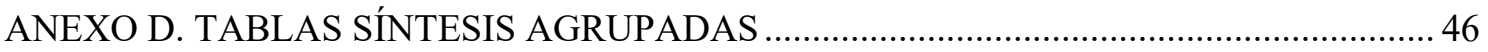




\section{INTRODUCCIÓN}

Este documento responde al trabajo fin de máster exigido como requisito de la Maestría en Didáctica de la Matemática de la Universidad de Granada, del curso 2020/2021 y consiste en una investigación educativa sobre las pruebas que se realizan para evaluar el aprendizaje geométrico, para ver cómo reflejan el aprendizaje funcional o sentido espacial los estudiantes de primer año de bachillerato uruguayo.

Los motivos que justifican la investigación son principalmente dos: el interés derivado de la actuación docente y los bajos resultados obtenidos por Uruguay en la evaluación de la OCDE/PISA (Programme for International Student Assessment). He ejercido la profesión docente en los distintos cursos de secundaria básica y en los últimos años particularmente en bachillerato, tanto en instituciones públicas como privadas, constatando la diversidad de criterios en los docentes a la hora de medir los aprendizajes de los alumnos a través de las pruebas escritas.

En cuanto a los resultados en PISA, el estudiante uruguayo promedio accede al nivel 1 de desempeño, de los seis niveles definidos en orden creciente de puntajes, de este modo es capaz de responder a preguntas que involucran contextos familiares donde la información está toda presente y las preguntas están bien definidas.

Se agrega la sospecha de que los profesores no se sienten cómodos con PISA, las reacciones y resonancias en los colectivos docentes han sido diferentes ante las mediciones y la publicación de los resultados de PISA después del 2003, año en que Uruguay participa por primera vez de un estudio internacional de aprendizajes de los estudiantes (ANEP, 2004) y luego del 2012, donde en ambas mediciones el dominio fue la cultura matemática.

Uno de los aportes para los docentes de un país al participar en una evaluación como PISA, puede ser "provocar la reflexión y el análisis crítico acerca de qué estamos enseñando, cómo lo estamos haciendo, qué esperamos que nuestros estudiantes sean capaces de hacer y cómo los evaluamos" (ANEP, 2004, p.3). Sin embargo, pareciera que hubiera cierto descrédito por parte de los docentes en relación con los resultados 
obtenidos, en tanto que el formato de las actividades planteadas en PISA difiere de las propuestas por los docentes en el aula, por lo cual queda cuestionado que sean un instrumento eficaz para medir los aprendizajes de los alumnos uruguayos.

Los docentes por su parte responden a los lineamientos que aparecen en los programas oficiales de matemática en secundaria, que en torno a geometría expresan la importancia del "planteamiento de problemas que permitan construcciones geométricas" (CES, 2010a, p.4), un tratamiento experimental de las figuras y sus relaciones que permita argumentar, conjeturar y justificar situaciones geométricas, además de escribir adecuadamente los algoritmos de construcción. Una cultura de la enseñanza que dista de la resolución de problemas a partir del contexto y la realidad inmediata del alumno (OECD, 2003).

OCDE/PISA define la competencia matemática como la capacidad de una persona "para identificar y comprender el papel que desempeñan las matemáticas en el mundo, emitir juicios bien fundados, utilizar las matemáticas y comprometerse con ellas, y satisfacer las necesidades de la vida personal como ciudadano constructivo, comprometido y reflexivo" (OECD, 2004, p. 26; OECD, 2003, p. 24). Un sentido amplio y funcional de las matemáticas enfocado al desarrollo competencial del individuo.

Con ello se reconoce que el estudio de la geometría, en concreto, proporciona al individuo una forma de ubicarse en el entorno que lo rodea, los elementos del espacio, sus relaciones, las dimensiones y medidas, los movimientos y los desplazamientos. La noción de sentido espacial tiene sus orígenes en el National Council of Teachers of Mathematics (1989), que el marco curricular de New Jersey en el estándar 7 referido a geometría y sentido espacial recoge:

Todos los estudiantes desarrollarán el sentido espacial y la capacidad de usar propiedades y relaciones geométricas para resolver problemas en matemáticas y en la vida cotidiana. El sentido espacial es un sentido intuitivo para la forma y el espacio. Implica los conceptos de geometría tradicional, incluyendo una habilidad para reconocer, visualizar, representar y transformar formas geométricas. La geometría está presente en el mundo que nos rodea: arte, naturaleza y las cosas que hacemos. Los estudiantes de geometría pueden aplicar su sentido espacial y conocimiento de las propiedades de las formas y del espacio en el mundo real. (New Jersey Mathematics Coalition, 1996, p. 209)

Flores, Ramírez y del Río (2015) describen el sentido espacial como una forma intuitiva de "entender el plano y el espacio, para identificar cuerpos, formas y relaciones entre ellos, que implica manejar relaciones y conceptos de geometría de forma no 
convencional, incluyendo la habilidad para reconocer, visualizar, representar y transformar formas geométricas" (pp.129-130).

Dado que las evaluaciones escritas tratan de medir aprendizajes y reflejan lo que se considera importante, queremos con esta investigación apreciar qué componentes del aprendizaje funcional de la geometría (sentido espacial), se exigen en las pruebas de aula uruguayas, con objeto de comprender qué diferencias tienen con las actividades de PISA.

El presente informe de investigación está organizado en cinco capítulos. El primero, presenta la justificación del estudio, la definición del problema y la formulación de los objetivos que se pretenden abordar. En el segundo, se revisan antecedentes y se define el marco teórico que da sustento a la investigación, en relación con el sentido espacial y la evaluación en matemáticas. El capítulo tres establece la metodología de la investigación, el diseño, naturaleza y características, los sujetos, instrumentos, los procedimientos de obtención de datos e interpretación de los mismos, incluyendo las categorías de análisis. En el siguiente, se presentan los resultados y por último se muestran las conclusiones que se extrajeron del estudio, sus limitaciones y posibles líneas que se abren a partir del mismo. 


\section{CAPÍTULO 1. JUSTIFICACIÓN Y DETERMINACIÓN DEL PROBLEMA DE INVESTIGACIÓN}

El aprendizaje de la geometría que se observa en el currículo oficial de matemáticas en la educación secundaria uruguaya enfatiza la enseñanza de los conceptos geométricos, las propiedades de las figuras, los movimientos en el plano y su correspondiente formalización. Por su parte, las actividades de PISA buscan evaluar la capacidad de los estudiantes para resolver problemas de la vida y requieren para ser superadas, desarrollar el razonamiento espacial, que en el contenido espacio y forma implica reconocer patrones y figuras, buscar diferencias y semejanzas entre los componentes de las formas, entender las propiedades y las posiciones relativas de los objetos geométricos.

\subsection{Justificación de la investigación}

La Real Academia Española define la geometría como la ciencia que estudia las propiedades de las figuras en el plano o en el espacio. Su estudio proporciona a los estudiantes una percepción profunda del mundo natural que los rodea.

La enseñanza de la geometría se desarrolla en forma progresiva en los programas oficiales propuestos por el Consejo de Educación Secundaria (CES) de la Administración Nacional de Educación Pública (ANEP) de Uruguay, utilizando los conocimientos aprendidos en primaria. Un enfoque deseable para el estudio de la geometría en el primer año del ciclo básico es "la experimentación, observación, posibles conjeturas y eventualmente una incipiente formalización" (CES, 2010a, p.4). Para el segundo año "describir, clasificar y comprender relaciones entre figuras en el plano y en el espacio, usando las propiedades que las caracterizan. Apreciar la geometría en ámbitos como el arte, la ciencia, la vida" (CES, 2010b, p.2). Mientras que para el tercer año se propicia "dedicar tiempo específico para la experimentación, la conjetura y la justificación de situaciones geométricas” (CES, 2010c, p.2).

Primero de bachillerato es considerado un año de articulación entre el ciclo básico y los cursos posteriores de bachillerato, y en él, la enseñanza de la geometría está centrada en el método de los lugares geométricos. Los conceptos de "circunferencia, círculo, 
mediatriz, bisectriz y elementos notables de un triángulo, se mencionarán en el momento que sea necesario para el tratamiento de otros temas" (CES, 2010d, p.2). En cuanto al algoritmo de resolución prevalece el cuidado por "la expresión matemática correcta" (CES, 2010d, p.2).

Los diferentes aspectos que buscan ser trabajados en los cursos de geometría en los currículos oficiales de la enseñanza secundaria uruguaya enfatizan los conceptos geométricos, las propiedades de las figuras y su correspondiente formalización. Aspectos que están considerados dentro del concepto de sentido espacial propuesto por Flores, Ramírez y del Río (2015) que asumiremos en este estudio.

Por su parte, el National Council of Teachers of Mathematics (1989), enfatiza el aspecto funcional del aprendizaje geométrico, que dirige a desarrollar el sentido espacial de los estudiantes, proponiendo con ello que cada uno de los estudiantes deba "utilizar la visualización, el razonamiento espacial y el modelado geométrico para resolver problemas".

A su vez, New Jersey Mathematics Coalition (1996) en el estándar 7, geometría y sentido espacial afirma que "todos los estudiantes desarrollarán el sentido espacial y la capacidad de usar propiedades y relaciones geométricas para resolver problemas en matemáticas y en la vida cotidiana" (p.209).

La OCDE en el proyecto PISA define el rango contenido desde una aproximación fenomenológica, es decir que describe el contenido en relación con los fenómenos y los tipos de problemas de los que surgieron (Rico, 2004, p.44). Considera los contenidos propuestos en los estándares curriculares de NTCM (2000) y en geometría define el contenido espacio y forma, relacionando el estudio de las formas con el espacio cercano y su construcción conceptual.

Por lo dicho anteriormente se puede observar cierta diferencia de énfasis entre la enseñanza de la geometría que promueve el currículo uruguayo y el enfoque funcional que pretende desarrollar el sentido espacial propuesto por el NCTM y la OCDE a través de los lineamientos de PISA.

Otro motivo que hace relevante este estudio es la diferencia entre los fines que persiguen las evaluaciones en geometría propuestas por los docentes de aula en Uruguay y los fines 
de las evaluaciones propuestos por el NCTM (1989) y por la OCDE en PISA. Las evaluaciones de los docentes se basan en algunos documentos nacionales como son: el régimen de evaluación y pasaje de grado, el Marco Curricular de Referencia Nacional (MCRN) y las orientaciones para la evaluación de los aprendizajes (2020).

La OCDE se vale de PISA para evaluar programas educativos de los países participantes. Para ello contrasta si las competencias desarrolladas por los estudiantes de 15 años de los diferentes países le permiten participar en la sociedad del saber y resolver problemas de la vida adulta. Los instrumentos de evaluación propuestos se refieren a cuestiones tales como los contenidos que deben adquirir los alumnos, los procesos que deben ser puestos en marcha o el contexto en el que los conocimientos y las competencias serán aplicados.

En el puntaje promedio obtenido en matemáticas por Uruguay en PISA se observa cierta tendencia a la baja ya que en 2003 fue 422, en 2006 y 2009 fue 427 puntos y en 2012 fueron 409 puntos. Esto significa que el estudiante promedio accede al nivel 1 de desempeño, de los seis niveles definidos en orden creciente de puntajes, de este modo el estudiante es capaz de responder a preguntas que involucran contextos familiares donde la información está toda presente y las preguntas están bien definidas.

El 44,3 \% de estudiantes accede al menos al nivel 2, considerado como el "umbral de competencia" es decir el nivel básico de competencias en las áreas evaluadas. Por tanto, el $55,7 \%$ de estudiantes uruguayos se ubican en el nivel 1 o bajo el nivel 1(que corresponde a un séptimo nivel). A su vez si miramos los resultados en el contenido espacio y forma el puntaje obtenido por Uruguay es 413 siendo el mejor puntaje promedio por área de contenido. En la Tabla 1, se muestra la distribución de porcentajes en los niveles, obtenidos en PISA 2012, destacando el contenido espacio y forma.

Tabla 1. Contenido espacio y forma: porcentaje de estudiantes por nivel de desempeño en Uruguay PISA 2012

\begin{tabular}{cccccccc}
\hline & Nivel bajo 1 & Nivel 1 & Nivel 2 & Nivel 3 & Nivel 4 & Nivel 5 & Nivel 6 \\
\hline $\begin{array}{c}\text { Espacio y forma } \\
(\%)\end{array}$ & 28,5 & 25,5 & 22,6 & 14,8 & 6,7 & 1,6 & 0,3 \\
\hline
\end{tabular}

Pues bien, es interés de esta investigación brindar elementos concretos que muestren diferencias y similitudes entre las actividades propuestas en las evaluaciones realizadas a los estudiantes en el aula y en PISA, señalando específicamente aquellos de partes que están enfocadas a apreciar el sentido espacial, con lo que preparan o se alejan de las actividades que proponen las evaluaciones de PISA en el contenido espacio y forma. 


\subsection{Problema de investigación}

A partir de los intereses planteados anteriormente que motivan este estudio, se realizan las siguientes preguntas:

- ¿Qué habilidades del sentido espacial son las más consideradas al resolver las actividades correspondientes al contenido geométrico de $1^{\circ}$ de bachillerato para alumnos de 15 años, en evaluaciones escritas de los docentes de matemáticas del estudio?

- ¿Qué habilidades del sentido espacial se evidencian mayormente a la hora de resolver actividades correspondientes al contenido espacio y forma para alumnos de 15 años, en las evaluaciones PISA del dominio de la cultura matemática?

- ¿Qué componentes geométricos del sentido espacial, se evidencian mayormente en las evaluaciones escritas de los docentes y en las evaluaciones PISA para alumnos de 15 años?

- ¿Qué aspectos son comunes y en cuáles difieren las actividades planteadas por PISA para evaluar espacio y forma, de las planteadas para evaluar el contenido geométrico de $1^{\circ}$ de bachillerato para alumnos de 15 años?

De este modo se puede considerar que el problema de investigación está centrado en analizar las actividades de evaluación planteadas para el contenido geométrico, examinando características, y especialmente, si se afronta como objetivo de la enseñanza de la geometría en Uruguay el desarrollo del sentido espacial en estudiantes de 15 años que se encuentran en su mayoría cursando $1^{\circ}$ de bachillerato, estudiando qué componentes y habilidades del sentido espacial están presentes en las actividades propuestas en las evaluaciones de algunos docentes de secundaria y las actividades referidas al contenido, espacio y forma, de las evaluaciones de PISA.

\subsection{Objetivos de la investigación}

Considerando las preguntas formuladas en el apartado anterior se plantean el objetivo general y los objetivos específicos que orientan la investigación. 
El objetivo general del estudio es: describir cuáles son los componentes del sentido espacial y los elementos que intervienen en las evaluaciones escritas de los docentes de matemáticas del estudio y en las evaluaciones PISA para los alumnos de 15 años.

Mientras que los objetivos específicos propuestos para poder abordar distintos aspectos contenidos en el anterior son los siguientes:

- O1. Determinar las componentes del sentido espacial que las evaluaciones escritas analizadas, promueven que sean aprendidas por los alumnos de 15 años.

- O2. Identificar las habilidades del sentido espacial que son utilizadas con mayor énfasis en las evaluaciones escritas analizadas por los alumnos de 15 años.

- O3. Identificar dimensiones en las que se asemejan y se diferencian las actividades planteadas en las pruebas PISA sobre geometría, con las planteadas por los profesores en el aula, para evaluar el aprendizaje geométrico. 


\section{CAPÍTULO 2. MARCO TEÓRICO Y ANTECEDENTES}

El interés de la investigación está en estudiar las diferencias y semejanzas entre las actividades de evaluación de geometría, planteadas en PISA respecto a las planteadas en una institución uruguaya. Para ello se va a diferenciar estas actividades atendiendo a dos dimensiones, su contenido, y los aprendizajes y destrezas requeridos para resolverlas.

La primera parte requiere buscar criterios para analizar las actividades. La segunda está encaminada a analizar el desarrollo del sentido espacial en los estudiantes de 15 años a través de las actividades propuestas en dos tipos de evaluaciones, las elaboradas por docentes de aula y las que aparecen en las pruebas estandarizadas PISA.

Para ello vamos a desarrollar aspectos teóricos referidos a dos elementos: evaluación en matemáticas y actividades de evaluación, y sentido espacial.

De este modo adquiere sentido revisar los aportes de las investigaciones referidas al desarrollo del sentido espacial o aquellas denominaciones que engloba, ya que el concepto lo acuñan los autores de los estándares curriculares y de evaluación de 1989 (Wheatley, 1990). Además, se presenta la revisión de los resultados provenientes de los estudios vinculados con la evaluación en matemáticas y en particular en geometría.

\subsection{Evaluación en educación matemática}

Dado que la investigación se centra en comparar las actividades propuestas en las evaluaciones de algunos docentes de secundaria y las actividades referidas a espacio y forma de las evaluaciones de PISA, será de nuestro interés profundizar en la evaluación en educación matemática.

La publicación "Investigations into assessment in mathematics education" (Niss, 1993) es el producto de una conferencia ICMI (International Commission of Mathematical Instruction) sobre valoración, tenida en España en 1992. A partir de los aportes realizados por Niss y Webb se establece el concepto, los objetivos y los componentes de evaluación en educación matemática. Asimismo, revisaremos el concepto de evaluación que 
presentan los estándares curriculares (NCTM), PISA y documentos de educación secundaria de Uruguay.

En el entendido que las evaluaciones de aula y de PISA consideradas en este estudio, están constituidas por actividades matemáticas, específicamente de geometría, se distingue entre ejercicio y problema; se considera el contexto y los datos que aparecen en el enunciado; además se establecen los niveles de demanda cognitiva con los que se medirán estas actividades.

\subsubsection{Evaluación y pruebas en educación matemática}

Niss (1993) distingue entre valoración y evaluación en educación matemática. La primera refiere al juicio de la capacidad, el desempeño y el logro matemáticos de los estudiantes, como individuos o grupos. Mientras que por evaluación en matemática considera el juicio de los sistemas educativos sobre la enseñanza de la matemática, por tanto, puede referirse a componentes del sistema como currículos, programas, profesores entre otros.

Para Niss (1993), las pruebas y los exámenes se podrían considerar en ambas categorías. Cuando juzgan el desempeño de los estudiantes, son formas especiales de valoración; y cuando se utilizan como indicadores de la calidad del subsistema educativo, como es el caso de las comparaciones de desempeño internacionales, pertenecen al ámbito de la evaluación.

Webb (1993) entiende la evaluación como la recopilación de datos e información con el fin de describir el nivel de conocimiento, desempeño o logro de un individuo o grupo dentro de las matemáticas o en su aplicación. En particular, una prueba ayuda a estandarizar condiciones para hacer inferencias sobre individuos y grupos en una situación bien determinada.

El NCTM (2000) brinda orientación para tomar decisiones en las matemáticas escolares y sobre la evaluación afirma que debe apoyar el aprendizaje de las matemáticas significativas y proporcionar información útil tanto a los profesores como a los estudiantes.

Por su parte, PISA valora el grado de desarrollo de competencia en los estudiantes en cada área evaluada. En el caso de matemáticas define seis niveles para determinar la variación del desempeño estudiantil, y establece el Nivel 2 como el "umbral de 
competencia" en el área correspondiente, aquel que le permitirá al joven seguir aprendiendo para incorporarse de manera efectiva y productiva en la sociedad. Asume el concepto de competencia propuesto por la OCDE, como la "capacidad de los estudiantes para aplicar los conocimientos y habilidades en contexto, y para analizar, razonar y comunicarse de manera efectiva al identificar, interpretar y resolver problemas en una variedad de situaciones" (ANEP, 2013, p.14).

Suurtamm et al. (2016) entienden que la evaluación forma parte de un procedimiento que permite hacer inferencias referidas a los estudiantes, a los planes de estudio o sobre la enseñanza. Consideran que, así como el currículo promulgado en el aula y el evaluado deben brindar información y mejorar el aprendizaje de forma productiva y positiva, las evaluaciones externas a gran escala no deberían operar aisladamente del aula. Estas evaluaciones, a gran escala y en el aula, interactúan entre sí y se basan en principios similares de sólida evaluación, la coherencia entre los dos ayudaría al éxito de los estudiantes.

El MCRN entiende la evaluación desde una perspectiva comprensiva y formativa, como componente integrado a la enseñanza y al aprendizaje; y es un medio para la acreditación de los aprendizajes y de los procesos de enseñanza.

El reglamento de evaluación y pasaje de grado del bachillerato uruguayo establece que será prioridad del docente la evolución de los estudiantes, individual y grupal. La evaluación "procesual consistirá en la valoración de las situaciones pedagógicas, de sus resultados y de los contextos y condiciones en que éstos se producen" (CES, 2006, p.10). La evaluación debe ser acorde con los objetivos provistos en cada asignatura y actividad. Mientras que las instancias de evaluación propuestas por el profesor se realizarán al final de cada unidad o segmento de contenido importante del curso.

En resumen, la investigación emplea la concepción de Webb (1993) acerca de la evaluación y de las pruebas en particular; y se establece la diferencia entre la valoración de la competencia propuesta por PISA y la valoración de las situaciones pedagógicas acordes con los objetivos de la asignatura propuesta por el CES. 


\subsubsection{Objetivos de la evaluación matemática}

Los propósitos de evaluar el desempeño de los estudiantes en matemáticas, según Niss (1993) parecen estar en tres categorías diferentes, pero no independientes. Uno es el suministro de información a quienes están vinculados con la educación matemática, es decir al estudiante, al profesor, al sistema y autoridades educativas y políticas. Otro objetivo es el establecimiento de bases para la toma de decisiones o acciones, en tal sentido la capacidad matemática se relaciona con las habilidades cognitivas e intelectuales significativas para la realización de cualquier actividad analítica. Por último, la conformación de la realidad social, en tanto que los modos y procedimientos de evaluación contribuyen a moldear las condiciones y vidas de los estudiantes.

Webb (1993) establece cuatro objetivos de la evaluación. El primero es que los profesores la utilicen como una herramienta para proporcionar evidencia y retroalimentación sobre lo que los estudiantes saben y pueden hacer. Un segundo propósito es expresar a los estudiantes sobre lo que es importante saber, hacer o creer. El tercero, es proporcionar información a los tomadores de decisiones, incluidos los del sistema educativo, los encargados de la formulación de políticas gubernamentales y otros. El cuarto es brindar información sobra la efectividad del sistema educativo en su conjunto; los resultados de ciertas formas de evaluación se han convertido en indicadores de la efectividad si bien es cuestionable la validez de sus conclusiones.

El objetivo general de PISA 2012 es informar en qué medida los estudiantes, "que se encuentran cursando el final de su educación media básica, han adquirido los conocimientos y desarrollado las habilidades que son esenciales para la plena participación en la sociedad" (ANEP, 2013, p.13).

El MCRN establece que evaluar implica: "establecer un grado de inteligibilidad en relación con el proceso educativo; tomar decisiones y desarrollar modalidades de intervención" (ANEP, 2017, p.27).

El artículo 42 del reglamento de evaluación y pasaje de grado, establece que las instancias de evaluación serán propuestas "cuando el profesor considere necesario para proceder a la reorientación y/o progresión del proceso educativo" (CES, 2006, p.11). 


\subsubsection{Componentes de la evaluación}

La formulación de una evaluación requiere según Webb (1993), considerar cuatro componentes interdependientes en el proceso: "la situación de la evaluación, la respuesta a esta situación, el análisis de la respuesta y la interpretación de los resultados" (Webb, 1993, p.258). Así también deben estar alineados y acordados con el propósito de la evaluación el conocimiento matemático que se evalúa y las características del individuo o grupo que debe responder.

Mientras que Niss (1993) establece un conjunto de siete componentes incluidos en la evaluación con sus correspondientes preguntas: los sujetos, ¿quién es evaluado?; el contenido, ¿qué se evalúa?; las actividades, ¿qué tipo de actividades se proponen?; las ocasiones, ¿cuándo se lleva a cabo la evaluación?; los procedimientos y circunstancias, ¿qué sucede, dónde y quién se espera que haga qué?; el juicio y el registro de la evaluación, ¿qué se enfatiza?; y el informe de los resultados, ¿qué se informa, a quién y en qué formato?

\subsubsection{Evaluación en geometría}

En geometría, la evaluación "nos debe indicar qué comportamientos de percepción espacial han sido adquiridos y cuál ha sido su grado de adquisición" (Alsina, Burgués y Fortuny, 1997, p.118). Los autores sugieren que para conocer el proceso de maduración y aprendizaje de los conceptos y relaciones geométricas será necesario diseñar diferentes métodos y técnicas de evaluación.

Por su parte, el NCTM (2000) en relación con la evaluación en geometría propone entre otros aspectos, analizar características y propiedades de formas geométricas y desarrollar argumentos matemáticos sobre relaciones geométricas. Se espera que los estudiantes de los grados 9-12 puedan: analizar propiedades y determinar atributos de objetos, explorar relaciones entre objetos, hacer conjeturas y establecer argumentos.

Asimismo, el NCTM (2000) plantea que los programas de geometría deben permitir a los estudiantes utilizar la visualización, el razonamiento espacial y el modelado geométrico para resolver problemas. Mientras las respectivas expectativas de logro para los grados 9-12 son: dibujar y construir representaciones de objetos, visualizar objetos desde diferentes perspectivas, utilizar modelos geométricos para responder en otras áreas de las 
matemáticas, usar ideas geométricas en la resolución de problemas y en el conocimiento de otras disciplinas y áreas de interés.

\subsubsection{El contexto y el enunciado en las actividades de evaluación}

El modelo matemático ofrecido por PISA (2003) considera las situaciones y los contextos, donde el tema de cada actividad presenta una situación que el estudiante de 15 años puede abordar y resolver mediante la activación de sus conocimientos, comprensión o habilidades matemáticas.

Los contextos que Caraballo, Rico y Lupiáñez (2011) utilizan en su estudio son los cuatro considerados por PISA: los contextos personales, educativos u ocupacionales, de orden público o científico. Los contextos personales se relacionan con las actividades cotidianas que tienen relevancia directa e inmediata para el estudiante. Los contextos educativos o laborales se manifiestan en situaciones que pudiera enfrentar en el ambiente escolar o laboral. Los contextos públicos, aluden a situaciones diarias que surgen en la interacción del estudiante con el mundo externo. Los contextos científicos reflejan situaciones más abstractas a las que el estudiante está poco relacionado o un problema explícitamente matemático.

En relación con los enunciados de las actividades, en PISA (2003), “consisten en varias piezas de información escrita con una introducción y una serie de preguntas al problema" (ANEP, 2004, p.9). Por su parte Arévalo (2009) en su estudio acerca de la comprensión de los enunciados en problemas matemáticos utiliza tres formas diferentes de enunciados: en forma de texto, esquemática y aritmética.

En forma de texto describe el enunciado matemático con información relevante e irrelevante para obtener la solución. En forma esquemática se escribe el enunciado con una instrucción corta y se agrega información importante a través de tablas, gráficos, dibujos y otros. En forma aritmética se presenta el enunciado describiendo variables y datos numéricos (Arévalo, 2009).

\subsubsection{Tipologías de las actividades de evaluación}

El NCTM (2000) organiza el currículo de matemáticas en cinco procesos transversales: resolución de problemas, razonamiento y demostración, comunicación, conexiones y 
representaciones. A su vez el CES (2010d) propone que el contenido de geometría "se trabajará a través de problemas y ejercicios" (p.2).

Considerar una determinada actividad matemática como ejercicio o problema depende, principalmente, del reto que proponga y de la demanda cognitiva planteada al estudiante. De acuerdo con el momento del proceso de enseñanza los profesores proponen tareas y ejercicios de reproducción o tareas que suponen un reto para la mente, que implican conexión y reflexión. De este modo dependiendo del desafío que se le exija al estudiante la tarea matemática propuesta, será un problema o un ejercicio (Castro y Ruiz, 2015).

Castro y Ruiz (2015) diferencian entre ejercicio, problema y enigma en matemáticas. Nos vamos a valer de la distinción, para establecer la diferencia entre ejercicio y problema. Un ejercicio es una tarea de reproducción en tanto que plantean al estudiante poner en marcha una rutina o un método para encontrar su solución, que es señalado en el enunciado y que el estudiante debe conocer el camino "los ejercicios se resuelven de forma rutinaria y sólo contribuyen a desarrollar destrezas" (p.94). Un problema es una tarea matemática cuya respuesta el estudiante quiere o necesita encontrar, implica un reto, "no hay un procedimiento fácilmente accesible que garantice o determine completamente la solución" (p.92), el resolutor tiene que examinar procedimientos de los que dispone, que no están implícitos en el enunciado y debe realizar intentos para resolverla.

\subsubsection{La demanda cognitiva en las actividades de evaluación}

Con el fin de responder a qué requiere de los estudiantes alcanzar la resolución de las actividades de geometría propuestas, tanto las planteadas por los profesores (que llamaremos actividades de aula) como las de PISA, nos fijamos en la demanda cognitiva de una actividad, definida como "el tipo y nivel de pensamiento requerido de los estudiantes para poder participar en la tarea y resolverla con éxito" (Stein, Smith, Henningsen y Silver, 2009, p. 1). Varias son las investigaciones que en sus conclusiones refieren a la demanda cognitiva que las actividades de geometría exigen a los estudiantes.

El modelo de Smith y Stein (1998) identifica cuatro niveles de demanda cognitiva de las tareas, que evalúa en el estudiante la reflexión y el razonamiento requeridos para resolverlas con éxito y permiten asociar cada tarea a uno de los niveles. Se presentan desde los de menor requerimiento a los de mayor demanda cognitiva: memorización, actividades que sólo requieren razonamientos simples; algoritmos sin conexiones, 
requiere algoritmos evidentes que se derivan de las instrucciones o consignas; algoritmos con conexiones, enfoca en procedimientos que utilizan conceptos más profundos; y hacer matemáticas, requiere un pensamiento complejo y no algorítmico, en el que se ubican las tareas de mayor demanda cognitiva.

Benedicto, Jaime y Gutiérrez (2015) en su investigación trabajan con problemas de patrones geométricos, su análisis de demanda cognitiva de las actividades lo realizan utilizando los cuatro niveles definidos por Smith y Stein (1998) y establecen seis categorías: el procedimiento de resolución; la finalidad con la que se propone la actividad; el esfuerzo cognitivo necesario para llevar a cabo su resolución; los contenidos matemáticos implícitos; el tipo de explicaciones requeridas; y las formas de representación de la solución. Llegan a la conclusión que "el nivel de demanda cognitiva necesario para resolver correctamente un problema no es único y que un factor clave para analizar la dificultad de un problema son las resoluciones" (p. 163).

Otro estudio, el realizado por Caraballo, Rico y Lupiáñez (2011) analiza si las actividades de la evaluación diagnóstica de la competencia matemática se adecuan al modelo de evaluación de la competencia matemática propuesta por PISA. El modelo matemático ofrecido por PISA (2003) considera entre otros los agrupamientos de competencias que los autores refieren como niveles de complejidad, en tanto que atienden la capacidad y conocimiento requeridos para resolver cada actividad.

Los tres niveles de complejidad cognitiva utilizados son: reproducción, conexión y reflexión. La reproducción, involucra reproducir el conocimiento aprendido y practicado; comprende el conocimiento de formas comunes de representación, el reconocimiento de equivalencias, la retención memorística de objetos y propiedades, la aplicación de procedimientos de rutina, de algoritmos y expresiones estándar. Actividades que "requieren que el estudiante demuestre que domina el conocimiento aprendido" (Caraballo, Rico y Lupiáñez, 2011, p.310).

La conexión implica resolver problemas no rutinarios, con grados relativamente bajos de conceptualización, que involucran aún contextos familiares; exige mayor demanda de interpretación y trabajo en conectar con diferentes aspectos de la situación para desarrollar una solución (ANEP, 2004). Actividades que "requieren que el estudiante 
muestre que puede establecer relaciones entre distintos dominios matemáticos" (Caraballo, Rico y Lupiáñez, 2011, p.310).

Mientras la reflexión requiere un pensamiento reflexivo acerca de los procesos necesarios para resolver el problema, requiere conceptualizar situaciones, es decir, reconocer y extraer la matemática incluida en la situación y emplearla para resolver el problema; requiere analizar, interpretar, desarrollar sus propias estrategias y presentar argumentos matemáticos (ANEP, 2004). "Situaciones poco estructuradas que requieren que el estudiante comprenda, reflexione y use su creatividad para reconocer las matemáticas involucradas en el problema" (Caraballo, Rico y Lupiáñez, 2011, p.310).

\subsection{Sentido espacial}

Para abordar los antecedentes del sentido espacial vamos a buscar los aportes recibidos de las investigaciones realizadas desde la enseñanza y el aprendizaje de la matemática, de la geometría y en particular en aquellas que se centran en el desarrollo del sentido espacial, con los diferentes aspectos que lo constituyen o lo favorecen hasta poder definir las componentes y habilidades del sentido espacial que emplearemos en este estudio.

\subsubsection{Antecedentes del sentido espacial}

El comienzo de la intervención sistemática sobre el estudio de la habilidad espacial se le adjudica a Galton (1883), cuyo interés estuvo en el análisis de factores de prueba. Posteriormente otros estudios se centraron en la habilidad espacial y numérica pero no en la habilidad matemática (Spearman, 1927; Thurstone, 1938). Mientras que otros aportan un análisis detallado de la relación entre la habilidad matemática y la habilidad espacial (MacFarlane Smith, 1964), de sus resultados se desprende que la capacidad espacial implica percepción, retención y reconocimiento (o reproducción) de una configuración como un todo organizado, patrón o figura en sus proporciones correctas.

Con la mirada en la habilidad espacial, algunos análisis demuestran que es inadecuado concebirla como un constructo unitario (Michael, Guilford, Fruchter y Zimmerman, 1957). Otras investigaciones aportan a esta visión, la distinción entre visualización espacial, referida por ejemplo a la capacidad de rotar objetos en el espacio, y orientación espacial que implica reconocer y comprender relaciones entre las partes de una figura o patrón y su posición (McGee, 1979). 
Otros estudios hablan de habilidades espaciales en plural (Clements y Wattanawaha, 1978). Mientras que Guay y McDaniel (1977) investigaron la relación entre las habilidades espaciales y el rendimiento en matemáticas en la escuela primaria, logran distinguir entre habilidades espaciales de bajo nivel como aquellas que requieren la visualización de configuraciones bidimensionales, pero no las transformaciones mentales de esas imágenes visuales y las de alto nivel, que requieren la visualización de configuraciones tridimensionales con su correspondiente manipulación mental.

Es oportuno señalar que desde estos momentos para la investigación es un área problemática la distinción entre habilidad y habilidades. La primera referida a una cualidad posiblemente heredada, dentro de cada niño que constituye una diferencia individual, y las segundas como capaces de desarrollarse en el niño, por lo que pueden ser objeto de enseñanza.

Como las habilidades se desarrollan en los niños, no son menores los aportes recibidos desde la psicología del desarrollo. Al centro de los estudios sobre la geometría espacial y las transformaciones geométrica están los realizados por la tradición piagetiana (Piaget e Inhelder, 1956 y Piaget, Inhelder y Szeminska, 1960) con sus correspondientes críticas sobre las edades y etapas, el lenguaje matemático utilizado, las evidencias sobre las que se basan sus hallazgos. También se encuentran dos investigaciones más recientes sobre conceptos espaciales y geométricos en esta misma corriente (Martin, 1976 y Lesh, 1976). Otras visiones del desarrollo psicológico proponen tres niveles de representación, sensorio motor, perceptivo y contemplativo (Werner, 1964), enactivo, icónico y simbólico (Bruner, 1964).

El trabajo de van Heile muestra la preocupación del educador matemático por integrar las concepciones provenientes de la psicología en la enseñanza de las matemáticas, sus descripciones parecen tener más ideas en común con las de Werner que con las de Bruner o Piaget (van Heile, 1959). Otros estudios correspondientes con el desarrollo evolutivo son abordados en el contexto de la enseñanza de la geometría (Lesh, 1976).

Otras investigaciones centran la atención en los aspectos culturales del alumno: el entorno físico, las actividades ocupacionales, el lenguaje y las prácticas sociales, y su relación con el desarrollo de las habilidades espaciales (Berry, 1971; Bishop, 1979; Mitchelmore, 1980). 
La educación formal se considera como uno de los aspectos perteneciente al contexto del alumno, por tanto, el enfoque de la enseñanza podría ser un factor determinante en las habilidades espaciales. Algunas investigaciones con niños de primaria manifiestan que el uso de materiales estructurados y manipulativos en la enseñanza tiende a mejorar los desempeños en las pruebas de capacidad espacial (Bishop, 1972 y 1973; Mitchelmore, 1980 y 1984; Marriott, 1978). Otros estudios establecen por género, diferencias de puntuaciones en las pruebas espaciales, los niños obtienen puntuaciones más altas que las niñas debido al número de cursos vinculados con el espacio que eligen los niños en su enseñanza (Fennema y Sherman, 1977).

En relación con la enseñanza, uno de los enfoques se centra en las interacciones de aptitud-tratamiento (ATI), explora las diferentes aptitudes del alumno para que las utilice al máximo y su relación con los diversos tratamientos de enseñanza (Radatz, 1979; Webb y Carry, 1975; Young y Becker, 1979). Esta técnica tiene problemas en su metodología, así como en la calidad y generalidad de sus resultados.

Otro enfoque de la enseñanza se ocupa de identificar las diferencias individuales en habilidades espaciales y luego enseñar habilidades espaciales específicas a través de un entrenamiento con experiencias apropiadas considerando las diversas habilidades involucradas en la interpretación de información figurativa (Dawson, 1967; Brinkmann, 1966; Frandsen y Holder, 1969; Saunderson, 1973; Lean y Clements, 1981).

En nuestra sociedad tecnológica es fundamental la educación visual para lograr una buena adaptación, por tal motivo se debieran de impartir cursos de intuición visual en geometría antes de los cursos deductivos recomendación dada por los educadores matemáticos involucrados en el currículum (Arcavi, 2003; Battista, 2007; Cunningham, 1991; Guillén, 2000; Mariotti, 2001; Rivera, 2011; Stylianou, 2001).

Los estudios que se interesan por el papel que desempeña el docente para favorecer el desarrollo de las habilidades espaciales concluyen que siendo un proceso tan personal e individual la incidencia del docente es sutil (Kent y Hedger, 1980; Presmeg, 1986). Serán necesarias investigaciones que examinen los propios procesos de los docentes en el desarrollo de las habilidades espaciales y los efectos de estos en los procesamientos individuales de los alumnos. 
Mientras que Owens y Outhreda (2006) consideran que el contexto del aula puede influir en la resolución de problemas espaciales. La interacción alumno-docente puede influir en lo que los alumnos notan cuando trabajan con sus percepciones y las vinculan con lo que ya conocen para dar sus respuestas.

Un aspecto que ha recibido mucha atención en las investigaciones es la visualización espacial. Algunos distinguen entre visualización y orientación espacial (McGee, 1979), otros estudian la relación entre la capacidad de visualización espacial y el comportamiento para la resolución de problemas, obteniendo una relación positiva entre el tiempo dedicado a ver el material esencial para obtener la solución y la visualización espacial, reduciendo el tiempo dedicado a ver información no esencial (Fry, 1988).

Bishop (1989) presenta dos tipos de procesos para la manipulación de las imágenes mentales, visuales y físicas: la interpretación de información figurativa (IFI) que permite comprender e interpretar las representaciones visuales para extraer la información que contienen; y el procesamiento visual (VP) que convierte información abstracta o no figurativa en imágenes visuales, o transforma imágenes visuales ya formadas en otras.

Gutiérrez (1996) considera la visualización como una actividad basada en el uso de elementos visuales o espaciales, sean mentales o físicos, con el fin de probar propiedades o resolver problemas. La visualización está compuesta por cuatro elementos: las imágenes mentales, las representaciones externas, los procesos de visualización y las habilidades de visualización.

Breen (1997) describe dos tipos de pensamiento matemático, a través de dos tendencias: hacia la abstracción y hacia la comprensión intuitiva con énfasis en las imágenes y en los procesos de visualización. Por su parte Stylianou (2001) deja activo en la investigación el papel de las imágenes visuales en la resolución de problemas matemáticos.

La relación de la tecnología informática con los procesos de visualización matemática fue introducida por los estudios de Zimmerman y Cunningham en 1991, mientras que Yerushalmy, Shternberg y Gilead (1999) y Parzysz (1999) enfatizaron que la visualización puede ser poderosa no solo en temas como geometría y trigonometría, sino también en álgebra. Otras investigaciones abordan la visualización por parte de los estudiantes a través de software de geometría dinámica (Markopoulos y Potina, 1999; Hadas y Arcavi, 2001; Arcavi y Hadas, 2002; Pratt y Davison, 2003; Sinclair, 2003). 
Algunos investigadores (Presmeg, 1991; Woolner, 2004; Fernández, 2013) consideran que una línea abierta para este período es "cómo la visualización interactúa con la didáctica de las matemáticas; pedagogía eficaz que puede mejorar el uso y el poder de la visualización en la educación matemática" (Presmeg, 2006, p.227), en tanto que es un área hasta ahora descuidada, son muy pocos los estudios al respecto además de ser un tema continuo e importante.

Dörfler (1991) considera que los esquemas de imágenes mentales inducen a dar significado en matemática y propone cuatro tipos de esquemas: figurativo, operativo, relacional y simbólico. Después son varios los autores que afirman que el procesamiento de imágenes es fundamental para el razonamiento matemático (Wheatley, 1997; Wheatley y Brown, 1994).

Algunos estudios refieren a la interacción entre las representaciones externas e internas como parte fundamental para la enseñanza y el aprendizaje de las matemáticas. La representación interna o imaginaría visual se infiere a partir de las interacciones con la producción de la representación externa, subyace a la creación de una disposición espacial o a un dibujo o diagrama (Goldin, 2007; Presmeg, 2006, Duval 1999).

\subsubsection{Componentes y habilidades del sentido espacial}

A este punto es oportuna la afirmación de Wheatley (1990), "los autores de los estándares (NCTM, 1989) utilizan el término sentido espacial para referirse a lo que se ha conocido por una variedad de otras etiquetas, desde visualización espacial, razonamiento espacial, percepción espacial e imágenes visuales hasta rotaciones mentales” (p.10). Asimismo, se podría afirmar "que cada uno de estos estudios está considerando el sentido espacial" (Owens y Outhreda, 2006, p.89).

Flores, Ramírez y del Río (2015) describen el sentido espacial como una forma intuitiva de "entender el plano y el espacio, para identificar cuerpos, formas y relaciones entre ellos, que implica manejar relaciones y conceptos de geometría de forma no convencional, incluyendo la habilidad para reconocer, visualizar, representar y transformar formas geométricas" (pp.129-130). Los mismos autores, distinguen dos componentes del sentido espacial: el manejo de conceptos geométricos y las destrezas necesarias para la visualización de estos conceptos. 
La primera componente, el manejo de conceptos geométricos está compuesta por algunos apartados: conocer formas y figuras, que implica identificarlas, definirlas, construirlas y caracterizarlas; reconocer y establecer relaciones geométricas, que consiste en apreciar cualidades de las formas y los cuerpos geométricos; la ubicación y los movimientos como la capacidad para situar los elementos en el espacio y en el plano, realizar movimientos e identificar elementos invariantes y regularidades; y la orientación espacial entendida como la capacidad para comprender cómo se disponen los elementos en el espacio y no confundirlos.

La segunda componente, la destreza necesaria para visualizar los conceptos geométricos, la visualización la entienden como "un amplio conjunto de imágenes, capacidades y habilidades necesarias y útiles para elaborar, analizar, transformar y comunicar información relativa a las posiciones entre figuras objetos y modelos geométricos" (Flores, Ramírez y del Río, 2015, p. 133).

La mayor fortaleza del sentido espacial consiste en la conexión entre las componentes como se expresa en la figura 1.

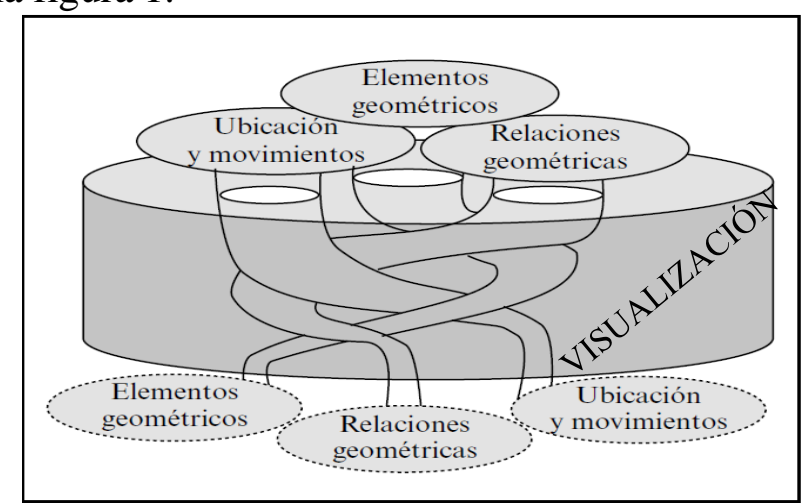

Figura 1. Conexión entre los conceptos geométricos. (Flores, Ramírez y del Río, 2015, p.134)

Del Grande (1987 y 1990) establece siete habilidades espaciales de visualización que parecen tener mayor relevancia en el desarrollo académico de la percepción espacial: coordinación ojo-motor, percepción figura-contexto, conservación de la percepción, percepción de la posición en el espacio, percepción de las relaciones espaciales, discriminación visual y memoria visual. Se basa en los materiales de prueba producidos por Frosting y Home (1964) para las primeras cinco y de Hoffer (1977) las otras dos. Afirma que son los educadores "los que deben relacionar la base teórica con la práctica pedagógica para ayudar a los alumnos a mejorar su sentido espacial que consiste en las habilidades necesarias para el éxito futuro en las matemáticas y también en otros campos" (Del Grande, 1990, p.20). 
La habilidad coordinación ojo-motor la entiende como la capacidad de coordinar la visión con el movimiento del cuerpo; las actividades geométricas que involucra son, por ejemplo, trazar figuras o rellenar regiones con pautas o sin ellas. La percepción figuracontexto es identificar un componente en una situación e implica cambios en la percepción de las figuras contra fondos complejos; las actividades que involucra son, por ejemplo, identificar una figura entre un conjunto de figuras superpuestas, completar o ensamblar una figura.

La conservación de la percepción es la capacidad de reconocer que un objeto tiene propiedades invariantes como el tamaño y la forma; las actividades geométricas involucradas son, por ejemplo, identificar figuras que tienen la misma forma y diferente tamaño, ordenar objetos según su tamaño, identificar figuras que tienen el mismo tamaño y forma. La percepción de la posición en el espacio es la capacidad de determinar la relación de un objeto con otro objeto o con el observador. La percepción de las relaciones espaciales es la capacidad de ver dos o más objetos relacionados con uno mismo o entre sí.

La discriminación visual es la capacidad de identificar las similitudes y diferencias entre objetos, las actividades de clasificar y ordenar objetos y formas geométricas son un ejemplo. La memoria visual es la capacidad de recordar con precisión objetos que ya no están a la vista y relacionar sus características con otros objetos que están o no a la vista.

Por último, Owens (2006) afirma que pensar las habilidades y el sentido espacial en términos de creación de imágenes, involucra procesos y estrategias funcionales. 


\section{CAPÍTULO 3. MARCO METODOLÓGICO}

\subsection{Diseño de la investigación}

La investigación se caracteriza por su enfoque cualitativo cuyo fundamento es la "perspectiva interpretativa centrada en el entendimiento del significado de las acciones" (Hernández Sampieri, Fernández-Collado y Baptista, 2014, p. 9) de las personas y sus instituciones, en nuestro caso de la educación. En el enfoque cualitativo hay una variedad de marcos de interpretación, pero todos buscan analizar los aspectos explícitos y manifiestos, así como los implícitos y subyacentes.

Tiene un carácter descriptivo, "los estudios descriptivos buscan especificar las propiedades, las características y los perfiles de personas, grupos, comunidades, procesos, objetos o cualquier otro fenómeno que se someta a un análisis" (Hernández Sampieri, Fernández-Collado y Baptista, 2014, p. 92).

Su diseño metodológico corresponde a un análisis de contenido que se caracteriza como "un método de investigación del significado simbólico de los mensajes" (Krippendorff. 1990, p.30), sabiendo que el significado no es único y depende del contexto. En tanto que esfuerzo de interpretación, el análisis de contenido acredita "lo oculto, lo latente, lo no aparente, lo potencial inédito, lo «no dicho», encerrado en todo mensaje" (López Noguero, 2009, p.173).

En un estudio cualitativo, la aplicación del análisis de contenido permite analizar el contenido latente en un texto y "en la investigación educativa puede ayudarnos a inferir significados interpretativos a un texto" (Rico y Fernández Cano, 2013, p.9). En educación matemática, se emplea como "un método para establecer y estudiar la diversidad de significados escolares de los conceptos y procedimientos de las matemáticas que aparecen en un texto (discurso del profesor, textos y producciones escolares)" (Rico, 2013, p. 18), en nuestro caso en las evaluaciones escritas de los docentes de matemática de $1^{\circ}$ de bachillerato y las estandarizadas que ofrece PISA. 


\subsection{Elementos de la investigación}

En este apartado se describen los elementos que constituyen la investigación: los sujetos, el instrumento de toma de datos y la determinación de las categorías de análisis.

\subsubsection{Sujetos de la investigación}

Una de las primeras tareas de una investigación consiste "en decidir qué se ha de observar" (López Noguero, 2009, p.175). Este estudio se lleva a cabo, se observan las actividades propuestas en evaluaciones. La selección y recolección de las actividades sujetos de esta investigación implica dos procesos diferentes, el referente a la recolección de las actividades liberadas por PISA y la recolección y selección de las actividades de aula.

Como fue dicho en la introducción, Uruguay participa por primera vez en las evaluaciones PISA en el 2003, año en el que el dominio es la cultura matemática así también el 2012. Por tal motivo se contacta con una docente de matemáticas que trabaja en la ANEP en el proyecto PISA Uruguay quien facilita las actividades liberadas en 2003 y 2012 además de materiales vinculados, oportunos para el estudio, como son algunas presentaciones que resumen información de los resultados obtenidos por el país en cada una de las mediciones. De las actividades liberadas interesan sólo siete, las referidas al contenido espacio y forma. En 2003 son tres, que llevan por título: escalera, dados y carpintero (ANEP, 2004); mientras que las correspondientes a 2012 son cuatro: garaje (pregunta 1 y 2) y puerta giratoria (pregunta 1 y 2) (ANEP, 2013).

Para la recolección de las actividades de aula, se determina el curso de $1^{\circ}$ de bachillerato porque en ese nivel se encuentran la mayoría de los alumnos con 15 años correspondiente a uno de los cortes etarios en la que se lleva a cabo la evaluación de PISA. En ese curso se seleccionan las actividades de evaluación correspondientes al contenido curricular de geometría, por tanto, actividades que evaluarán el aprendizaje de los lugares geométricos (CES, 2010d).

Se tiene acceso a 24 actividades referentes a lugares geométricos, propuestas por tres profesores de secundaria de una institución privada de Montevideo. Las actividades de aula fueron planteadas en el año lectivo 2020, en un período de clase en modalidad presencial. Es muy frecuente que las actividades de geometría requieran emplear y calcular medidas de magnitudes geométricas. Nuestro interés está en el sentido espacial, 
evitando las inclusiones de aspectos relacionados con la medida. Es por esto que para la selección se tuvo en cuenta que la solución de la actividad no fuera una medida, sea como cantidad de longitud, superficie o volumen, como de amplitud de ángulo; además se selecciona solo una de las que teniendo igual enunciado, cambian los valores de los datos proporcionados, de este modo son nueve las actividades de aula seleccionadas.

Las actividades de evaluación consideradas como sujetos de esta investigación son 16, entre las propuestas en el aula, por docentes de secundaria, de $1^{\circ}$ de bachillerato y las evaluaciones internacionales de PISA (Ver Anexo A). En la tabla 2 se establecen las referencias adjudicadas a cada actividad para facilitar el proceso de análisis de la información.

Tabla 2. Referencias de actividades seleccionadas

\begin{tabular}{lllll}
\hline \multicolumn{2}{c}{ Actividades de PISA } & \multicolumn{2}{c}{ Actividades de aula } \\
\hline 2003 & Escalera & E & Actividad 1 & A1 \\
& Dados & D & Actividad 2 & A2 \\
& Carpintero & C & Actividad 3 & A3 \\
& & & Actividad 4 & A4 \\
2012 & Garaje & G1 & Actividad 5 & A5 \\
& & G2 & Actividad 6 & A6 \\
& Puerta Giratoria 7 & A7 \\
& & PG1 & Actividad 8 & A8 \\
& PG2 & Actividad 9 & A9 \\
\hline
\end{tabular}

\subsubsection{La recolección de datos}

Esta investigación se caracteriza por su enfoque cualitativo, lo que busca un estudio cualitativo es obtener datos, que se convertirán en información, de personas, situaciones o procesos en profundidad. La recolección de datos se entiende como el acopio de datos de los sujetos o unidades de análisis (Hernández Sampieri, Fernández-Collado y Baptista, 2014). Por su parte, López Noguero (2009) habla de registrar lo que se considera como “datos, ya que toda investigación de carácter empírico abarca una multitud de unidades portadoras de información" (p.175).

Ante la pregunta ¿cuál es el instrumento de recolección de los datos?, Hernández Sampieri et al. (2014) consideran que la respuesta más adecuada es el propio investigador, característica fundamental del proceso cualitativo. A la vez establecen que un tipo de unidad de análisis son los procesos. Los autores definen los procesos como "conjuntos de actividades, tareas o acciones que se realizan con un fin determinado" (p.398). 
En este caso, el trabajo abarca dos tipos de dimensiones de estudio: características de las actividades, y componentes del sentido espacial requeridos para su resolución. La recolección de datos para la primera dimensión se realiza examinando características de los enunciados y de los procesos de resolución de dichas actividades. La recolección de datos para examinar las componentes del sentido espacial se realiza a través de la resolución amplia y detallada de cada una de las 16 actividades que son sujetos de esta investigación (Ver Anexo B). Se resuelven las nueve actividades de aula en torno al contenido lugares geométricos y las siete actividades liberadas de PISA en los dos años 2003 y 2012 cuyo dominio fue la cultura matemática, específicamente en el contenido espacio y forma. Cada una de las resoluciones fueron sometidas a la mirada experta y cualificada del director que permitió agregar nuevas resoluciones en las actividades.

Es oportuno decir que no fueron considerados los procedimientos que no conducen a encontrar la solución de cada una de las actividades porque no atienden a los objetivos de la investigación. Asimismo, interesa señalar que las actividades de aula los alumnos de $1^{\circ}$ de bachillerato las resuelven a lápiz y papel, no fueron actividades propuestas para ser resueltas por medio de programas de geometría, como geogebra.

\subsubsection{Determinación de las categorías de análisis}

El trabajo de determinación de las categorías de análisis busca ajustarse a los objetivos planteados en esta investigación. Algunas de las recomendaciones que establece López Noguero (2002) para la creación de categorías es que deben ser: exclusivas, un mismo elemento del contenido no puede ser clasificado en categorías diferentes; y adecuadas o pertinentes, adaptadas al contenido y al objetivo.

En relación a las características destacables de las actividades, se plantean las siguientes subcategorías: contexto, es decir, señalar cuál es el contexto en que se presenta, siguiendo la tipología PISA (personales, educativos $\mathrm{u}$ ocupacionales y de orden público o científicos); forma del enunciado, que, siguiendo a Arévalo (2009), distinguimos el texto y la forma esquemática, incluyendo el papel que desempeña el gráfico y los datos en el enunciado; el nivel de complejidad, que, siguiendo a PISA, diferenciamos en nivel de reproducción, conexión y reflexión; según la forma de la actividad, caracterizamos si es ejercicio o problema (Castro y Ruiz, 2015). A modo de resumen, estas categorías se recogen en la tabla 2. 
Tabla 2. Características de las actividades

\begin{tabular}{ll}
\hline \multicolumn{1}{c}{ Características } & \multicolumn{1}{c}{ Valores } \\
\hline Contexto & Personal, educativo/ocupacional, científico \\
Datos del enunciado & Forma del enunciado (texto, esquemático/figuras); \\
& Pertinencia de datos \\
Tipología de tarea & Ejercicio / Problema \\
Complejidad & Reproducción, conexión, reflexión \\
\hline
\end{tabular}

En relación con las componentes del sentido espacial se establecen dos categorías: manejo de conceptos geométricos y las habilidades de visualización.

A la vez para cada una de las categorías se establecen las subcategorías que fueron descritas y definidas en el marco teórico. Para la categoría manejo de conceptos geométricos se definen cuatro subcategorías: conceptos de las figuras, propiedades de las formas, relaciones geométricas, ubicación y movimientos, orientación; para las habilidades de visualización se definen siete subcategorías: coordinación ojo-motor, percepción figura-contexto, conservación de la percepción, percepción de la posición en el espacio, percepción de las relaciones espaciales, discriminación visual, memoria visual; y para las características se definen cuatro subcategorías antes dichas: contexto, datos en el enunciado, tipología de tarea y niveles de complejidad cognitiva. Se sistematiza la información de las categorías con las correspondientes subcategorías en la tabla 3.

Tabla 3. Categorías y subcategorías de análisis

\begin{tabular}{ll}
\hline Categorías & Subcategorías \\
\hline Manejo de conceptos & Conceptos de las figuras \\
geométricos & Propiedades de las formas \\
& Relaciones geométricas \\
& Ubicación y movimientos \\
& Orientación \\
Habilidades de visualización & Coordinación ojo-motor \\
& Percepción figura-contexto \\
& Conservación de la percepción \\
& Percepción de la posición en el espacio \\
& Percepción de las relaciones espaciales \\
& Discriminación visual \\
& Memoria visual \\
& Contexto \\
Características & Tipología de tarea \\
& Datos en el enunciado \\
& Complejidad \\
\hline
\end{tabular}




\section{CAPÍTULO 4. ANÁLISIS Y RESULTADOS}

En este capítulo se presentan los datos que proceden de analizar las actividades que forman parte de esta investigación, a través de las categorías y subcategorías de análisis que fueron determinadas anteriormente. El análisis a su vez se resume a los efectos de la presentación de resultados, de ese modo se atienden las características de las actividades y las componentes del sentido espacial que se requieren para resolverlas.

\subsection{Descripción del análisis}

El análisis se realiza a partir de las diferentes resoluciones de las 16 actividades que forman parte de esta investigación. La mirada está puesta en identificar en cada paso de la resolución, los componentes del sentido espacial requeridos al estudiante de $1^{\circ}$ de bachillerato en el momento que las resuelve para luego identificar con más información las características de las actividades.

Para todas las actividades se confeccionan dos tablas, una con los componentes del sentido espacial, con sus dos categorías y correspondientes subcategorías y otra para la categoría de las características. De este modo para cada actividad se completan dos tablas, algunas de ellas presentes en este análisis y todas se encuentran en el Anexo C.

Los análisis fueron puestos en consideración, recibieron agregados y correcciones de parte del director y de dos colegas con los que compartimos tener el sentido espacial en el marco teórico de las respectivas investigaciones.

Las cuatro actividades que se presentan en este apartado fueron seleccionadas por su nivel de complejidad, de conexión o reflexión, como fueron definidos en el marco teórico a partir de PISA 2003 (ANEP, 2004). El nivel de conexión implica vincular los datos ofrecidos con los caminos de solución, mientras que la reflexión exige, entre otros aspectos deducir datos que no aparecen en forma directa en el enunciado de la actividad. 


\subsubsection{Análisis de las actividades de PISA}

De las siete actividades analizadas de PISA, se seleccionan dos cuya complejidad responde al nivel de conexión y reflexión, y se presentan las cuatro tablas correspondientes.

En la tabla 4 (Anexo C, tabla 5) se detalla el análisis de los componentes del sentido espacial realizado a la actividad D, queda de manifiesto los conceptos, propiedades, relaciones geométricas y las habilidades de visualización requeridas al estudiante para obtener la solución de la situación planteada. Esta solicita señalar las respuestas que correspondan, entre cuatro desarrollos planos de un dado, que deben cumplir con la consigna que "la suma de las caras opuestas suma 7" (PISA, 2003).

Tabla 4. Componentes del sentido espacial en Actividad D

\begin{tabular}{|c|c|c|}
\hline Componentes & lel sentido espacial & Actividad D \\
\hline \multirow{12}{*}{$\begin{array}{l}\text { Manejo de } \\
\text { conceptos } \\
\text { geométricos }\end{array}$} & Conceptos de las & Concepto de cubo, desarrollo plano del cubo. \\
\hline & figuras & Caras contiguas. Caras opuestas. \\
\hline & Propiedades de las & Caras paralelas dos a dos. \\
\hline & formas & Tres caras determinan cada vértice. \\
\hline & $\begin{array}{l}\text { Relaciones } \\
\text { geométricas }\end{array}$ & $\begin{array}{l}\text { Cada cara tiene contacto con otras cuatro, sólo no tiene } \\
\text { contacto con su opuesta. }\end{array}$ \\
\hline & & $\begin{array}{l}\text { Vínculo entre el cubo y su desarrollo plano. Caras no } \\
\text { consecutivas de un dado suman } 7 \text {. }\end{array}$ \\
\hline & & $\begin{array}{l}\text { Caras contiguas en desarrollo son adyacentes en } \\
\text { cuerpo. }\end{array}$ \\
\hline & & $\begin{array}{l}\text { Caras opuestas en cuerpo no pueden tener arista común } \\
\text { en desarrollo. }\end{array}$ \\
\hline & $\begin{array}{l}\text { Ubicación y } \\
\text { movimientos }\end{array}$ & $\begin{array}{l}\text { Ubicación del cubo en el espacio y su correlato con su } \\
\text { desarrollo plano. }\end{array}$ \\
\hline & Orientación & Disposición de las caras del dado. \\
\hline & & Disposición de los números en el desarrollo. \\
\hline & & La capacidad de girar la imagen visual del cubo, o de \\
\hline \multirow{10}{*}{$\begin{array}{l}\text { Habilidades de } \\
\text { visualización }\end{array}$} & Coordinación ojo- & -- \\
\hline & motor & \\
\hline & $\begin{array}{l}\text { Percepción figura- } \\
\text { contexto }\end{array}$ & -- \\
\hline & $\begin{array}{l}\text { Conservación de la } \\
\text { percepción }\end{array}$ & $\begin{array}{l}\text { Se conserva el tamaño y la forma de las caras en los } \\
\text { desarrollos planos. }\end{array}$ \\
\hline & $\begin{array}{l}\text { Percepción de la } \\
\text { posición en el }\end{array}$ & Se conserva la posición de las caras en los desarrollos \\
\hline & espacio & Identificación de la relación que existe entre las caras \\
\hline & & de desarrollo y las caras en el cubo. \\
\hline & \multirow{2}{*}{$\begin{array}{l}\text { Percepción de las } \\
\text { relaciones } \\
\text { espaciales }\end{array}$} & Caras paralelas dos a dos suman 7 . \\
\hline & & $\begin{array}{l}\text { Dos caras contiguas en desarrollo que sumen } 7 \text { no son } \\
\text { opuestas en cubo. }\end{array}$ \\
\hline & $\begin{array}{l}\text { Discriminación } \\
\text { visual }\end{array}$ & Diferenciar los desarrollos presentados. \\
\hline
\end{tabular}


Dos desarrollos planos conservan que caras paralelas suman 7: II y III y dos no conservan: I y IV. Identificar el cubo que resulta de los desarrollos II y Memoria visual III, pese a que son diferentes.

En la tabla 5 (Anexo C, tabla 6) se presenta el análisis realizado a la actividad D para ver las características de contexto, modo de presentación de los datos en el enunciado, tipo de tarea y nivel de complejidad cognitiva como elementos que intervienen para poder resolver la situación.

\section{Tabla 5. Características en la Actividad D}

\begin{tabular}{ll}
\hline \multicolumn{1}{c}{ Características } & \multicolumn{1}{c}{ Actividad D } \\
\hline Contexto & $\begin{array}{l}\text { Los dados se consideran elementos integrantes de los juegos del } \\
\text { estudiante, corresponde a una situación real a nivel personal. } \\
\text { Datos del enunciado } \\
\text { Texto largo del que deben extraer datos relevantes, como "las caras } \\
\text { opuestas suman 7". La representación gráfica del dado en dos } \\
\text { dimensiones brinda la información para poder seleccionar la } \\
\text { respuesta correcta. Presentación de texto y esquemática de la } \\
\text { información. }\end{array}$ \\
Tipología de tarea & $\begin{array}{l}\text { Exige asociar las representaciones en dos y tres dimensiones del } \\
\text { dado. Para aplicar la regla establecida, "las caras opuestas suman 7" } \\
\text { no hay un camino establecido y previamente conocido por el }\end{array}$ \\
& $\begin{array}{l}\text { estudiante. Resulta ser un problema para resolver. } \\
\text { Asociar las dos representaciones del dado en dos y tres dimensiones. }\end{array}$ \\
& $\begin{array}{l}\text { Exige girar la imagen visual del cubo. } \\
\text { Diferenciar los desarrollos presentados y discriminar los que cumplan } \\
\text { la consigna establecida. Se establecen conexiones. }\end{array}$ \\
\hline
\end{tabular}

En la tabla 6 (Anexo C, tabla 9) se detalla el análisis realizado a la actividad G2, queda de manifiesto el manejo de conceptos geométricos y las habilidades de visualización requeridas al estudiante para obtener la solución de la situación en la que se presenta la vista frontal y lateral de un garaje con las medidas de cada parte y se solicita el área del techo.

Tabla 6. Componentes del sentido espacial en Actividad G2

\begin{tabular}{|c|c|}
\hline Componentes del sentido espacial & Actividad G2 \\
\hline $\begin{array}{l}\text { Conceptos de las } \\
\text { figuras }\end{array}$ & $\begin{array}{l}\text { Triángulos rectángulos, rectángulos y altura (del } \\
\text { techo). }\end{array}$ \\
\hline $\begin{array}{l}\text { Propiedades de las } \\
\text { formas }\end{array}$ & Teorema de Pitágoras, área del rectángulo. \\
\hline $\begin{array}{l}\text { Relaciones } \\
\text { geométricas }\end{array}$ & $\begin{array}{l}\text { Lados opuestos de un rectángulo son paralelos. } \\
\text { Lados consecutivos de un rectángulo son } \\
\text { perpendiculares. La altura es perpendicular a la } \\
\text { horizontal. El lado del rectángulo del tejado es la } \\
\text { hipotenusa de un triángulo rectángulo } \\
\text { determinado por dos medidas que no }\end{array}$ \\
\hline
\end{tabular}


Manejo de

conceptos

geométricos

Ubicación y

movimientos

Orientación corresponden a ningún objeto físico (la mitad de la anchura del tejado y la altura del mismo)

$-$

Identificar que el rectángulo superior de la vista lateral no representa el techo.

Considerar la vista frontal y la lateral como parte de un todo.

Sintetizar la información en un nuevo rectángulo que se corresponde con el techo.

Coordinación ojo-

motor

Habilidades de

visualización
Percepción figura-

contexto

Identificación de medidas que corresponden a objetos, como el largo del garaje se corresponde con el largo del techo.

Identificación de distancias entre objetos, como los que determinan el triángulo rectángulo que tiene por hipotenusa al lado del tejado.

Conservación de la Reconocer el ancho y el largo del techo.

percepción

Percepción de la posición en el espacio

Percepción de las relaciones espaciales

Discriminación visual Memoria visual
Vincular la posición del ancho del techo en la vista frontal con un segmento perpendicular al largo de la vista lateral.

Identificar el largo del techo con el largo de la vista lateral.

Identificar el ancho del techo como la hipotenusa de un triángulo rectángulo.

Determinar un nuevo rectángulo para el techo.

Diferenciar la altura del ancho techo.

La tabla 7 (Anexo C, tabla 10) presenta el análisis realizado, en esta oportunidad atiende las características que la misma actividad G2 cumple.

Tabla 7. Características en la Actividad G2

\begin{tabular}{ll}
\hline \multicolumn{1}{c}{ Características } & \multicolumn{1}{c}{ Actividad G2 } \\
\hline Contexto & Un fabricante de garaje corresponde a una situación real a \\
& nivel ocupacional o laboral. \\
Datos del enunciado & Texto breve que contextualiza la situación y aporta \\
& información "techo formado por dos rectángulos iguales". \\
& La representación gráfica del garaje en dos dimensiones, la \\
& vista frontal con puerta y la lateral dos rectángulos \\
& diferentes. Multiplicidad de medidas, relevante e \\
& irrelevantes. Presentación esquemática de toda la situación. \\
& Exige asociar las representaciones en dos dimensiones del \\
& garaje del frente y la lateral. Para realizar el cálculo \\
Tipología de tarea & solicitado se deben hacer cálculos previos a través de \\
& algoritmos que se deben conocer. El camino de resolución \\
& demanda creatividad y conocimientos previos, es un \\
& problema. \\
& Asociar las dos representaciones en dos dimensiones del \\
& garaje, la frontal y la de fondo.
\end{tabular}


Conocer el área del rectángulo. Asociar las dimensiones que se corresponden entre las dos vistas.

Discriminar datos necesarios de los que no.

Determinar qué dato le falta para el cálculo del área del techo.

Considerar el nuevo rectángulo y sus dimensiones para poder calcular el área y luego duplicarla.

Exige reflexión para poder identificar los datos pertinentes y elaborar la estrategia de resolución.

\subsubsection{Análisis de las actividades de aula}

Se seleccionan dos de las nueve actividades de aula que constituyen los datos de esta investigación. Todas demandan al estudiante de $1^{\circ}$ de bachillerato un nivel de complejidad de conexión para obtener la solución, dado que toda la información se brinda en el enunciado debe establecer conexiones entre los lugares geométricos conocidos.

En la tabla 8 (Anexo C, tabla 15) se hace el análisis de la actividad A1 en los componentes del sentido espacial presentes al momento de buscar todos los puntos del plano que equidistan de dos rectas secantes y están a menos de una distancia dada de un punto fijo.

Tabla 8. Componentes del sentido espacial en Actividad A1

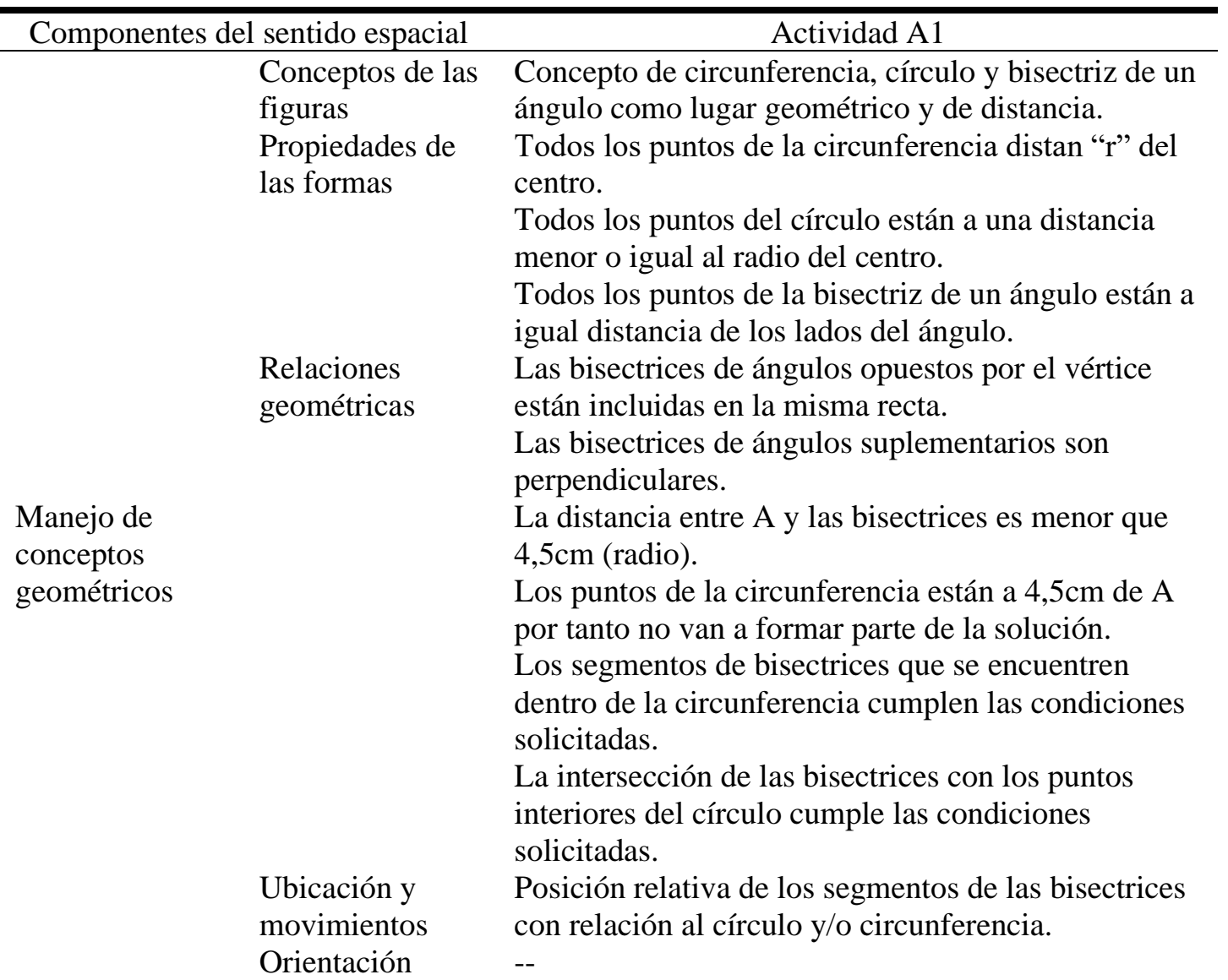




\begin{tabular}{|c|c|c|}
\hline \multirow{7}{*}{$\begin{array}{l}\text { Habilidades de } \\
\text { visualización }\end{array}$} & $\begin{array}{l}\text { Coordinación } \\
\text { ojo-motor }\end{array}$ & $\begin{array}{l}\text { Conocer y lograr el trazado del procedimiento de } \\
\text { construcción de la circunferencia y de las dos } \\
\text { bisectrices. }\end{array}$ \\
\hline & $\begin{array}{l}\text { Percepción } \\
\text { figura-contexto }\end{array}$ & $\begin{array}{l}\text { Considerar los segmentos de bisectrices incluidos en } \\
\text { el círculo. }\end{array}$ \\
\hline & $\begin{array}{l}\text { Conservación de } \\
\text { la percepción }\end{array}$ & -- \\
\hline & $\begin{array}{l}\text { Percepción de la } \\
\text { posición en el } \\
\text { espacio }\end{array}$ & -- \\
\hline & $\begin{array}{l}\text { Percepción de } \\
\text { las relaciones } \\
\text { espaciales }\end{array}$ & $\begin{array}{l}\text { Determinación de todos los puntos que cumplen con } \\
\text { estar a menos de } 4,5 \mathrm{~cm} \text { y equidistantes de las rectas } \\
\text { AB y EF. }\end{array}$ \\
\hline & $\begin{array}{l}\text { Discriminación } \\
\text { visual }\end{array}$ & -- \\
\hline & Memoria visual & -- \\
\hline
\end{tabular}

En la tabla 9 (Anexo C, tabla 16) se hace el análisis de las características presentes en la actividad A1.

Tabla 9. Características en la Actividad A1

\begin{tabular}{ll}
\hline \multicolumn{1}{c}{ Características } & \multicolumn{1}{c}{ Actividad A1 } \\
\hline Contexto & Indicar los puntos del plano, es una situación específicamente \\
Datos del & matemática, perteneciente al ámbito académico, situación científica. \\
enunciado & Texto breve con los datos relevantes, con elementos geométricos. La \\
& representación gráfica muestra la situación dos rectas que se cortan, y \\
& sitúa en ellas los puntos indicados en el enunciado, dando distancias \\
& diferentes a los segmentos AB y EF. La única alusión métrica en el \\
& dibujo es el ángulo que forman las rectas, no hay distancias. La \\
& representación gráfica completa la información relevante de los datos \\
& geométricos. \\
Tipología de tarea & Requiere de conocimientos previos específicos, acerca de los lugares \\
& geométricos vistos en el curso, presenta un desafío, cuál o cuáles \\
& resuelven la situación. Resulta ser un problema. \\
& Exige conocer todos los lugares geométricos vistos en el curso. \\
& Exige interpretar la representación gráfica brindada porque se trabajará \\
& en ella. \\
& Es necesario saber trazar bisectriz y circunferencia con lápiz y papel. \\
& Determinar los puntos equidistantes de los lados de un ángulo y asociar \\
& a la bisectriz del ángulo \\
& Descubrir que hay cuatro ángulos y no sólo quedarse con el agudo. \\
& Descifrar los elementos de una circunferencia. Determinar el círculo a \\
& través de la expresión “a menos de 4,5cm". \\
& Interceptar las figuras y seleccionar los puntos que cumplen las dos \\
& condiciones a la vez, con la precisión de excluir los puntos del borde. \\
& Para acceder a la solución se necesita emplear conocimiento \\
& matemático, analizar y armar un plan, por tal necesita proceso de \\
& conexión.
\end{tabular}

En la tabla 10 (Anexo C, tabla 29) se analizan los componentes del sentido espacial requeridos para resolver la actividad A8, que solicita la construcción de un trapecio con 
datos precisos de medidas de segmentos, distancias, amplitud de ángulos, y conocimiento de conceptos de diagonal y lados paralelos.

Tabla 10. Componentes del sentido espacial en actividad A8

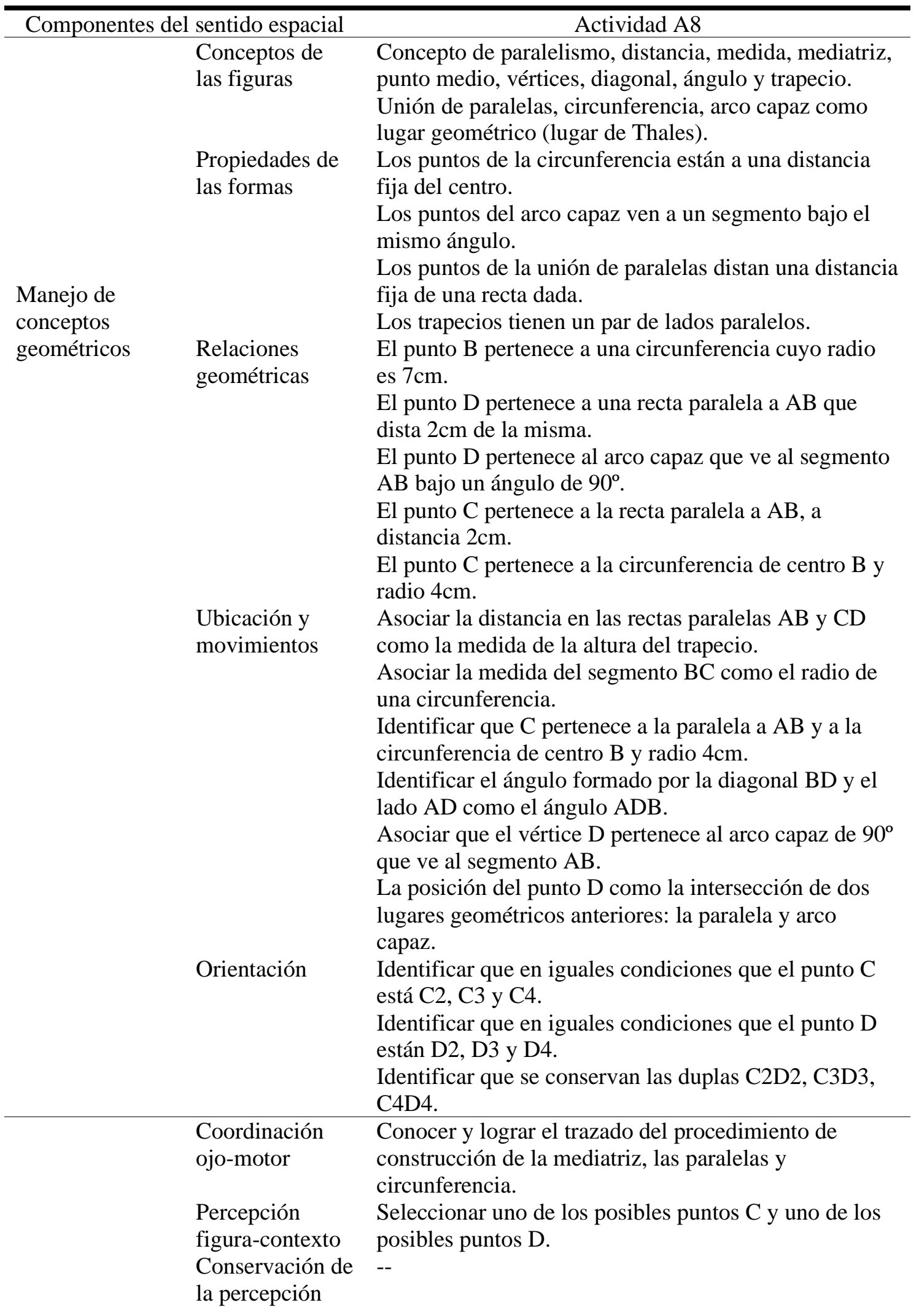


Habilidades de visualización
Percepción de la posición en el espacio Percepción de las relaciones espaciales Discriminación visual Memoria visual
Relacionar la posición del punto C con D y seleccionar un de los posibles para cada posición.

Determinar que la posición de $\mathrm{C}$ y $\mathrm{D}$ teniendo en cuenta la posición de la recta $\mathrm{AB}$.

En la tabla 11 (Anexo C, tabla 30) el análisis corresponde a las características que presenta la actividad A8.

Tabla 11. Características en la Actividad A8

\begin{tabular}{ll}
\hline \multicolumn{1}{c}{ Características } & \multicolumn{1}{c}{ Actividad A8 } \\
\hline Contexto & Construir un trapecio ABCD, es una situación específicamente \\
& matemática, perteneciente al ámbito académico, situación \\
& científica. \\
Datos del enunciado & Texto breve con los datos relevantes, específicamente \\
Tipología de tarea & geométricos. \\
& Requiere de conocimientos previos específicos, acerca de los \\
& lugares geométricos vistos en el curso, presenta un desafío, cuál o \\
& cuáles se deben combinar para determinar el trapecio. Resulta ser \\
& un problema. \\
& Saber qué es un trapecio. \\
& Exige conocer todos los lugares geométricos vistos en el curso. \\
& Asociar el dato de la distancia entre paralelas como la altura del \\
& trapecio y la ubicación de esa distancia en un segmento \\
& perpendicular a uno de los lados AB o CD. \\
& Identificar que conviene comenzar a construir por el segmento \\
& AB, en tanto que es uno de los lados paralelos y se tiene la \\
& medida. \\
& Asociar la medida del lado BC y el punto B como elementos de \\
& una circunferencia. \\
& Formar el ángulo ADB de $90^{\circ}$ con los datos dados y asociarlo al \\
& segmento AB para construir el arco capaz. \\
& Asociar que el vértice C y D se van a encontrar la paralela a AB. \\
& Interceptar paralela y arco capaz de $90^{\circ}$ para encontrar D \\
& Interceptar paralela y circunferencia de centro B para encontrar C. \\
& Saber trazar paralelas a una distancia dada, mediatriz, \\
circunferencia y arco capaz de $90^{\circ}$ con lápiz y papel. & Para acceder a la solución se necesita emplear conocimiento \\
matemático, analizar y armar un plan, por tal necesita proceso de \\
reflexión.
\end{tabular}

\subsection{Discusión y resultados}

Esta investigación en sus objetivos se propone identificar algunas dimensiones de semejanza y diferencias entre las actividades propuestas en PISA sobre geometría y las 
planteadas en el aula para evaluar aprendizaje geométrico e identificar componentes del sentido espacial que promueven sean aprendidos por los estudiantes de 15 años.

Para la presentación de los resultados se confeccionan dos tablas, una que atiende las características de las actividades y otra para los componentes del sentido espacial, esta vez agrupándolas de acuerdo con su procedencia, es decir, actividades de aula y actividades de PISA 2003 y 2012, que se presentan en el Anexo D.

Con los análisis agrupados en el Anexo D se confecciona la tabla 14 que sintetiza la información acerca de las componentes del sentido espacial, en sus dos categorías: manejo de conceptos geométricos y habilidades de visualización, que fueron definidas en el marco teórico; en ella se señala ausencia o presencia de la componente en la resolución.

Para la clasificación de las características de las actividades, se utiliza la presentada por PISA 2003 (ANEP, 2004) en relación con el contexto y los niveles de complejidad, para los datos del enunciado se considera la realizada por Arévalo (2009), y la que proponen Castro y Ruiz (2015) para la tipología de tarea.

Los resultados atienden las tres categorías de análisis que se establecieron en el marco metodológico: el manejo de los conceptos geométricos, las habilidades de visualización y las características de las actividades. De este modo se discuten los hallazgos encontrados en las propuestas de PISA y de aula.

\subsubsection{Resultados de las actividades de PISA}

Características. Con los análisis agrupados en el Anexo D se confecciona la tabla 12 que sintetiza la información acerca de las características que presentan las actividades liberadas por PISA.

Contexto. Cuatro de las actividades propuestas se presentan en un contexto laboral, la cerca del carpintero, la altura de los escalones, el garaje que se va a comprar o el área de su techo; mientras que el ángulo entre dos hojas de una puerta giratoria y la longitud de la abertura de esta, son clasificadas en PISA 2012 como contexto científico; la restante del dado, en tanto que elemento vinculado al juego se considera un contexto personal.

Datos del enunciado. Los datos brindados en el enunciado de la actividad, según la clasificación que realiza (Arévalo, 2009), todas se clasifican en forma esquemática dado 
que en los esquemas, diseños o dibujos se brinda información relevante para la resolución y en tres de las actividades en su esquema se agregan datos irrelevantes. Una sola de las tareas además se categoriza en forma de texto, es decir que proporciona datos relevantes para la solución; las otras donde hay texto, lo datos no son relevantes.

Tipología de tarea. Seis actividades se consideran problemas, según la clasificación que hace Castro y Ruiz (2015), le implican un reto al estudiante, para encontrar la solución debe examinar procedimientos que no le son fácilmente accesibles, es el caso del carpintero, el dado, el garaje y la puerta giratoria; mientras que la escalera es considerada un ejercicio porque el estudiante conoce un método o rutina para encontrar la solución.

La complejidad cognitiva. Tres de las actividades, se consideran en niveles de conexión, en tanto que exigen resolver problemas no rutinarios, algunas de ellas tienen una mayor demanda de interpretación de los datos, si bien la resolución se obtiene con algoritmos conocidos como puede ser girar el garaje para encontrar la respuesta correcta. Otras tres exigen un nivel de complejidad de reflexión en tanto que se precisa deducir los elementos para acceder a la resolución. Mientras que en la actividad de la escalera la complejidad es de reproducción, se emplea la división para encontrar la solución.

Tabla 12. Características en actividades de PISA

\begin{tabular}{lllll}
\hline Actividad & Contexto & Datos del enunciado & $\begin{array}{c}\text { Tipología de } \\
\text { tarea }\end{array}$ & Complejidad \\
\hline $\mathbf{C}$ & Laboral & $\begin{array}{l}\text { Esquemática } \\
\text { Esquemática con } \\
\text { datos irrelevantes. }\end{array}$ & $\begin{array}{l}\text { Problema } \\
\text { Ejercicio }\end{array}$ & $\begin{array}{l}\text { Conexión } \\
\text { Reproducción }\end{array}$ \\
D & Paboral & $\begin{array}{l}\text { Texto. Esquemática. } \\
\text { Texto con datos } \\
\text { G1 }\end{array}$ & $\begin{array}{l}\text { Problema } \\
\text { Problema }\end{array}$ & $\begin{array}{l}\text { Conexión } \\
\text { Conexión }\end{array}$ \\
Gaboral & Esquemática & Problema & Reflexión \\
PG1 & Laboral & $\begin{array}{l}\text { Esquemática con } \\
\text { datos irrelevantes. }\end{array}$ & Problema & Reflexión \\
PG2 & Científico & $\begin{array}{l}\text { Esquemática con } \\
\text { datos irrelevantes. } \\
\text { Texto irrelevante. } \\
\text { Esquemática. }\end{array}$ & Problema & Reflexión \\
\hline
\end{tabular}

Manejo de los conceptos geométricos. Todas las actividades requieren en su resolución conocer conceptos de algunas figuras geométrica en dos y tres dimensiones tales como triángulo, rectángulo, paralelogramo, cubo, prisma, ángulos, distancia y medida entre otros. A la vez requieren del empleo de las propiedades de las formas tales como perímetro, área y teorema de Pitágoras. Están implicas en la resolución de todas las 
actividades las relaciones geométricas tales como paralelismo entre lados y entre planos, perpendicularidad entre lados y entre planos, amplitud de un sector de circunferencia, ángulos completos, obtusos, entre otras.

La ubicación y los movimientos se requieren en cuatro de las siete actividades, es el caso del cubo, del garaje en G1 y en los dos casos de la puerta giratoria. Mientras la orientación se emplea en cinco de las siete actividades, en la escalera, el dado, en las dos del garaje y en la puerta giratoria $\mathrm{G} 2$.

Habilidades de visualización. Las habilidades visuales más requeridas para resolver las actividades de PISA son tres: conservación de la percepción, percepción de la posición en el espacio y percepción de las relaciones espaciales, aparecen en cinco o en seis de las actividades para su resolución. Mientras que la discriminación visual es utilizada en cuatro actividades, en el carpintero, en el dado, en el garaje G1 y en la puerta giratoria.

De los resultados de la tabla 14 se puede afirmar que no hay una habilidad que sea necesaria para la resolución de todas las actividades. Asimismo, la habilidad ojo-motor y memoria visual no resultaron necesarias para resolver las actividades; y una habilidad poco requerida es la percepción figura-contexto, en sólo dos actividades aparece, en el carpintero y en el garaje G1.

\subsubsection{Resultados de las actividades de aula}

Características. A partir del Anexo D se confecciona la tabla 13 que sintetiza la información de las características de las nueve actividades de aula, que los docentes consideran al momento de proponer una evaluación en geometría.

Contexto. Todas las actividades de aula son propuestas en un contexto científico (ANEP, 2004) en tanto que presentan situaciones abstractas, solicitan determinar conjunto de puntos, triángulos y trapecios que deben cumplir con condiciones establecidas.

Datos del enunciado. Los datos brindados en el enunciado de todas las actividades de aula, según la clasificación de Arévalo (2009), se caracterizan por la forma de texto, un texto breve que sólo contiene información relevante; además cuatro de ellas presentan forma esquemática sobre la que se debe trabajar para resolverlas: la A1 dos rectas secantes con cuatro puntos en cada una las semirrectas determinadas, la A3 un segmento no paralelo a la horizontal, la A5 un trapecio y la A9 dos rectas paralelas y un punto en una 
de ellas. En todas las actividades, la información brindada es necesaria, no hay datos irrelevantes.

Tipología de tarea. Todas las actividades de aula, según la clasificación de Castro y Ruiz (2015) se consideran problemas, el estudiante debe examinar los procedimientos que dispone y combinarlos, ya que en ningún caso con un solo procedimiento es suficiente, además debe saberlos trazar con regla y compás para arribar a la solución.

La complejidad cognitiva. Todas las actividades de aula presentan un nivel de complejidad de conexión (ANEP, 2004), en tanto que exigen establecer relaciones entre la información brindada y los datos requeridos para identificar los lugares geométricos, que le fueron presentados en el curso porque no aparecen en el enunciado y tienen diferentes elementos que los permiten reconocer, además de conocer los procedimientos de obtención de los mismo. Tal vez el más sencillo de identificar por sus los elementos sea la circunferencia y el más complejo el arco capaz.

Tabla 13. Características en actividades de aula

\begin{tabular}{|c|c|c|c|c|c|}
\hline Actividades & Contexto & Dato & del enunciado & $\begin{array}{l}\text { Tipología } \\
\text { de tarea }\end{array}$ & Complejidad \\
\hline A1 & \multirow{9}{*}{ 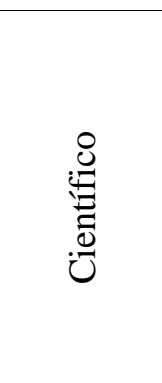 } & \multirow{9}{*}{ 章 } & \multirow[t]{2}{*}{ Esquemática } & \multirow{9}{*}{$\begin{array}{l}\frac{\widetilde{Z}}{0} \\
\frac{0}{0} \\
\frac{0}{2}\end{array}$} & \multirow{9}{*}{ ن̃ } \\
\hline A2 & & & & & \\
\hline A3 & & & Esquemática & & \\
\hline A4 & & & & & \\
\hline A5 & & & Esquemática & & \\
\hline A6 & & & & & \\
\hline A7 & & & & & \\
\hline A8 & & & & & \\
\hline A9 & & & Esquemática & & \\
\hline
\end{tabular}

Manejo de los conceptos geométricos. Todas las actividades de aula son de construcción geométrica, requieren conocer conceptos de lugares geométricos: circunferencia, círculo, mediatriz, bisectriz, paralelas, paralela media y arco capaz, además de distancia, medida, ángulos, triángulos, paralelogramos y trapecios entre otros.

Propiedades de las formas. Todas estas actividades requieren del empleo de las propiedades que cumplen todos los puntos del plano que están en los respectivos lugares geométricos, por ejemplo, la equidistancia entre rectas, que requiere pensar en distancias como medida de segmentos perpendiculares a ambas rectas, trazados desde cada punto de estas para obtener la paralela media o la bisectriz. 
Relaciones geométricas. Están implicas en la resolución de todas las actividades las relaciones geométricas, todas las soluciones implican interceptar lugares geométricos, es decir identificar los puntos que cumplen dos condiciones a la vez que no aparecen en el enunciado. Buscar todos los puntos que se encuentran, más cerca de un punto que de otro y en un arco capaz, A3 es una de las actividades de aula con menor habilidades espaciales requeridas.

Ubicación y movimientos. La ubicación y los movimientos se requieren en ocho de las nueve actividades, exige establecer posiciones relativas de segmentos de bisectrices en relación a un círculo (A1), asociar la medida de la altura de un triángulo a la distancia entre rectas paralelas (A4) y la distancia del circuncentro a un vértice como el radio de una circunferencia con centro el vértice (A6).

Orientación. Cinco de las nueve actividades requieren orientación para determinar la solución, las que solicita la construcción de triángulos y trapecios, ya que encontrar los vértices exige la intersección de dos lugares geométricos que, en general, tiene más de un punto en la solución, de ese modo se tiene que seleccionar qué punto obtenido se corresponde con qué vértice de la figura solicitada.

Habilidades de visualización. Tres son las habilidades de visualización que se ponen en juego a la hora de resolver todas las actividades de aula: coordinación ojo-motor, percepción figura-contexto y percepción de relaciones espaciales.

Coordinación ojo-motor, es la habilidad que se requiere para construir con regla y compás, no sólo es preciso conocer el procedimiento de trazado sino lograr hacerlo. De los procedimientos más simples puede resultar el trazado de la circunferencia, no así las paralelas y menos aún el arco capaz.

Percepción figura-contexto, se requiere al momento de determinar la solución de cada una de las actividades, después de tener todos los trazados, se requiere seleccionar los puntos que cumplen las condiciones solicitadas.

Percepción de las relaciones espaciales. Para determinar la solución se necesita establecer cuáles son los puntos que se deben seleccionar en función de las relaciones que deben cumplir (A7, A8), en otros es preciso identificar un punto que no fue nombrado en el enunciado, que es auxiliar para llegar a los vértices de la figura buscada (A9). 
Menos requerida es la percepción de la posición en el espacio, aparece en dos actividades, en A7 y A8, porque exige relacionar dos vértices encontrados, para cada par de vértices encontrados, se pueden construir diferentes trapecios. Las otras dos habilidades de visualización: conservación de la percepción y memoria visual, parecieran no ser requeridas en las construcciones solicitadas.

\subsubsection{Resultados de las actividades de evaluación en geometría}

En este apartado se profundiza en algunas semejanzas y diferencias que se han encontrado en las actividades de evaluación en geometría propuestas en el aula y en PISA.

Características. En cuanto a los contextos, se podría generalizar que las actividades de PISA del estudio se contextualizan en situaciones laborales, mientras las de aula son en contextos científicos.

En atención a los datos del enunciado, todas las actividades salvo los dados, el garaje (G1) y la puerta giratoria (PG2), presentan medidas en sus datos. La diferencia está en las respuestas solicitadas, son cuatro las actividades de PISA que solicitan una medida por respuesta; mientras que en las actividades de aula las medidas son una mediación para la construcción solicitada. Otro aspecto para señalar como diferencia es la aparición en los enunciados de PISA de datos irrelevantes mientras que en las actividades de aula todos los datos brindados son necesarios para obtener la solución.

En relación con la tipología de tarea, se puede decir que la mayoría de las actividades analizadas se corresponden con ser un problema para que el estudiante resuelva, sin embargo, es oportuno señalar que las estrategias para encontrar la solución son diversas. Tres de las siete actividades de PISA requieren identificar respuestas, mientras que en todas las actividades de aula se requiere construir, la solución se obtiene si se conocen los procedimientos y si se logran los trazados.

En cuanto al nivel de complejidad cognitiva, si se considera la caracterización realizada por PISA 2012 (ANEP, 2013), son sólo tres de las 16 actividades analizadas en el nivel de reflexión, que se corresponden con las de PISA, G2, PG1 y PG2, en todas se solicita una medida por respuesta y en dos de ellas es preciso conocer un algoritmo directo de resolución. Sin embargo, las actividades de aula exigen un nivel de conexión, que supone cierto grado de comprensión de los datos, ya que los lugares geométricos no se citan en 
el enunciado, se debe comenzar por seleccionar cuál de los posibles es necesario utilizar, conocer su procedimiento de obtención y combinarlo con otro para determinar lo solicitado.

Manejo de los conceptos geométricos. De los datos presentes en la tabla 14, todas las actividades analizadas, tanto las de aula como las de PISA, requieren conocer conceptos y propiedades, y hacer uso de las relaciones geométricas; en menor medida es necesario la ubicación, el uso de los movimientos y la orientación para obtener la solución.

Habilidades de visualización. La habilidad requerida en la mayoría de las actividades es la percepción de las relaciones espaciales, que más arriba se analizó con detalle. Mientras que las actividades de PISA requieren de la conservación de la percepción, la percepción de la posición en el espacio y en menor medida la discriminación visual; las actividades de aula requieren las habilidades de coordinación ojo-motor y percepción figura-contexto, necesarias para construir, en particular cuando se trabaja con regla y compás.

Tabla 14. Componentes del sentido espacial en las actividades

\begin{tabular}{|c|c|c|c|c|c|c|c|c|c|c|c|c|c|c|c|c|c|}
\hline \multicolumn{2}{|c|}{$\begin{array}{l}\text { Componentes del sentido } \\
\text { espacial }\end{array}$} & $\mathrm{C}$ & $\mathrm{E}$ & $\mathrm{D}$ & $\begin{array}{l}\mathrm{G} \\
1\end{array}$ & $\begin{array}{l}\mathrm{G} \\
2\end{array}$ & $\begin{array}{l}P \\
G \\
1\end{array}$ & $\begin{array}{l}\mathrm{P} \\
\mathrm{G} \\
2\end{array}$ & $\begin{array}{l}\text { A } \\
1\end{array}$ & $\begin{array}{l}\mathrm{A} \\
2\end{array}$ & $\begin{array}{l}\mathrm{A} \\
3\end{array}$ & $\begin{array}{l}\text { A } \\
4\end{array}$ & $\begin{array}{l}\text { A } \\
5\end{array}$ & $\begin{array}{l}\text { A } \\
6\end{array}$ & $\begin{array}{l}\text { A } \\
7\end{array}$ & $\begin{array}{l}\text { A } \\
8\end{array}$ & $\begin{array}{l}\text { A } \\
9\end{array}$ \\
\hline \multirow{5}{*}{$\begin{array}{l}\text { Manejo de } \\
\text { conceptos } \\
\text { geométricos }\end{array}$} & $\begin{array}{l}\text { Conceptos de } \\
\text { las figuras }\end{array}$ & $\mathrm{x}$ & $\mathrm{X}$ & $\mathrm{X}$ & $\mathrm{x}$ & $\mathrm{x}$ & $\mathrm{x}$ & $\mathrm{x}$ & $\mathrm{x}$ & $\mathrm{x}$ & $\mathrm{x}$ & $\mathrm{X}$ & $\mathrm{x}$ & $\mathrm{x}$ & $\mathrm{x}$ & $\mathrm{x}$ & $\bar{x}$ \\
\hline & $\begin{array}{l}\text { Propiedades de } \\
\text { las formas }\end{array}$ & $\mathrm{x}$ & $\mathrm{x}$ & $\mathrm{x}$ & $\mathrm{x}$ & $\mathrm{x}$ & $\mathrm{x}$ & $\mathrm{X}$ & $\mathrm{x}$ & $\mathrm{x}$ & $\mathrm{x}$ & $\mathrm{x}$ & $\mathrm{x}$ & $\mathrm{X}$ & $\mathrm{X}$ & $\mathrm{X}$ & $\mathrm{x}$ \\
\hline & $\begin{array}{l}\text { Relaciones } \\
\text { geométricas }\end{array}$ & $\mathrm{x}$ & $\mathrm{X}$ & $\mathrm{X}$ & $\mathrm{x}$ & $\mathrm{x}$ & $\mathrm{x}$ & $\mathrm{x}$ & $\mathrm{X}$ & $\mathrm{X}$ & $\mathrm{X}$ & $\mathrm{X}$ & $\mathrm{x}$ & $\mathrm{x}$ & $\mathrm{x}$ & $\mathrm{x}$ & $\mathrm{X}$ \\
\hline & $\begin{array}{l}\text { Ubicación y } \\
\text { movimientos }\end{array}$ & & & $\mathrm{X}$ & $\mathrm{x}$ & & $\mathrm{X}$ & $\mathrm{X}$ & $\mathrm{X}$ & $\mathrm{X}$ & $\mathrm{X}$ & $\mathrm{X}$ & & $\mathrm{X}$ & $\mathrm{X}$ & $\mathrm{x}$ & $\mathrm{X}$ \\
\hline & Orientación & & $\mathrm{x}$ & $\mathrm{X}$ & $\mathrm{X}$ & $\mathrm{X}$ & & $\mathrm{X}$ & & $\mathrm{X}$ & & $\mathrm{X}$ & & & $\mathrm{X}$ & $\mathrm{X}$ & $\mathrm{X}$ \\
\hline \multirow{7}{*}{$\begin{array}{l}\text { Habilidades } \\
\text { de } \\
\text { visualización }\end{array}$} & $\begin{array}{l}\text { Coordinación } \\
\text { ojo-motor }\end{array}$ & & & & & & & & $\mathrm{X}$ & $\mathrm{X}$ & $\mathrm{x}$ & $\mathrm{X}$ & $\mathrm{x}$ & $\mathrm{X}$ & $\mathrm{X}$ & $\mathrm{x}$ & $\mathrm{X}$ \\
\hline & $\begin{array}{l}\text { Percepción } \\
\text { figura-contexto }\end{array}$ & $\mathrm{X}$ & & & $\mathrm{x}$ & & & & $\mathrm{X}$ & $\mathrm{X}$ & $\mathrm{X}$ & $\mathrm{X}$ & $\mathrm{X}$ & $\mathrm{X}$ & $\mathrm{X}$ & $\mathrm{X}$ & $\mathrm{X}$ \\
\hline & $\begin{array}{l}\text { Conservación de } \\
\text { la percepción }\end{array}$ & $\mathrm{x}$ & $\mathrm{x}$ & $\mathrm{x}$ & $\mathrm{x}$ & & $\mathrm{x}$ & & & & & & & & & & \\
\hline & $\begin{array}{l}\text { Percepción de la } \\
\text { posición en el } \\
\text { espacio }\end{array}$ & & $\mathrm{x}$ & $\mathrm{x}$ & $\mathrm{x}$ & $\mathrm{X}$ & $\mathrm{X}$ & $\mathrm{x}$ & & & & & & & $\mathrm{x}$ & $\mathrm{X}$ & \\
\hline & $\begin{array}{l}\text { Percepción de } \\
\text { las relaciones } \\
\text { espaciales }\end{array}$ & $\mathrm{X}$ & $\mathrm{X}$ & $\mathrm{X}$ & $\mathrm{X}$ & $\mathrm{X}$ & & $\mathrm{X}$ & $\mathrm{X}$ & $\mathrm{X}$ & $\mathrm{X}$ & $\mathrm{X}$ & $\mathrm{X}$ & $\mathrm{X}$ & $\mathrm{X}$ & $\mathrm{X}$ & $\mathrm{X}$ \\
\hline & $\begin{array}{l}\text { Discriminación } \\
\text { visual }\end{array}$ & $\mathrm{x}$ & & $\mathrm{x}$ & $\mathrm{x}$ & & $\mathrm{x}$ & & & & & & & & & & \\
\hline & Memoria visual & & & & & & & & & & & & & & & & \\
\hline
\end{tabular}




\section{CAPÍTULO 5. CONCLUSIONES}

Este capítulo está dedicado a mostrar las relaciones y significados que se establecen entre los resultados obtenidos en esta investigación, el marco teórico que le dio sustento y los objetivos propuestos. Además, se detallan algunas limitaciones del estudio y se dejan planteadas futuras líneas de investigación.

\subsection{Conclusiones generales}

A lo largo de la investigación la atención estuvo centrada en la evaluación en matemáticas, en particular en geometría, en dos tipos de pruebas, las propuestas por PISA y las de los docentes de aula. En ambas se atienden algunas características presentes en las actividades, así como las componentes del sentido espacial requeridas para resolverlas a los estudiantes de 15 años que en su mayoría cursan $1^{\circ}$ de bachillerato.

Determinar las componentes del sentido espacial que las actividades del estudio promueven que sean aprendidas por los estudiantes, en tanto que son evaluadas, es uno de los objetivos planteados al inicio. Las actividades de PISA buscan evaluar un aprendizaje funcional de la geometría, evaluar el desarrollo del sentido espacial en los estudiantes (ANEP, 2004) y las actividades de aula por su parte buscan evaluar el aprendizaje de los elementos geométricos (CES, 2010d). Es significativo considerar que de los resultados se desprende que tanto las actividades de PISA como las de aula buscan evaluar el aprendizaje del manejo de conceptos geométricos en todos sus aspectos (Flores, Ramírez y del Río, 2015) y de algunas habilidades de visualización.

Nuestro estudio puede unirse a la distinción que McGee (1979) hace respecto de la visualización y la orientación espacial, hemos encontrado actividades como el carpintero, la puerta giratoria (PG1) y algunas actividades de aula (A1, A5 y A6) que se resuelven utilizando las habilidades de visualización: percepción figura-contexto, percepción de las relaciones espaciales, y conservación de la percepción o coordinación ojo-motor, sin que se requiera específicamente la orientación espacial.

Identificar las habilidades del sentido espacial utilizadas con mayor énfasis en las actividades de PISA y de aula, es un objetivo que este estudio permitió abordar en su 
totalidad. Se establece que las habilidades más requeridas, por tanto, evaluadas en PISA son: conservación de la percepción, percepción de la posición en el espacio y percepción de las relaciones espaciales, y en menor medida la discriminación visual. Las habilidades necesarias en las actividades de aula y por tanto evaluadas por los docentes son: coordinación ojo-motor, percepción figura-contexto y percepción de las relaciones espaciales (Del Grande, 1990; Frosting y Home, 1964; Hoffer, 1977).

En relación con el planteo de Presmeg (2006), de cómo interactúa la visualización con la didáctica de la matemática, a partir de los resultados de las actividades de aula, como actividades de evaluación del aprendizaje de los elementos geométricos, se puede inferir que los docentes con su enseñanza buscan desarrollar las habilidades de visualización en los estudiantes, si bien no es posible establecer cuánto influye ese desarrollo en el aprendizaje de las matemáticas.

Identificar dimensiones en las que se asemejan y se diferencian las actividades propuestas en PISA y en el aula, es otro de los objetivos de este estudio. En relación con las semejanzas, a partir de los resultados se da respuesta a una de las preguntas que Niss (1993) formula como componentes de la evaluación, ¿qué tipo de actividades se proponen?, todas menos una son problemas, de acuerdo con la clasificación de Castro, Ruiz (2015).

Otra semejanza la encontramos al responder a la pregunta de Niss (1993), ¿qué se evalúa?, ambas evalúan a través de las actividades propuestas el manejo de los conceptos geométricos, en sus distintos apartados: las propiedades, las relaciones geométricas, la ubicación y los movimientos, y la orientación (Flores, Ramírez y del Río, 2015) y de este modo se cumple con algunos de los aspectos planteados en el NCTM (2000) acerca de la evaluación en geometría que pretende que el estudiante pueda analizar propiedades y explorar relaciones entre objetos, entre otros.

Un aspecto vinculado al anterior, que es semejanza y diferencia a la vez entre las actividades de aula y las de PISA son las habilidades de visualización que forman parte de ¿qué se evalúa? (Niss, 1993). Todas las actividades, tanto las de aula como las de PISA requieren de habilidades de visualización, ya detalladas en los resultados, y se diferencian en cuáles son las requeridas. 
Las diferencias encontradas en las actividades propuestas por PISA y por los docentes en el aula parecieran ser mayores que las semejanzas. Webb (1993) entiende que el fin de la evaluación es describir el nivel de conocimiento y desempeño, el grado de adquisición (Alsina et al., 1997), se unen a esta idea las investigaciones acerca de la demanda cognitiva (Stein et al., 2009; Benedicto et al., 2015). A partir de los resultados se puede concluir que las actividades de aula requieren un desempeño de conexión, mientras que las actividades de PISA, entre los dos años considerados, 2003 y 2012, presentan actividades que abarcan los tres niveles de complejidad, reproducción, conexión y reflexión (ANEP, 2004 y 2013; Caraballo et al., 2011).

Otra diferencia entre las actividades viene dada por el contexto (ANEP, 2004 y 2013; Caraballo et al., 2011), en su mayoría las de PISA presentan un contexto laboral, mientras que todas las de aula un contexto científico.

Se diferencian también por los datos del enunciado (ANEP, 2004; Arévalo, 2009), las actividades de PISA priorizan la representación esquemática de la información o a través de textos largos, en ambos casos con aparición de datos considerados irrelevantes. Las actividades de aula, por el contrario, son textos breves con esquemas, que solo presentan información necesaria.

\subsection{Limitaciones de la investigación}

En el proceso realizado en el estudio se identifican limitaciones. Una de ellas se encuentra en la recogida de información, que en nuestra investigación refiere a las formas de resolver las actividades seleccionas. Si bien se buscó resolver en detalle, se confrontó con la mirada experta del director, sería oportuno además proveerse de las resoluciones de otras personas calificadas, por ejemplo, otros colegas, con el fin de enriquecer el análisis y brindar mayor validez al proceso.

Otra limitación puede ser, no contar con la resolución por parte de los estudiantes de las actividades propuestas por PISA, se pudo acceder a las resoluciones de las actividades de aula. Contar con ese material supondría basar la investigación en las resoluciones efectivas, realizadas por los alumnos y no a partir de los supuestos caminos de resolución.

Una tercera limitación es, no incorporar el error como componente de la evaluación. Considerar los errores que podrían cometer los estudiantes ante las diferentes actividades 
complementaría el análisis y ayudaría a detectar algunas dificultades ante el aprendizaje de la geometría.

Una cuarta limitación es que en la búsqueda de antecedentes se fue muy atrás en el tiempo, las investigaciones del sentido espacial más recientes fueron poco consideradas. El concepto está bien definido, se podría haber enriquecido y complementado con estas.

\subsection{Líneas abiertas}

La realización de esta investigación deja algunas líneas abiertas en relación con las actividades de evaluación en secundaria atendiendo a los estudiantes de 15 años. Se podría realizar una investigación similar ampliando la diversidad de orígenes de las actividades de aula, considerando actividades provenientes de diferentes instituciones, para corroborar o no los resultados obtenidos en esta.

Se puede pensar si las semejanzas y diferencias encontradas entre las actividades de PISA y las actividades de evaluación en el aula, para el contenido espacio y forma y los contenidos curriculares de geometría, aparecen también para otro contenido del dominio de la cultura matemática, cambio y relaciones y los contenidos curriculares relacionados con el sentido algebraico.

Si bien los resultados muestran que los docentes están planteando actividades de evaluación que requieren muchas componentes del sentido espacial, se podría desarrollar una investigación con docentes, que pueda aportar estrategias para el pasaje de un aprendizaje de los elementos geométricos a un aprendizaje competencial y funcional de la geometría. 


\section{REFERENCIAS}

Administración Nacional de Educación Pública (ANEP). (2004). La evaluación de la “cultura matemática” en PISA 2003. Marco conceptual y actividades de las pruebas. Gerencia de Investigación y Evaluación. https://www.anep.edu.uy/codicen/dspe/division-investigacion/departamentoevaluaci\%C3\%B3n-aprendizajes/pisa/2003

ANEP. (2013). Uruguay en PISA 2012. Gerencia de Investigación y Evaluación. https://www.anep.edu.uy/codicen/dspe/division-investigacion/departamentoevaluaci\%C3\%B3n-aprendizajes/pisa/2012/publicaciones

ANEP. (2017). Marco Curricular de Referencia Nacional (MCRN). Una construcción colectiva. ANEP. https://mcrn.anep.edu.uy/sites/default/files/Documento MCRN agosto 2017.pdf

Alsina, C., Burgués, C y Fortuny, J.M. (1997). Invitación a la didáctica de la geometría ( $4^{\mathrm{a}}$ Ed.). Síntesis.

Arcavi, A. (2003). The role of visual representations in the learning of mathematics. Educational Studies in Mathematics, 52, 215-241.

Arcavi, A. y Hadas, N. (2002). Computer mediated learning: an example of an approach. En F. Hitt (Ed.), Representations and mathematical visualization. Cinvestav IPN.

Arévalo, M. (2009). Comprensión de enunciados de problemas matemáticos. Respuestas, $14(2), 5-10$.

Battista, M. T. (2007). The development of geometric and spatial thinking. En F. Lester, (Ed.), Second Handbook of Research on Mathematics Teaching and Learning (pp. 843-908). Information Age Publishing.

Benedicto, C., Jaime, A. y Gutiérrez, A. (2015). Análisis de la demanda cognitiva de problemas de patrones geométricos. En C. Fernández, M. Molina y N. Planas (eds.), Investigación en Educación Matemática XIX (pp. 153-162). SEIEM.

Berry, J.W. (1971). Ecological and cultural factors in spatial perceptual development. Canadian Journal of Behavioural Science, 3(4), 324-336.

Bishop, A.J. (1972). Use of structural apparatus and spatial ability - a possible relationship. Psychology of Mathematics Education Workshop. Chelsea College. 
Bishop, A.J. (1973). The use of structural apparatus and spatial ability - a possible relationship. Research in Education, 9, 43-49.

Bishop, A.J. (1979). Visualising and mathematics in a pre-technological culture. Educational Studies in Mathematics, 10, 135-146.

Bishop, A.J. (1980). Spatial abilities and mathematics education. A review. Educational Studies in Mathematics, 11(3), 257-269. https://doi.org/10.1007/BF00697739

Bishop, A. J. (1989). Review of research on visualization in mathematics education. Focus on Learning Problems in Mathematics, 11 (1), 7-16.

Breen, C. (1997). Exploring imagery in P, M and E. En E. Pehkonen (Ed.), Proceedings of the 21st PME International Conference, 2, (pp. 97-104). Gummerus.

Brinkmann, E. H. (1966). Programmed instruction as a technique for improving spatial visualization. Journal of Applied Psychology, 50, 179-184.

Bruner, J. S. (1964). The course of cognitive growth. American Psychologist, 19, 1-15.

Caraballo, R.M., Rico, L. y Lupiáñez, J.L. (2011). Pruebas autonómicas de diagnóstico para evaluar la competencia matemática en educación secundaria. En M. Marín, G. Fernández García, L.J. Blanco y M. Palarea (Coords.), Investigación en educación matemática XV, 307-318. SEIEM.

Castro, E., Ruíz, J.F. (2015). Matemáticas y resolución de problemas. En P. Flores y L. Rico (Coords.), Enseñanza y aprendizaje de las matemáticas en educación primaria (pp. 89-106). Pirámide.

Clements, M. A. y Wattanawaha, N. (1978). The classification of spatial tasks suitable for the classroom. En D. Williams, (ed.), Learning and applying mathematics. Australian Association of Mathematics Teachers.

Consejo de Educación Secundaria (CES). (2006). Reglamento de evaluación y pasaje de grado de bachillerato de plan de reformulación 2006. ANEP. https://www.ces.edu.uy/index.php/340-propuestas-educativas/20103-planreformulacion-2006-bachillerato

CES. (2010a). Programa de matemática primer año. Ciclo básico, reformulación 2006, ajuste 2010. ANEP. https://www.ces.edu.uy/index.php/propuestaeducativa/20150

CES. (2010b). Programa de matemática segundo año. Ciclo básico, reformulación 2006, ajustes 2010. ANEP. https://www.ces.edu.uy/index.php/propuestaeducativa/20237 
CES. (2010c). Programa de matemática tercer año. Ciclo básico, reformulación 2006, ajustes 2010. ANEP. https://www.ces.edu.uy/index.php/propuestaeducativa/20234

CES. (2010d). Programa de matemática primer año. Bachillerato, reformulación 2006, ajuste 2010. ANEP. https://www.ces.edu.uy/index.php/propuestaeducativa/20207

CES. (2020). Orientaciones vinculadas con la evaluación de los aprendizajes: la calificación. Administración Nacional de Educación Pública. https://www.ces.edu.uy/index.php/noticias/30734-orientaciones-vinculadas-conla-evaluacion-de-los-aprendizajes-la-calificacion

Cunningham, S. (1991). The visualization environment for mathematics education. In W. Zimmermann y S. Cunningham (Eds.), Visualization in teaching and learning mathematics, 19, (pp. 67-76). Mathematical Association of America.

Dawson, J. L.M. (1967). Cultural and physiological influences upon spatial-perceptual processes in West Africa. Part 1. International Journal of Psychology, 2, 115-128.

Del Grande, J. (1987). Spacial perception and primary geometry. En M. M. Lindquist (Ed.) Learning and teaching geometry, K-12. Yearbook, 49, (pp.126-135). NTCM.

Del Grande, J. (1990). Spatial sense. The arithmetic teacher, 37 (6), 14-20.

Dörfler, W. (1991). Meaning: image schemata and protocols. En F. Furinghetti (Ed.), Proceedings of the 15th PME International Conference, 1, (pp.17-32). Program Committee of the 15th PME Conference.

Duval, R. (1999). Representation, vision and visualization: cognitive functions in mathematical thinking. Basic issues for learning. En F. Hitt y M. Santos (Eds.), Proceedings of the 21st North American PME Conference, 1, (pp.3-26). Gummerus.

Fennema, E. y Sherman, J. A. (1977). Sex-related differences in mathematics achievement, spatial visualization and socio-cultural factors. American Educational Researeh Journal 14, 51-71.

Fernández, T. (2013). La investigación en visualización y razonamiento espacial. Pasado, presente y futuro. En A. Berciano, G. Gutiérrez, A. Estepa y N. Climent (Eds.), Investigación en Educación Matemática XVII (pp. 19-42). SEIEM. 
Flores, P., Ramírez, R. y del Río, A. (2015). Sentido Espacial. En P. Flores y L. Rico (Coords.), Enseñanza y aprendizaje de las Matemáticas en Educación Primaria (pp. 127-146). Pirámide.

Frandsen, A. N. y Holder, J. R. (1969). Spatial visualization in solving complex verbal problems. Journal of Psychology, 73, 229-233.

Fry, C. J. (1988). Fijación ocular durante la lectura y solución de problemas verbales que contienen información extraña: relación con la capacidad de visualización espacial. En A. Borbas (Ed.). Actas de la $12^{a}$ Conferencia Internacional PME, 1 , (pp. 326-333). PME-NA.

Galton, F. (1883). Inquiries into the human faculty and its development. Macmillan.

Goldin, G.A. (2007). Representation in school mathematics a unifying research perspective. En J. Kilpatrick (Ed.), A research companion to principles and standards for school mathematics (pp.275-285). NCTM.

Guay, R. B. y McDaniel, E. D. (1977). The relationship between mathematics achievement and spatial abilities among elementary school children. Journal for Research in Mathematics Education 8, 211-215.

Guillén, G. (2001). Las relaciones entre familias de prismas. Una experiencia con estudiantes de Magisterio. Enseñanza de las Ciencias, 19(3), 415-431.

Gutiérrez, A. (1996). Visualization in 3-dimensional geometry: In search of a framework. En L. Puig y A. Gutierrez (Eds.), Proceedings of the 20th PME Conference, 1 (pp. 3-19). Universidad de Valencia.

Hadas, N. y Arcavi, A. (2001). Relearning mathematics - the case of dynamic geometrical phenomena and their unexpected Cartesian representations. En M. van den Heuvel-Panhuizen (Ed.), Proceedings of the 25th PME International Conference, 3, (pp.81-88). Utrecht University.

Hernández Sampieri, R.; Fernández-Collado, C. y Baptista, P. (2014). Metodología de la investigación ( $6^{\mathrm{a}}$ ed.). McGraw-Hill.

Kent, D. y Hedger, K. (1980). Growing tall. Educational Studies in Mathematics 11, 137179.

Krippendorff, K. (1990). Metodología de análisis de contenido. Teoría y práctica. Paidós.

Lean, G. A. y Clements, M. A. (1981). Spatial ability, visual imagery and mathematical performance. Educational Studies in Mathematics, 12, 1-33. 
Lesh, R. (1976). Transformation geometry in elementary school: some research issues. En J. L. Martin (Ed.), Space and geometry. ERIC/SMEAC, (pp. 185-243). Columbus.

López Noguero, F. (2002). El análisis de contenido como método de investigación. XXI Revista de Educación, 4, 167-179.

MacFarlane Smith, I. (1964). Spatial ability: its educational and social significance. University of London Press.

Markopoulos, C. y Potari, D. (1999). Forming relationships in three-dimensional geometry through dynamic environments. En O. Zaslavsky (Ed.), Proceedings of the 23rd PME International Conference, 3, (pp.73-280). Technion.

Mariotti, M.A. (2001). Justifying and proving in the Cabri environment. International Journal of Computers for Mathematical Learning, 6, 257-281.

Marriott, P. (1978). Fractions: now you see them, now you don't. En D. Williams (Ed.), Learning and applying mathematics. Australian Association of Mathematics Teachers.

Martin, J. L. (Ed.). (1976). Space and geometry. ERIC/SMEAC. Columbus.

McGee, M. G. (1979). Human spatial abilities: psychometric studies and environmental, genetic, hormonal, and neurological influences. Psychological Bulletin, 86, 889918.

Michael, W. B., Guilford, J. P., Fruchter, B. y Zimmerman, W. S. (1957). The description of spatial-visualization abilities. Educational and Psychological Measurement, 17, 185-199.

Mitchelmore, M. C. (1976). Cross-cultural research on concepts of space and geometry. En J. L. Martin (Ed.), Space and geometry. ERIC/SMEAC. (pp. 143-184). Columbus.

Mitchelmore, M.C. (1980). Three-dimensional geometrical drawing in three cultures. Educational Studies in Mathematics, 11, 205-216.

NCTM (1989). Curriculum and Evaluation Standards for School Mathematics. NCTM

NCTM (1995). Assessment Standards for School Mathematics. NCTM.

NCTM (2000). Principles and Standards for School Mathematics. NCTM.

New Jersey Mathematics Coalition (1996). Geometry and spatial sense, Standard 7. En New Jersey Mathematics Curriculum Framework, (pp. 209-249).

Niss, M. (1993). Assessment in mathematics education and its effects: an introduction. In M. Niss (eds.), Investigations into assessment in mathematics education. New 
ICMI Study Series, 2 (pp.1-30). Springer. https://doi.org/10.1007/978-94-0171974-2_1

OECD (2003). The PISA 2003 assessment framework. Mathematics, reading, science and problem solving knowledge and skills. OECD.

OECD (2004). Learning for tomorrow's world: First results from PISA 2003. OECD.

Owens, K. y Outhreda, L. (2006). The complexity of learning geometry and measurement. Á. Gutiérrez y P. Boero (eds.), Manual de investigación sobre la psicología de la educación matemática: pasado, presente y futuro, (pp. 83-115). Sense Publishers.

Parzysz, B. (1999). Visualization and modeling in problem solving: from algebra to geometry and back. En O. Zaslavsky (Ed.), Proceedings of the 23rd PME International Conference, 1, (pp.212-219). Technion.

Piaget, J. e Inhelder, B. (1956). The child's conception of space. Routledge y Kegan Paul.

Piaget, J., lnhelder, B. y Szeminska, A. (1960). The child's conception of geometry. Routledge y Kegan Paul.

Pratt, D. y Davison, I. (2003). Interactive whiteboards and the construction of definitions for the kite. En N. Pateman, B. J. Dougherty y J. Zillox (Eds.), Proceedings of the 27th PME International Conference, 4, (pp.31-38). IGPME.

Presmeg, N. C. (1986). Visualization in high school mathematics. For the Learning of Mathematics, 6(3), 42-46.

Presmeg, N. C. (1991). Classroom aspects which influence use of visual imagery in high school mathematics. En Furinghettti (Ed.), Proceedings of the 15th PME International Conference, 3, (pp.191-198). Program Committee of the 15th PME Conference.

Presmeg, N. C. (2006). Research on visualization in learning and teaching mathematics. En Á. Gutiérrez y P. Boero (Eds.), Handbook of research on the psychology of mathematics education. Past, present and future, (pp.205-236). Sense Publishers.

Radatz, H. (1979). Some aspects of individual differences in mathematics instruction. Journal for Research in Mathematics Education, 10, 359-363.

Rico, L. (2004). La evaluación de matemáticas en el proyecto Pisa. En R. Pajares, Á. Sanz y L. Rico. Aproximación a un modelo de evaluación: el proyecto Pisa 2000. Secretaría General Técnica.

Rico, L. (2013). El método del análisis didáctico. Unión. Revista Iberoamericana de Educación Matemática, 33, 11-27. 
Rico, L. y Fernández Cano, A. (2013). Análisis didáctico y metodología de investigación. En L. Rico, J.L. Lupiáñez y M. Molina (Coord.), Análisis didáctico en educación matemática, (pp.1-22).

Rivera, F. D. (2011). Toward a visually-oriented school mathematics curriculum. Research, theory, practice, and issues. Springer.

Saunderson, A. (1973). The effect of a special training programme on spatial ability test performance. New Guinea Psychologist, 5, 15-23.

Smith, M. S. y Stein, M. K. (1998). Selecting and creating mathematical tasks: From research to practice. Mathematics Teaching in the Middle School, 3(5), 344-350.

Sinclair, M. P. (2003). The provision of accurate images with dynamic geometry. En N. Pateman, B. J. Dougherty y J. Zillox (Eds.), Proceedings of the 27th PME International Conference, 4, (pp.191-198). IGPME.

Spearman, C. E. (1927). The abilities of man: their nature and measurement. Macmillan.

Stein, M. K., Smith, M. S., Henningsen, M. A. y Silver, E. A. (2009). Implementing standards-based mathematics instruction: a casebook for professional development. Teachers College Press.

Stylianou, D. (2001). On the reluctance to visualize in mathematics: Is the picture changing? En M. van den Heuvel-Panhuizen (Ed.), Proceedings of the 25th PME International Conference, 4, (pp.225-232). Utrecht University.

Suurtamm, C., Thompson, D. R., Kim, R. Y., Moreno, L. D., Sayac, N., Schukajlow, S., Silver, E., Ufer, S. y Vos, P. (2016). Assessment in mathematics education: Largescale assessment and classroom assessment. (pp. 27-33). Springer. https://doi.org/10.1007/978-3-319-32394-7

Thurstone, L. L. (1938). Primary mental abilities. Psychometric Monographs, 1-121.

van Hiele, P. M. (1959). La pensée de l'enfant et la geometrie. Bulletin de l'Association des Professeurs de l'Enseignement Public, 198, 199-205.

Webb, N.L. (1993) Visualizing a theory of the assessment of students' knowledge of mathematics. In M. Niss (eds.), Investigations into assessment in mathematics education. New ICMI Study Series, 2 (pp.253-264). Springer. https://doi.org/10.1007/978-94-017-1974-2_17

Webb, L.F. y Carry, L.R. (1975). Interaction of spatial visualization and general reasoning abilities with instructional treatment in quadratic inequalities: a followup study. Journal for Research in Mathematics Education 6, 132-140. 
Werner, H. (1964). Comparative psychology of mental development. International Univerisities Press.

Wheatley, G. H. (1990). Spatial sense and mathematics learning. The Arithmetic Teacher, 37(6), 10-11.

Wheatley, G. H. (1997). Reasoning with images in mathematical activity. En L. D. English (Ed.), Mathematical reasoning: analogies, metaphors and images. (pp. 281-297). Erlbaum.

Wheatley G. H. y Brown, D. (1994). The construction and representation of images in mathematical activity. En J. P. Ponte y J. F. Matos (Eds.), Proceedings of the 18th PME International Conference, 1, (p. 81). Program Committee of the 18th PME Conference.

Woolner, P. (2004). A comparison of a visual-spatial approach and a verbal approach to teaching mathematics. En M. J. Hoines y A. B. Fuglestad (Eds.), Proceedings of the 28th PME International Conference, 4, (pp. 449-456). Bergen University College.

Yerushalmy, M., Shternberg, G. y Gilead, S. (1999). Visualization as a vehicle for meaningful problem solving in algebra. En O. Zaslavsky (Ed.), Proceedings of the 23rd PME International Conference, 1, (pp.197-211). Technion.

Young, C.D. y Becker, J.P. (1979). The interaction of cognitive aptitudes with sequences of figural and symbolic treatments of mathematical inequalities. Journal for Research in Mathematics Education, 10, 24-36.

Zimmermann, W. y Cunningham, S. (1991). Visualization in teaching and learning mathematics. Mathematical Association of America. 


\section{ANEXO A. ACTIVIDADES SELECCIONADAS}

\section{PISA 2003}

\section{CARPINTERO}

\section{Pregunta 1}

Un carpintero cuenta con 32 metros de listones de madera y desea hacer un borde alrededor de una jardinera. Él ha considerado utilizar uno de los siguientes diseños en la construcción de este borde.
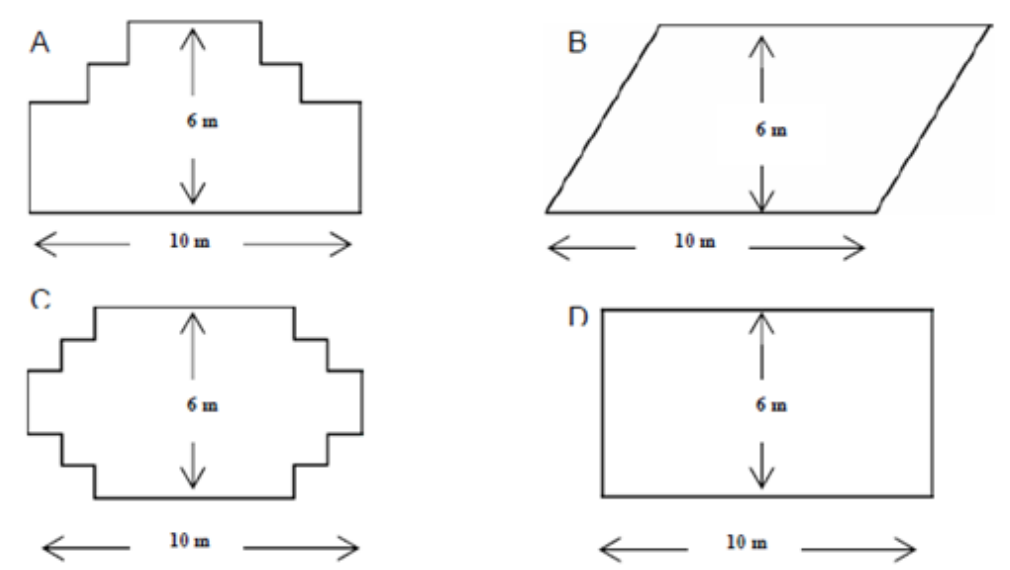

Encierra en un círculo según corresponda la palabra "Sí" o "No" para indicar cuáles diseños de bordes se pueden realizar con 32 metros de madera.

\begin{tabular}{|l|c|}
\hline Diseño & $\begin{array}{c}\text { Utilizando este diseño ¿puede hacer el borde } \\
\text { con } 32 \text { metros de madera? }\end{array}$ \\
\hline Diseño A & Sí / No \\
\hline Diseño B & Si / No \\
\hline Diseño C & Si / No \\
\hline Diseño D & Si / No
\end{tabular}

Figura 1. Pregunta 1: CARPINTERO 


\section{ESCALERA}

\section{Pregunta 1}

El diagrama a continuación, muestra una escalera de 14 escalones y una altura total de $252 \mathrm{~cm}$ :

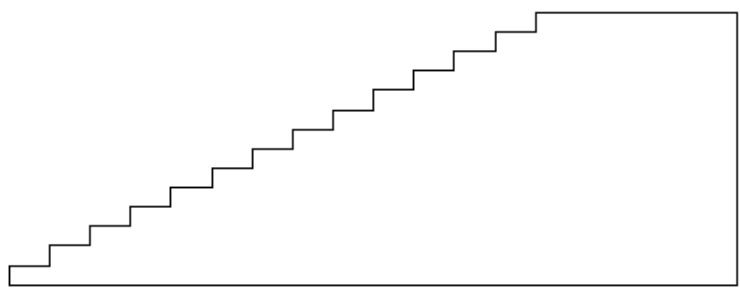

Altura total $252 \mathrm{~cm}$

Profundidad total $400 \mathrm{~cm}$

¿Cuál es la altura de cada uno de los 14 escalones?

Altura : $\mathrm{cm}$.

Figura 2. Resolución de Pregunta 1: ESCALERA 


\section{DADOS}

\section{Pregunta 2}

A la derecha hay un dibujo de dos dados.

Los dados son cubos especiales con números, para los cuales se
aplica la siguiente regla:

El número total de puntos en dos caras opuestas siempre suma siete.

Puedes hacer un dado cortando, doblando y pegando cartón. Esto puede hacerse de varias maneras. En la figura de abajo se muestran cuatro modelos que pueden usarse para hacer dados, con puntos en sus caras.

¿Cuál(es) del(de los) siguiente(s) modelo(s) puede(n) doblarse para formar un dado que respete la regla de que la suma de los puntos en caras opuestas es 7 ? Para cada modelo, encierra en un círculo según sea "Sí" o "No" en la tabla a continuación.
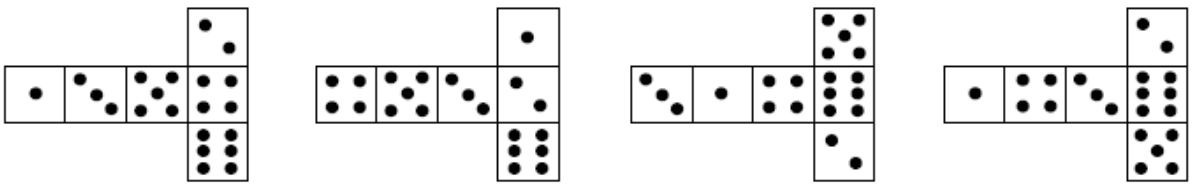

\begin{tabular}{|c|c|}
\hline Modelo & ¿Respeta la regla "la suma de los puntos en caras opuestas es 7"? \\
\hline I & $\mathrm{Si} /$ No \\
\hline II & $\mathrm{Si} /$ No \\
\hline III & $\mathrm{Si} /$ No \\
\hline IV & $\mathrm{Si} /$ No \\
\hline
\end{tabular}

Figura 3. Pregunta 2: DADOS 
PISA 2012

\section{GARAJE}

La propuesta «básica» de un fabricante de garajes incluye modelos de una sola ventana y una sola puerta.

Jorge elige el siguiente modelo de la propuesta "básica». A continuación se muestra la posición de la ventana y de la puerta.

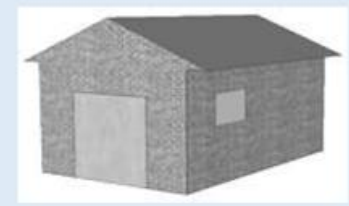

\section{Pregunta 1: GARAJE}

Las siguientes ilustraciones muestran distintos modelos «básicos» vistos desde la parte posterior. Solo una de las ilustraciones se corresponde con el modelo anterior elegido por Jorge.

¿Qué modelo eligió Jorge? Rodea con un círculo A, B, C o D.

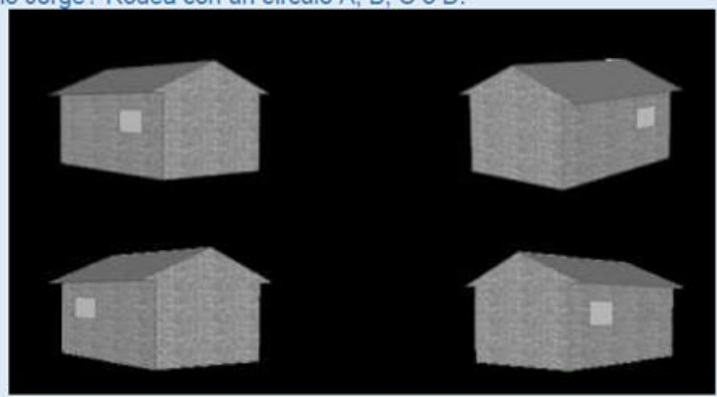

Figura 4. Pregunta 1: GARAJE

\section{Pregunta 2: GARAJE}

Los dos planos siguientes muestran las dimensiones, en metros, del garaje elegido por Jorge.
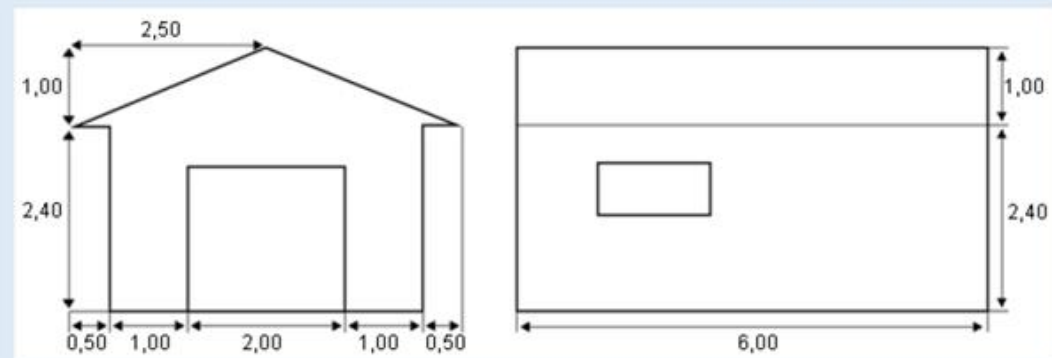

Vista frontal

Vista lateral

El techo está formado por dos rectángulos iguales.

Calcula la superficie total del techo. Escribe tus cálculos.

Figura 5. Pregunta 2: GARAJE 


\section{PUERTA GIRATORIA}

Una puerta giratoria consta de tres hojas que giran dentro de un espacio circular. El diámetro interior de dicho espacio es de 2 metros ( 200 centímetros). Las tres hojas de la puerta dividen el espacio en tres sectores iguales. El siguiente plano muestra las hojas de la puerta en tres posiciones diferentes vistas descle arriba.
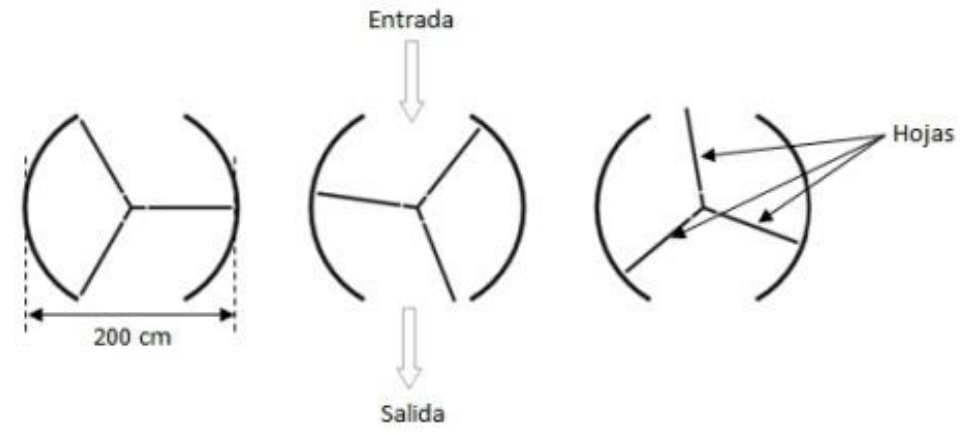

Pregunta 1: PUERTA GIRATORIA 019

¿Cuánto mide (en grados) el ángulo formado por dos hojas de la puerta?

Medida del ángulo:

Figura 6. Pregunta 1: PUERTA GIRATORIA

\section{Pregunta 2: PUERTA GIRATORIA}

Las dos aberturas de la puerta (los arcos punteados en el dibujo)son del mismo tamaño. Si estas aberturas son demasiado anchas las hojas giratorias no pueden proporcionar un espacio cerrado y el aire podria entonces circular libremente entre la entrada y la salida, originando pérdidas o ganacias de calor no deseadas. Esto se muestra en el dibujo de al lado.

¿Cuál es la longitud máxima del arco en centimetros $(\mathrm{cm})$ que puede tener cada abertura de la puerta para que el aire no circule nunca libremente entre la entrada y la salida?

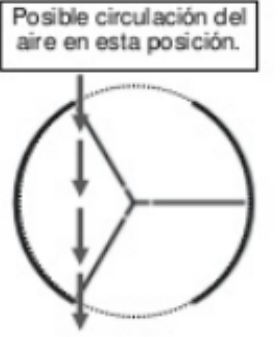

Figura 7. Pregunta 2: PUERTA GIRATORIA 


\section{Actividades de aula}

\section{Actividad 1}

Indica con un color todos los puntos del plano que equidistan de las rectas $\mathrm{AB}$ y $\mathrm{EF}$ y están a menos de $4,5 \mathrm{~cm}$ del punto A

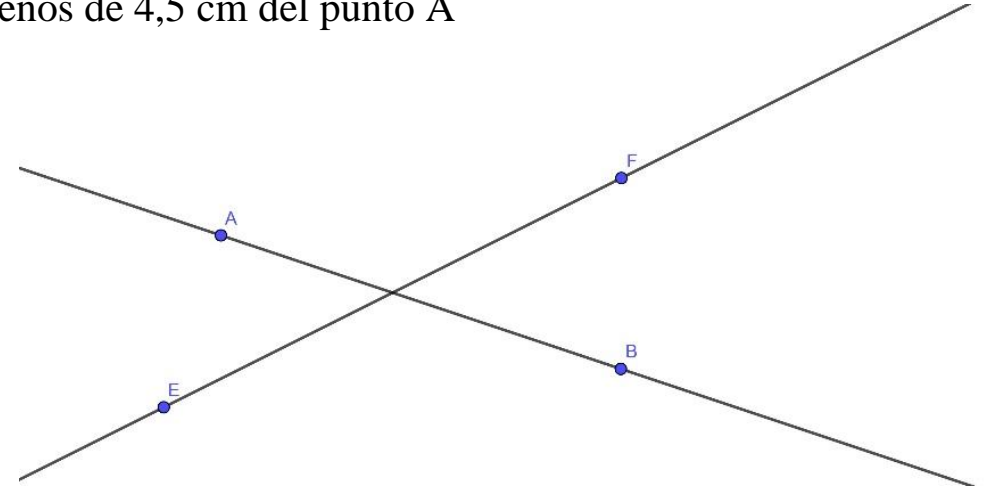

Observación: la representación gráfica se presenta distante del texto para que el alumno trabaje sobre la hoja en la que se brindada la actividad.

\section{Actividad 2}

Construye un triángulo $\mathrm{ABC}$ sabiendo que el lado $\mathrm{AC}$ mide $8 \mathrm{~cm}$, la mediana respecto a ese lado $\left(m_{B}\right)$ mide $5 \mathrm{~cm}$ y la amplitud del ángulo $\mathrm{ABC}$ es $70^{\circ}$. Escribe el algoritmo de construcción.

\section{Actividad 3}

Indica con un color todos los puntos del plano que ven al segmento $\mathrm{AB}$ bajo un ángulo de $60^{\circ}$ y están más cerca de B que de A.

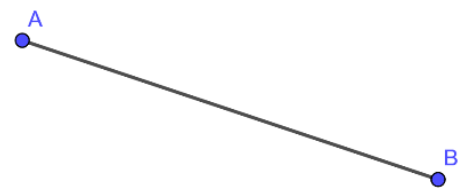

Observación: la representación gráfica se presenta distante del texto para que el alumno trabaje sobre la hoja en la que se brindada la actividad. 


\section{Actividad 4}

Construye un triángulo $\mathrm{PQR}$ sabiendo que el lado PQ mide $8 \mathrm{~cm}$, la mediana respecto a ese lado $\left(m_{B}\right)$ mide $7 \mathrm{~cm}$ y la altura respecto de ese mismo lado $\left(h_{B}\right)$ mide $4 \mathrm{~cm}$. Escribe el algoritmo de construcción.

\section{Actividad 5}

Dado el siguiente trapecio $\mathrm{ABCD}$, encuentra todos los puntos $\mathrm{P}$ del plano que cumplen las dos condiciones:

- Equidistan de las rectas $\mathrm{AB}$ y $\mathrm{CD}$

- $\widehat{B P C}=30^{\circ}$

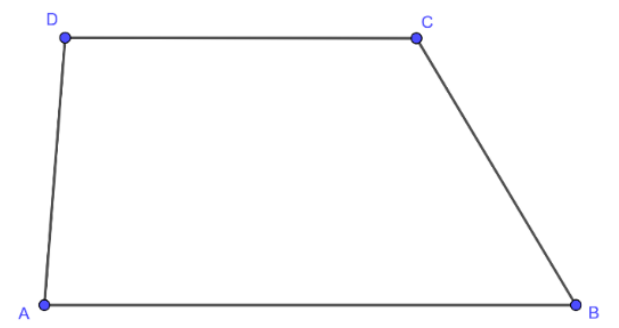

Observación: la representación gráfica se presenta distante del texto para que el alumno trabaje sobre la hoja en la que se brindada la actividad.

\section{Actividad 6}

Construye un triángulo $\mathrm{ABC}$ conociendo la longitud del lado $\mathrm{AB}=4 \mathrm{~cm}$, la distancia entre el circuncentro y el vértice $\mathrm{A}$ es $3 \mathrm{~cm}$, y $\overline{A C B}=60^{\circ}$. Escribe el algoritmo de construcción.

\section{Actividad 7}

a) Construye un trapecio $\mathrm{ABCD}$ sabiendo que $\mathrm{AB} / / \mathrm{CD}$, el lado $\mathrm{AB}$ mide $7 \mathrm{~cm}$, su altura mide $3 \mathrm{~cm}, \widehat{A D B}=90^{\circ}$ y el vértice $\mathrm{C}$ equidista de los vértices $\mathrm{B}$ y $\mathrm{D}$.

b) Define paralela media como lugar geométrico.

\section{Actividad 8}

a) Construye un trapecio $\mathrm{ABCD}$ con los siguientes datos:

- La distancia entre los lados paralelos, $\mathrm{AB}$ y $\mathrm{CD}$ es de $2 \mathrm{~cm}$

- El segmento $\mathrm{AB}$ es de $7 \mathrm{~cm}$ 
- El segmento BC es de $4 \mathrm{~cm}$

- El ángulo que forma la diagonal BD con el lado $\mathrm{AD}$ es de $90^{\circ}$

b) El siguiente conjunto de puntos, escrito en lenguaje simbólico, define un lugar geométrico: $\{P \in \pi / d(P, \overleftarrow{O x})=d(P, \overleftarrow{O y})\}$. Escribe la misma definición con palabras (en idioma español) y dinos cuál es el lugar geométrico que se está definiendo.

\section{Actividad 9}

a) Construye un paralelogramo $\mathrm{ABCD}$, sabiendo que

- B pertenece a la recta $r$

- $\mathrm{C}$ y D son puntos de la recta $\mathrm{s}$

- La longitud de la diagonal AC es de $6 \mathrm{~cm}$

- La diagonal BD es de $7 \mathrm{~cm}$

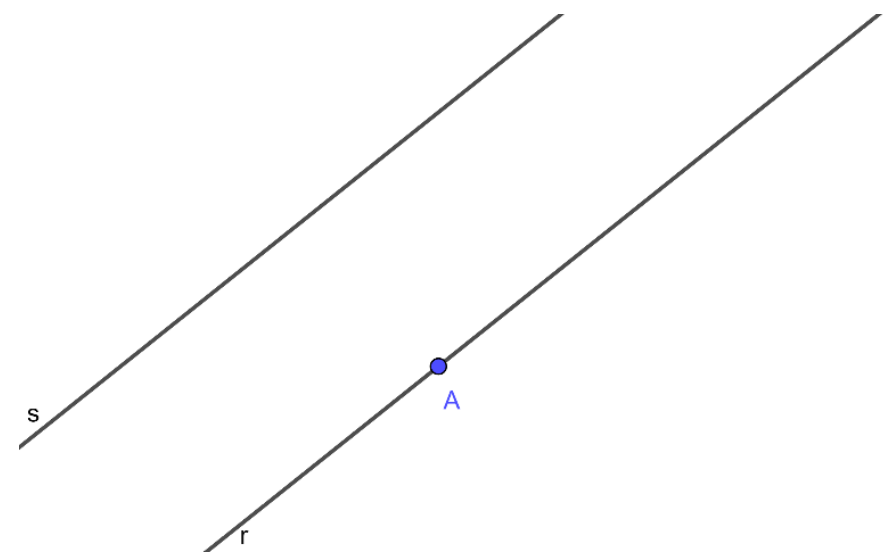

Observación: la representación gráfica se presenta distante del texto para que el alumno trabaje sobre la hoja en la que se brindada la actividad.

b) Explica por qué el punto de corte de las diagonales de un paralelogramo $\mathrm{ABCD}$, pertenece a la paralela media de las rectas $\mathrm{AB}$ y $\mathrm{CD}$. 


\section{ANEXO B. RESOLUCIÓN DE ACTIVIDADES \\ SELECCIONADAS}

\section{Actividad C}

\section{Resolución 1}

CARPINTERO - Pregunta 1

(A)

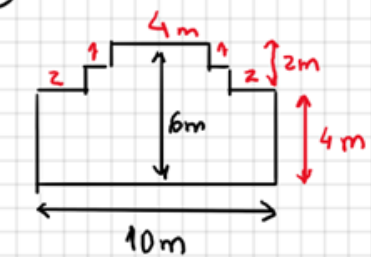

$3+4+3=10 \mathrm{~m}$

$2+4=6 \mathrm{~m}$

(C)

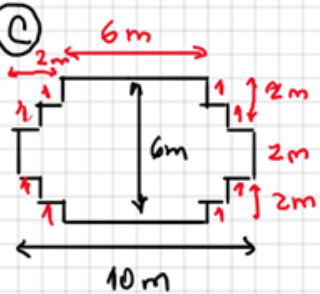

$2+6+2=10$

$2+2+2=6$

$10 \times 2+6 \times 2=32 \mathrm{~m}$
(B)

(D)

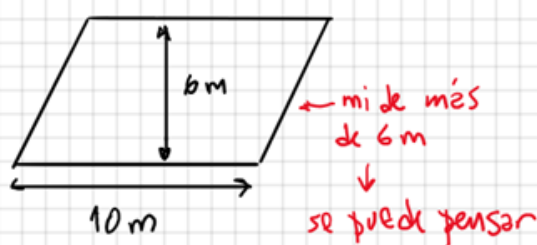

con el conclpto de distancia o armar un triéngulo rectíngulo zuxiliar, siendo la hipotenusa $X$

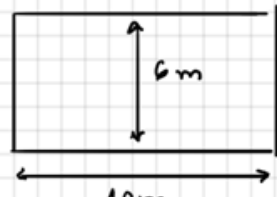

$10 \mathrm{~m}$

$10 \times 2+6 \times 2=32 m^{V}$

\section{Resolución 2}

Partiendo de trabajar con D, que cumple con la condición de que el perímetro suma 32. Podría por comparación de $\mathrm{A}$ con $\mathrm{D}$ y de $\mathrm{C}$ con $\mathrm{D}$, sin establecer unidades a cada segmento, usando paralelismo y perpendicularidad, decir que se conservan las distancias y por tanto A, C y D considerarlas como soluciones.

Del mismo modo comparar B con D, la medida del lado del rectángulo en B coincide con su altura y con la altura del paralelogramo en D, un segmento no perpendicular entre paralelas es mayor que la distancia entre ellas por tal motivo el lado del paralelogramo sin medida es mayor que la altura. De ese modo se descarta la respuesta B. 


\section{Resolución 3}

El estudiante utiliza la habilidad de visualización que tiene desarrollada de figuracontexto, comparando de algún modo $\mathrm{A}$ y $\mathrm{C}$ con $\mathrm{D}$ sin saber las propiedades que se cumplen.

Resolución 4

El estudiante selecciona posibilidades sin motivos, por azar.

\section{Actividad E}

Resolución 1

\section{ESCALERA - Pregunta 1}

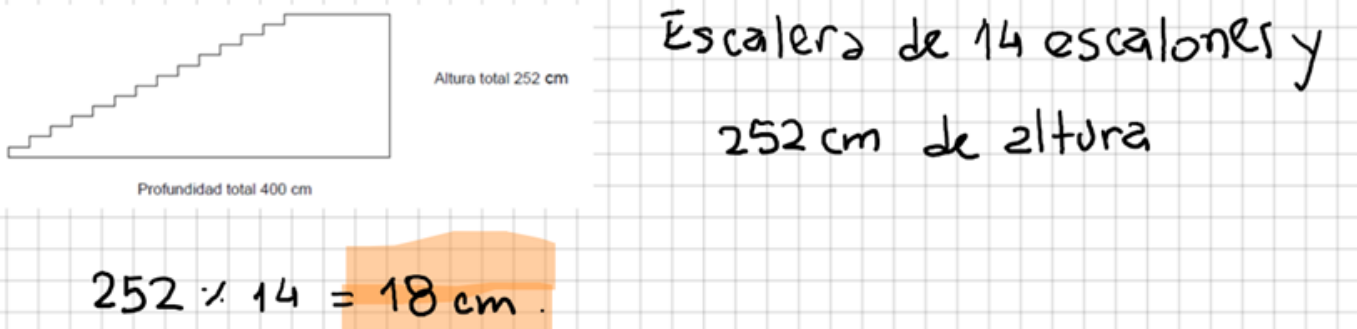




\section{Actividad D}

\section{Resolución 1}

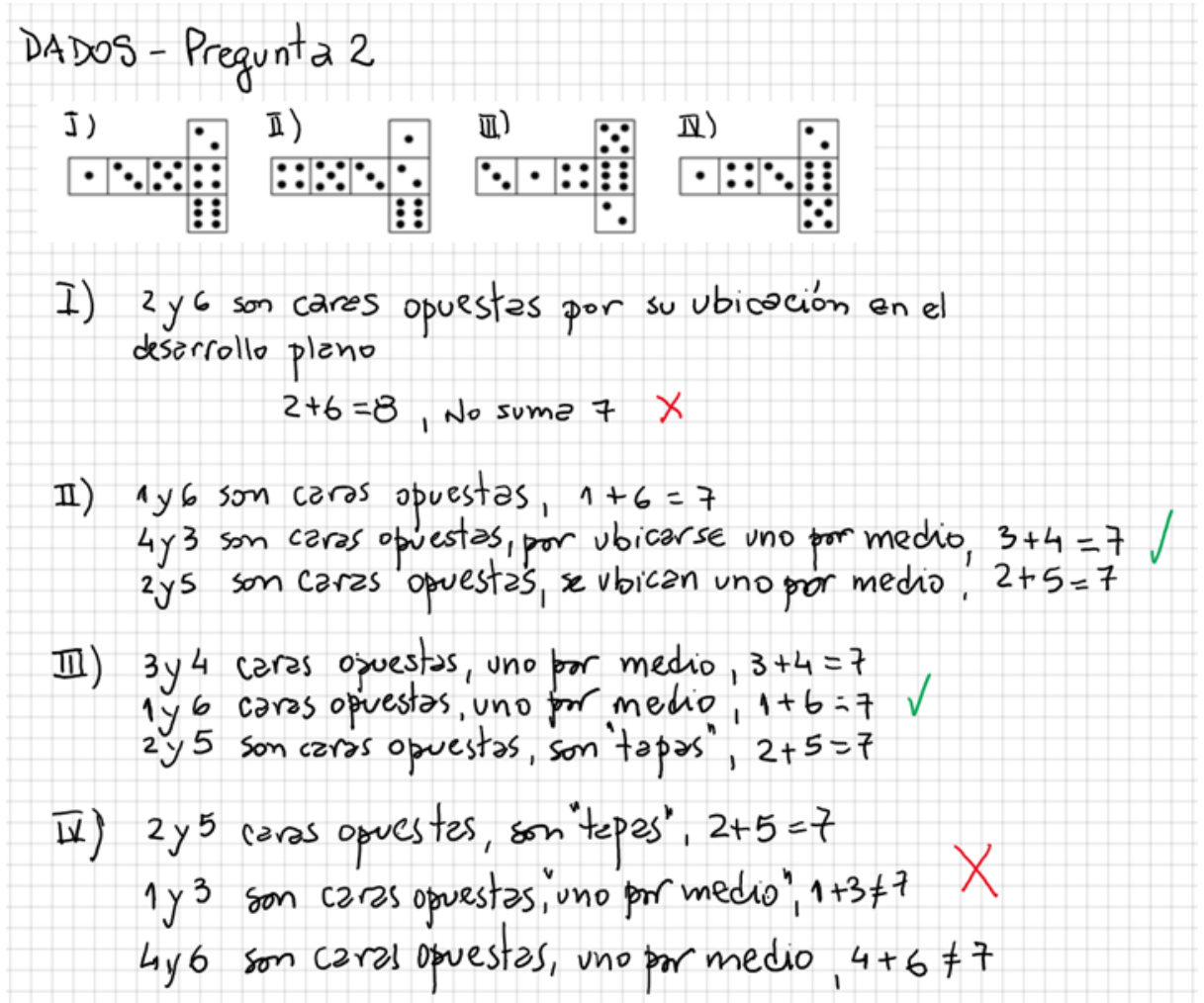

\section{Resolución 2}

Por descarte.

Las caras que están a un lado y a otro son opuestas, deben sumar 7 , de ese modo se descarta el modelo I, porque suma 8.

Las que están en las puntas, son consecutivas, no pueden sumar 7 por tanto se descarta el modelo IV.

De ese modo responden como solución el modelo II y III.

\section{Resolución 3}

Por azar. El estudiante selecciona posibilidades sin motivos.

\section{Actividad G1}

Resolución 1 


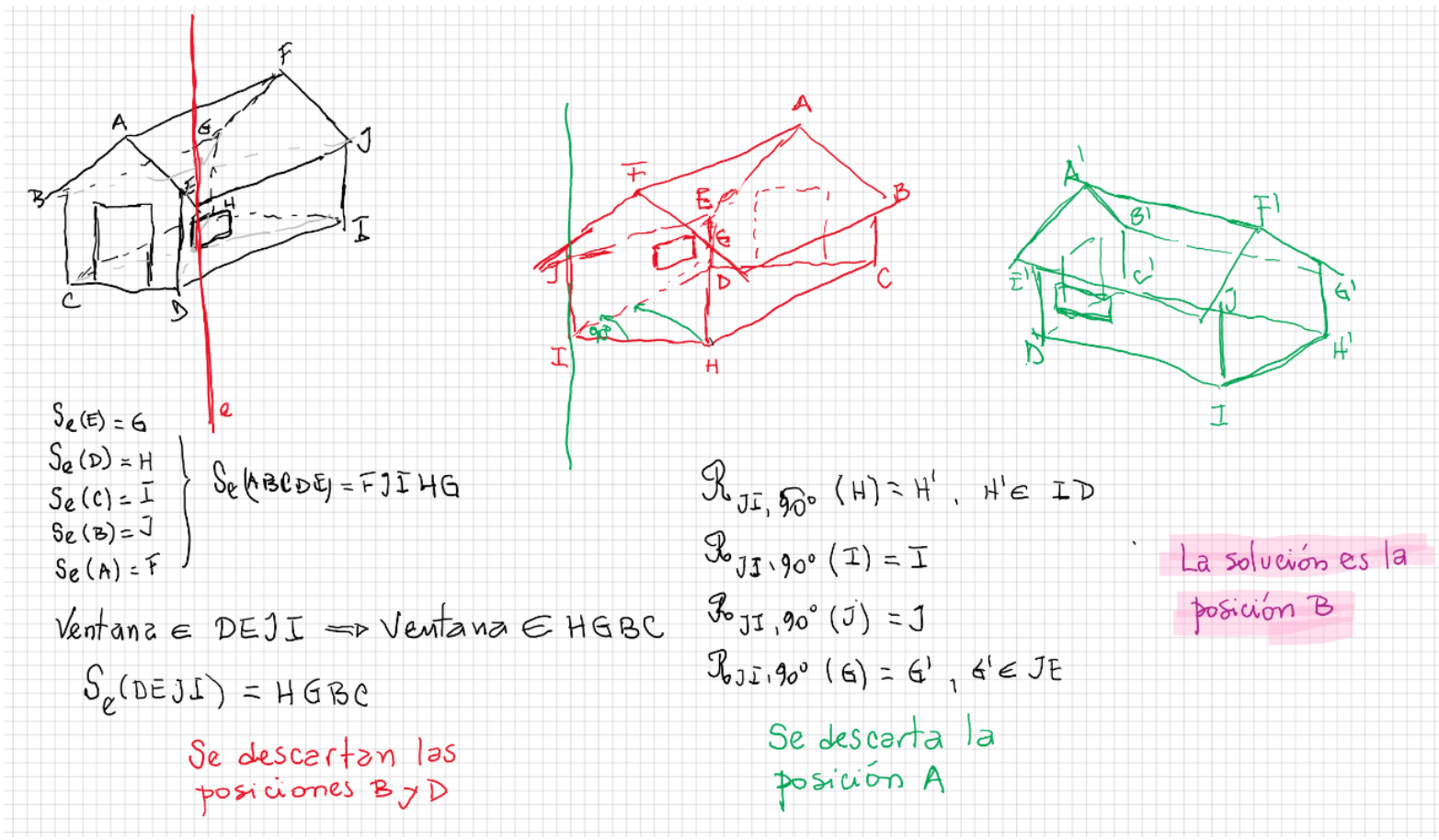

Resolución 2

Se descartan las ventanas que están cercanas a la pared del fondo (pared en que no hay puerta): A y D, porque la única ventana está cerca de la pared de enfrente (la puerta).

Se descarta la ventana que vista de atrás está a la derecha: $\mathrm{B}$, porque la ventana vista desde adelante (desde la puerta) está a la derecha.

Solución: C, porque la ventana está cercana a la pared de enfrente (de la puerta, opuesta a la que se ve sin puerta) y vista desde atrás está a la izquierda, por tanto, vista desde adelante está a la derecha. Ambas situaciones se corresponden con la posición que se muestra en la foto de frente.

\section{Resolución 3}

Por azar. El estudiante selecciona posibilidades sin motivos. 


\section{Actividad G2}

Resolución 1

Pregunta 2: GARAGE

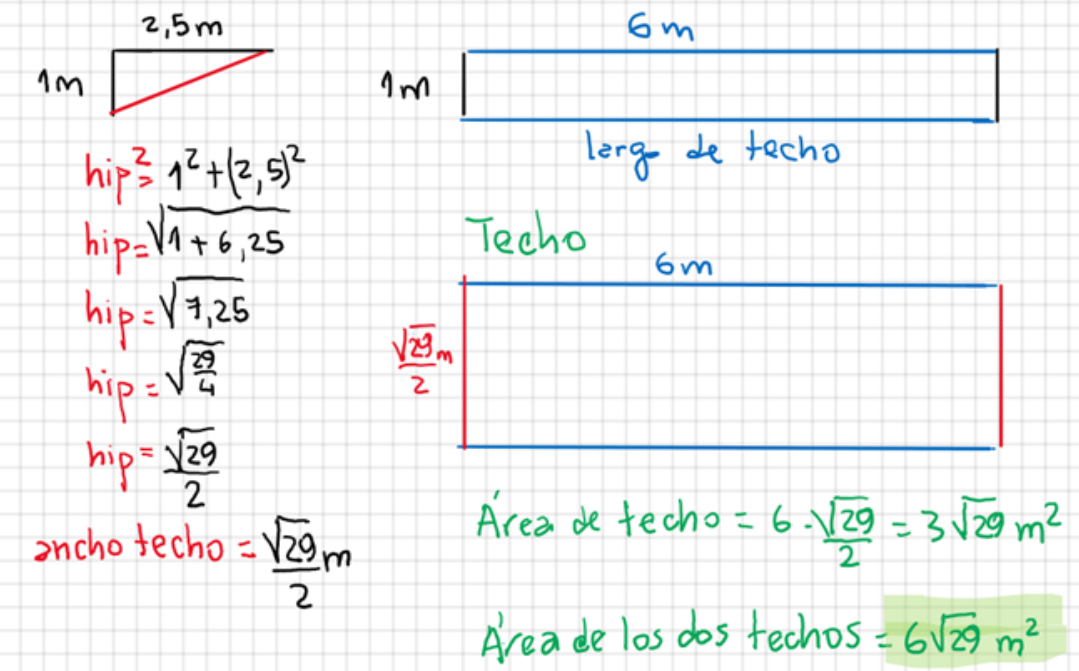

\section{Actividad PG 1}

\section{Resolución 1}

Pregunta 1-PUERTA GIRATORIA

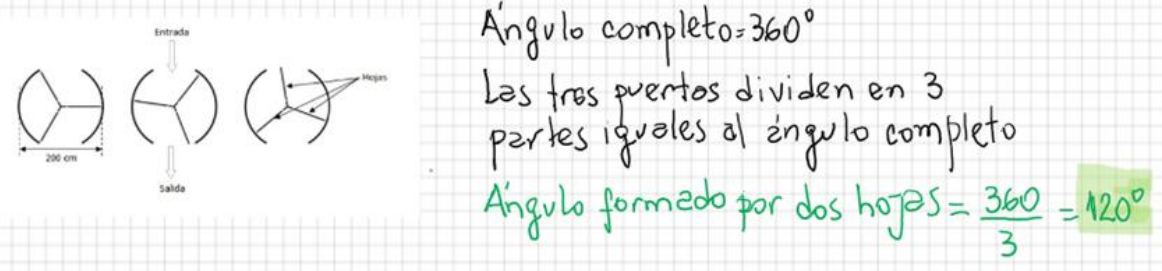




\section{Actividad PG 2}

\section{Resolución 1}

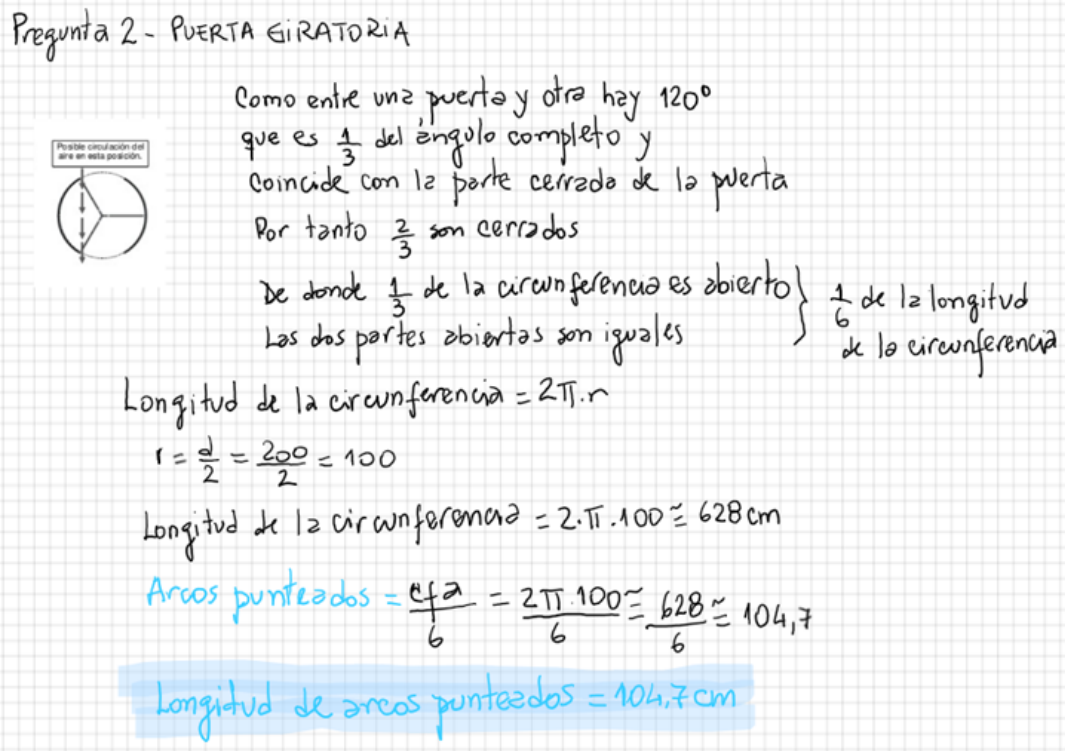

\section{Actividad A1}

\section{Resolución 1}

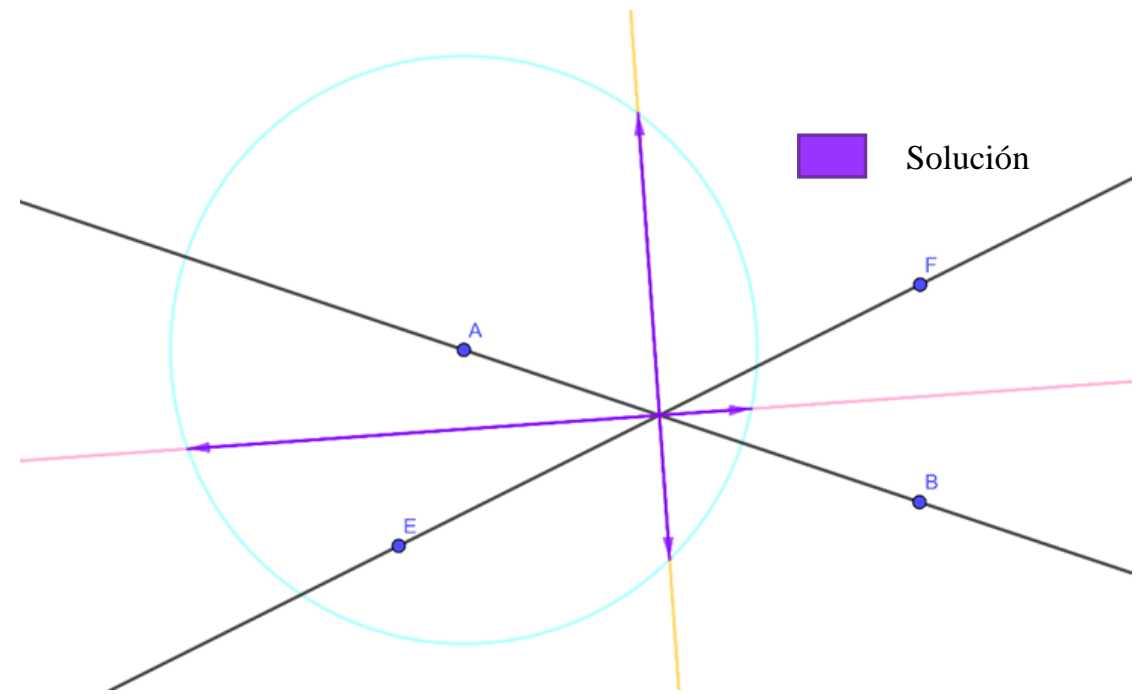

Resolución 2

La diferencia en esta resolución es el orden de construcción de cada uno de lo lugares geométricos, si se construye primero la circunferencia, se determinan los puntos del círculo, para luego construir las bisectrices y determinar los puntos de intersección que son solución. El otro procedimiento sería al revés. 


\section{Actividad A2}

\section{Resolución 1}
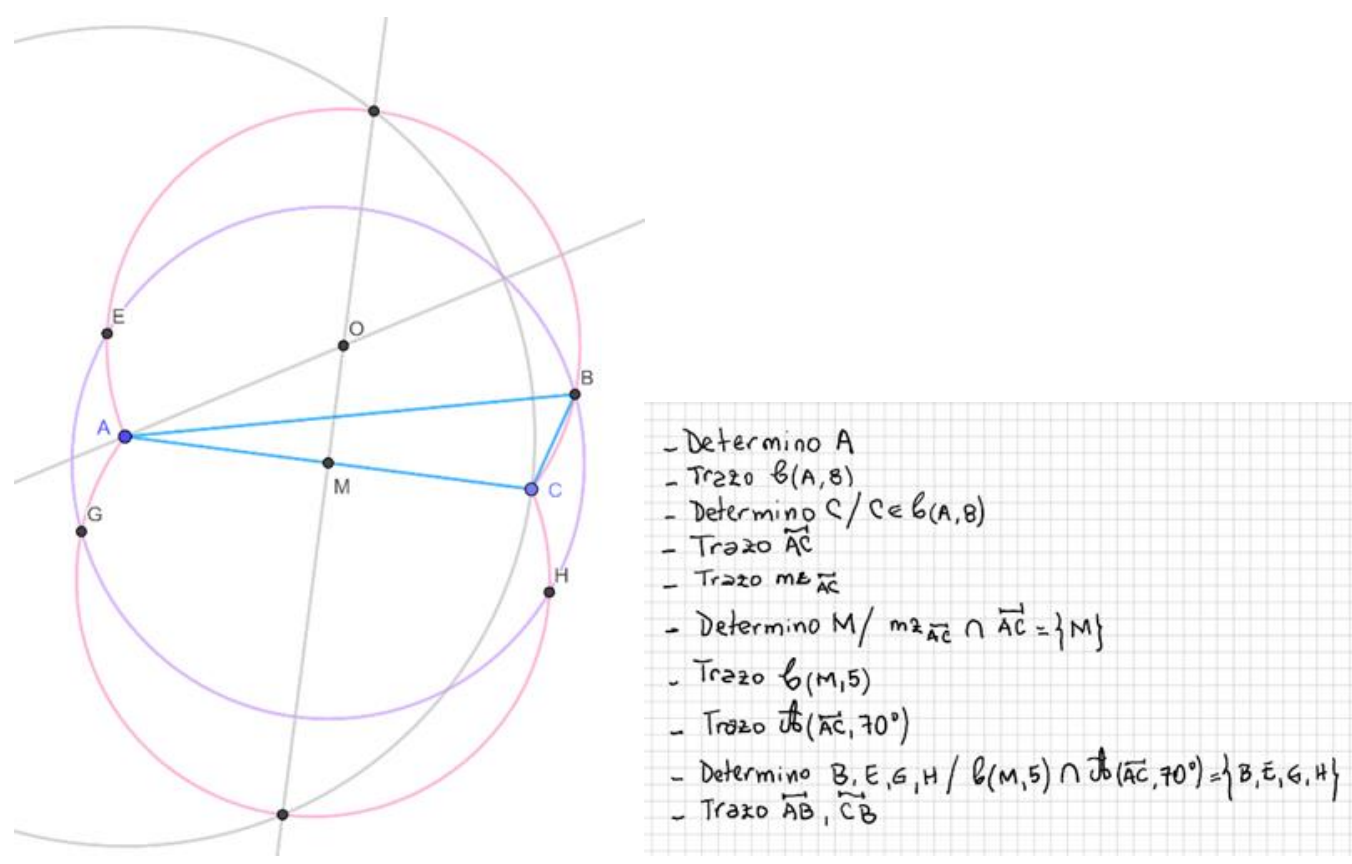

\section{Resolución 2}

En idénticas condiciones que la resolución anterior, pero en vez de trabajar con B, se trabaja con E y encuentran como solución el triángulo AEC (aquí se respetaría el sentido horario) o en el semiplano opuesto trabajan con $\mathrm{G}$ o con $\mathrm{H}$, determinando el triángulo AGC o AHC (en este caso sería antihorario).

\section{Resolución 3}

Si se cambia el orden de construcción de los dos lugares geométricos, el arco capaz de segmento $\mathrm{AC} \mathrm{y} 70^{\circ}$ y luego la circunferencia con radio de igual medida que la mediana. 


\section{Actividad A3}

Resolución 1

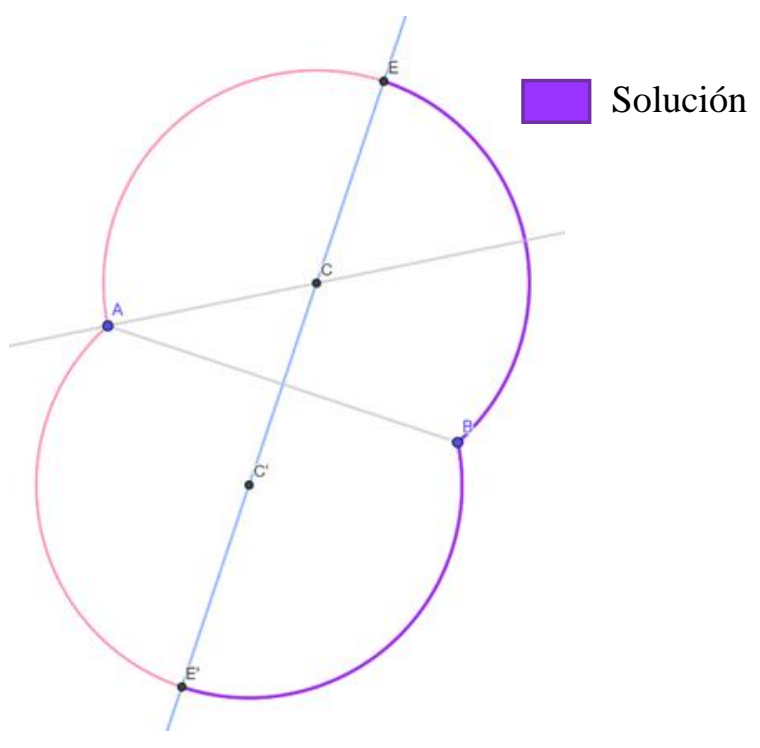

Resolución 2

La diferencia en esta resolución es el orden de construcción de cada uno de los lugares geométricos, si se construye primero el arco capaz y después la mediatriz para identificar los puntos que están más cerca de B que de A, así determinar los puntos de intersección que son solución. El otro procedimiento sería al revés. 


\section{Actividad A4}

\section{Resolución 1}

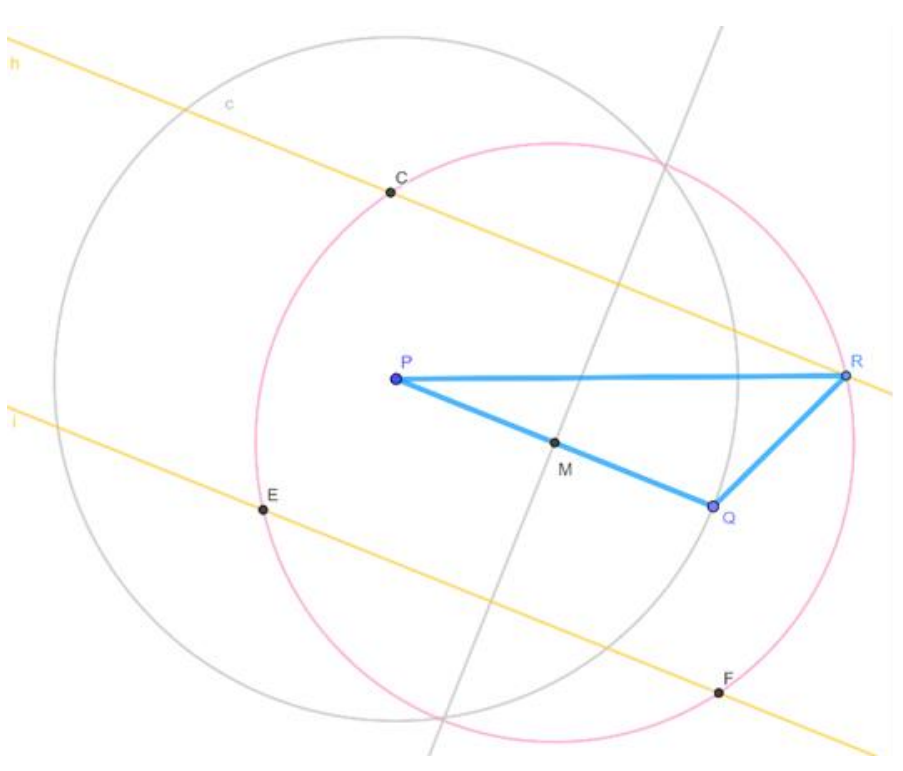

- Determino P

- Trozo b(P,8)

- Determino $Q / Q \in b(P, B)$

- Sea M/Mpuntomedio de $\overrightarrow{P Q}$

- Trazo b(M, Z)

- Trazo h,i/h//PQ, i//PQ $d(h, P Q)=4, d(i, P Q)=4$

- Sea $R_{y} C / b(M, z) \cap h=\left\{R_{1} C\right\}$

- Sea EyF/ $b(M, Z) \cap i=\{E, F\}$

- Trazo $\overrightarrow{P R}$ y $\overrightarrow{Q R}$

\section{Resolución 2}

En idénticas condiciones que la resolución anterior, pero en vez de trabajar con $\mathrm{R}$, se trabaja con $\mathrm{C}$ y encuentran como solución el triángulo PQC (aquí se respetaría el sentido antihorario) o en el semiplano opuesto trabajan con $\mathrm{E}$ o con $\mathrm{F}$, determinando el triángulo PQE o PQF (en este caso sería sentido horario).

\section{Resolución 3}

Si se cambia el orden de construcción de los dos lugares geométricos, la unión de paralelas a PQ cuya distancia es igual a la medida de la altura del triángulo y luego la circunferencia con radio de igual medida que la mediana. 


\section{Actividad A5}

Resolución 1

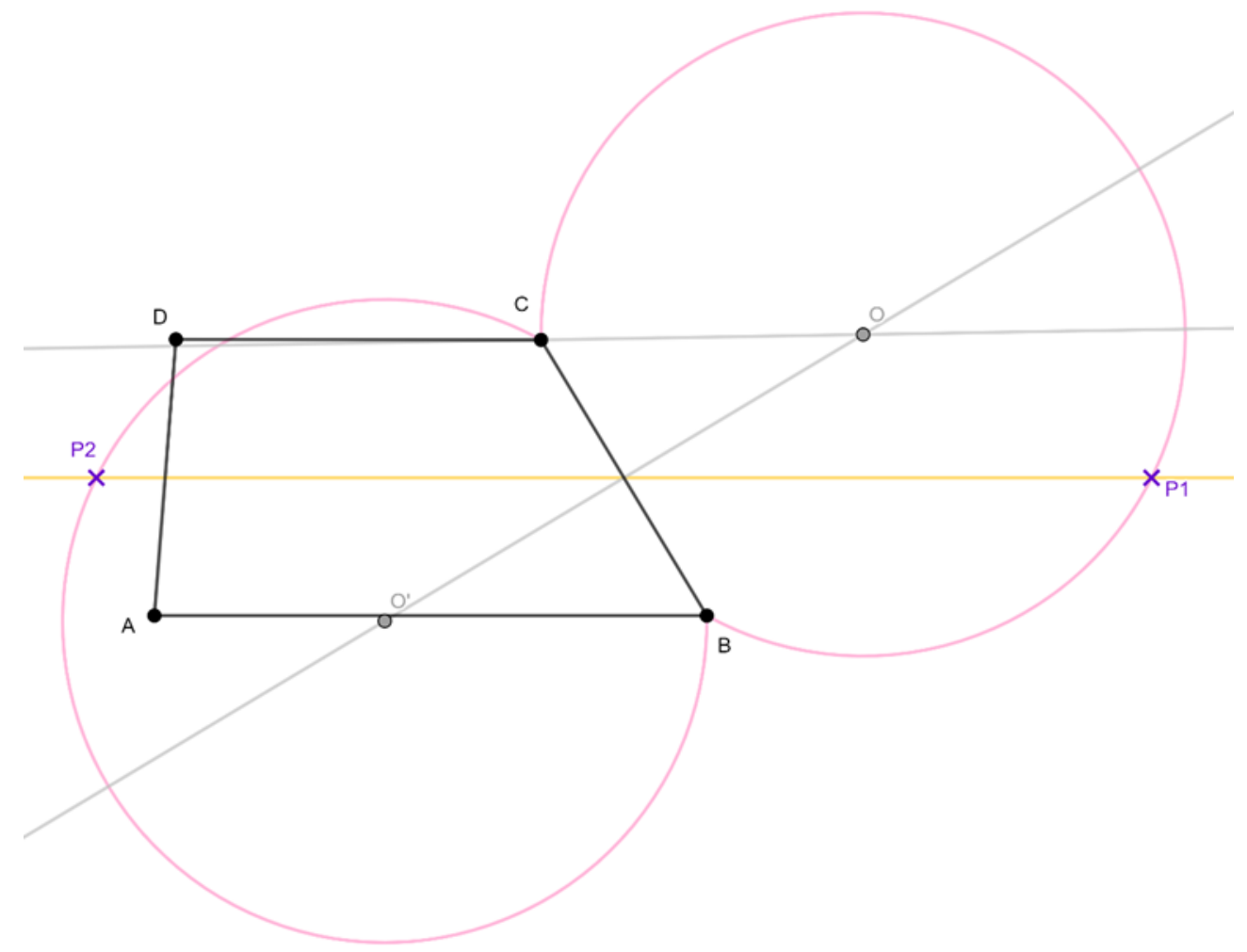

Resolución 2

La diferencia en esta resolución es el orden de construcción de cada uno de los lugares geométricos, si se construye primero el arco capaz y después la paralela media y determinar los puntos de intersección que son solución. El otro procedimiento sería al revés. 


\section{Actividad A6}

\section{Resolución 1}

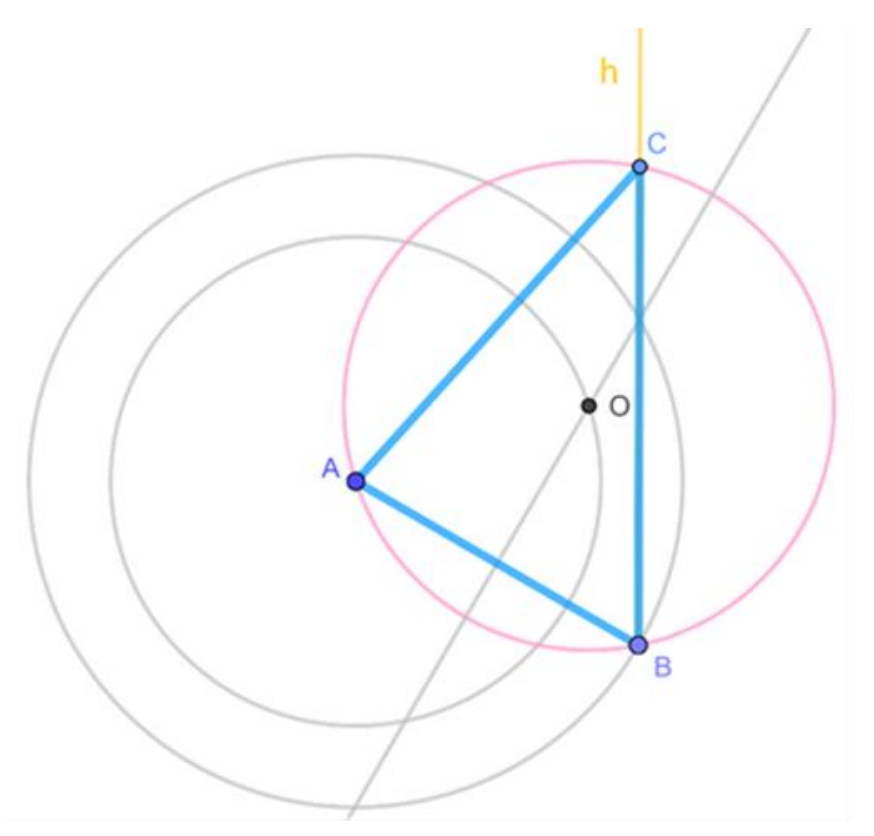

- Determino A

- Trazo $b(A, 4)$

- Determino $B / B \in b(A, 4)$

- Trezo $b(A, B)$

- Trazo mzaB

- Sea $O / b(A, B) \cap m z_{A B}=\{0\}$

- Trazo $b(0,3)$

- Sea $h / \hat{A B h}=60^{\circ}$ (antihorario)

- Sea $C /$ Bh $\cap b(0,3)=\{c\}$

- Trezo $\overrightarrow{A C} y \overrightarrow{B C}$

\section{Resolución 2}

Una construcción igual a la anterior, pero en el semiplano opuesto.

\section{Resolución 3}

La diferencia en esta resolución es el orden de construcción de cada uno de los lugares geométricos, si se construye primero el lado del ángulo formado con $\mathrm{AB}$, después la circunferencia y determinar los puntos de intersección que son solución. 


\section{Actividad A7}

Resolución 1

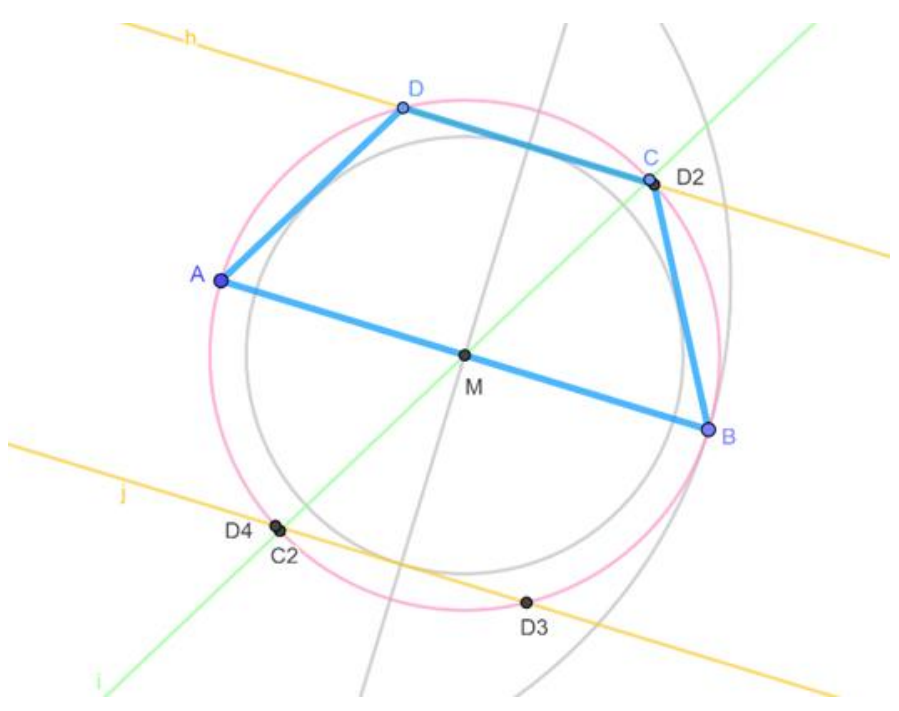

Resolución 2

La misma construcción que la anterior, considerando el trapecio en el semiplano opuesto, eso significa utilizar D4 y trazar la mediatriz del segmento BD4 intersección la circunferencia de centro M y radio 3,5 (la rosada), allí estaría el C4 correspondiente.

\section{Resolución 3}

Después de determinar el segmento $A B$, el siguiente vértice a determinar es $D$ ya que $C$ equidista de B y D. El cambio de orden que se puede realizar es construir las paralelas a $\mathrm{AB}$ y luego la circunferencia de centro $\mathrm{M}$ y radio $3,5 \mathrm{~cm}$ o al revés, para determinar el punto D. 


\section{Actividad A8}

Resolución 1

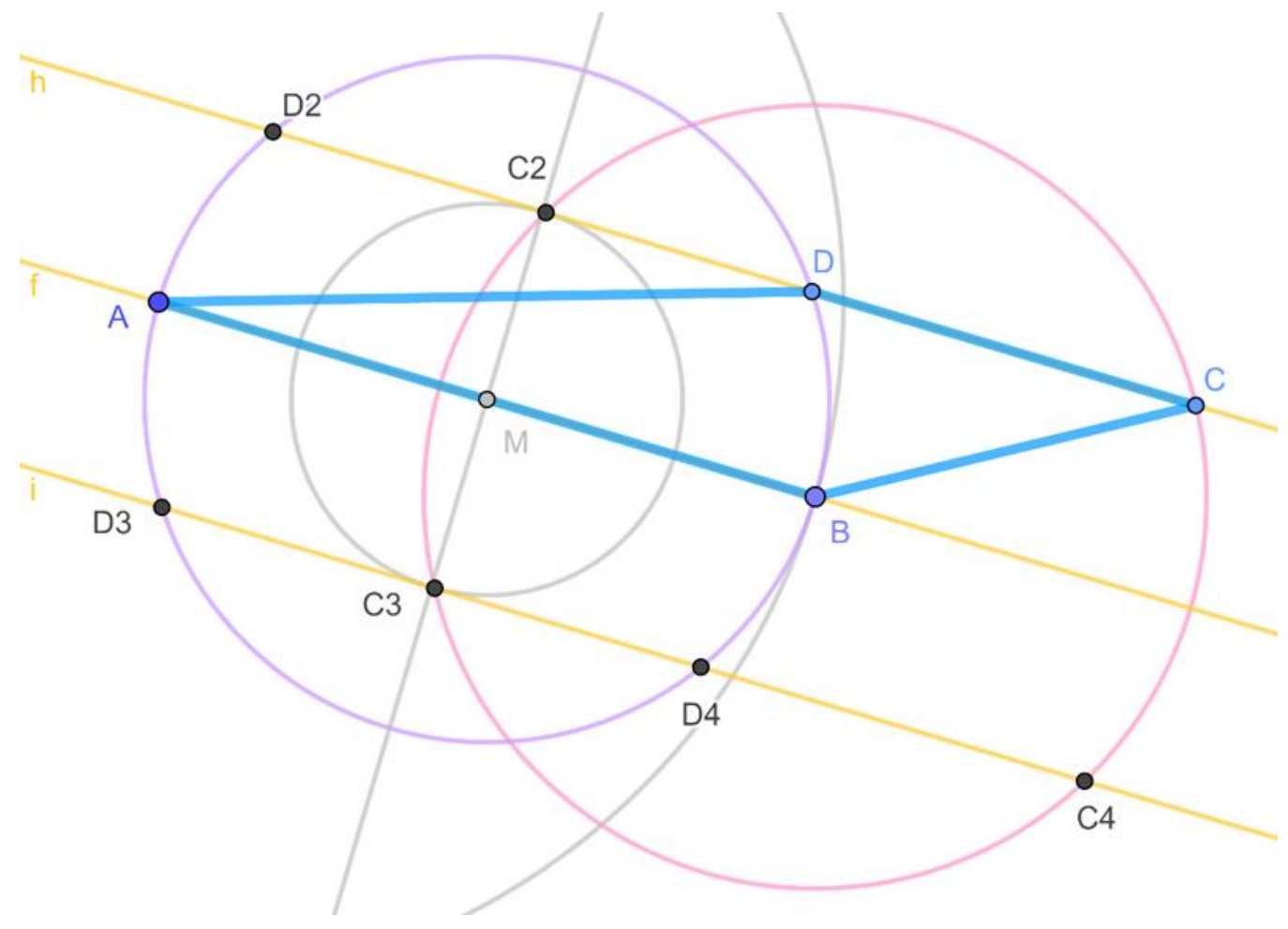

Resolución 2

Considerar los otros pares de puntos que verifican las condiciones, es decir los trapecios $\mathrm{ABC} 2 \mathrm{D} 2, \mathrm{ABC} 3 \mathrm{D} 3$ o ABC4D4.

Resolución 3

Cambiar el orden de los lugares geométricos que se originan con cada dato. Se debe comenzar determinando el segmento $\mathrm{AB}$ en primer lugar. 


\section{Actividad A9}

Resolución 1

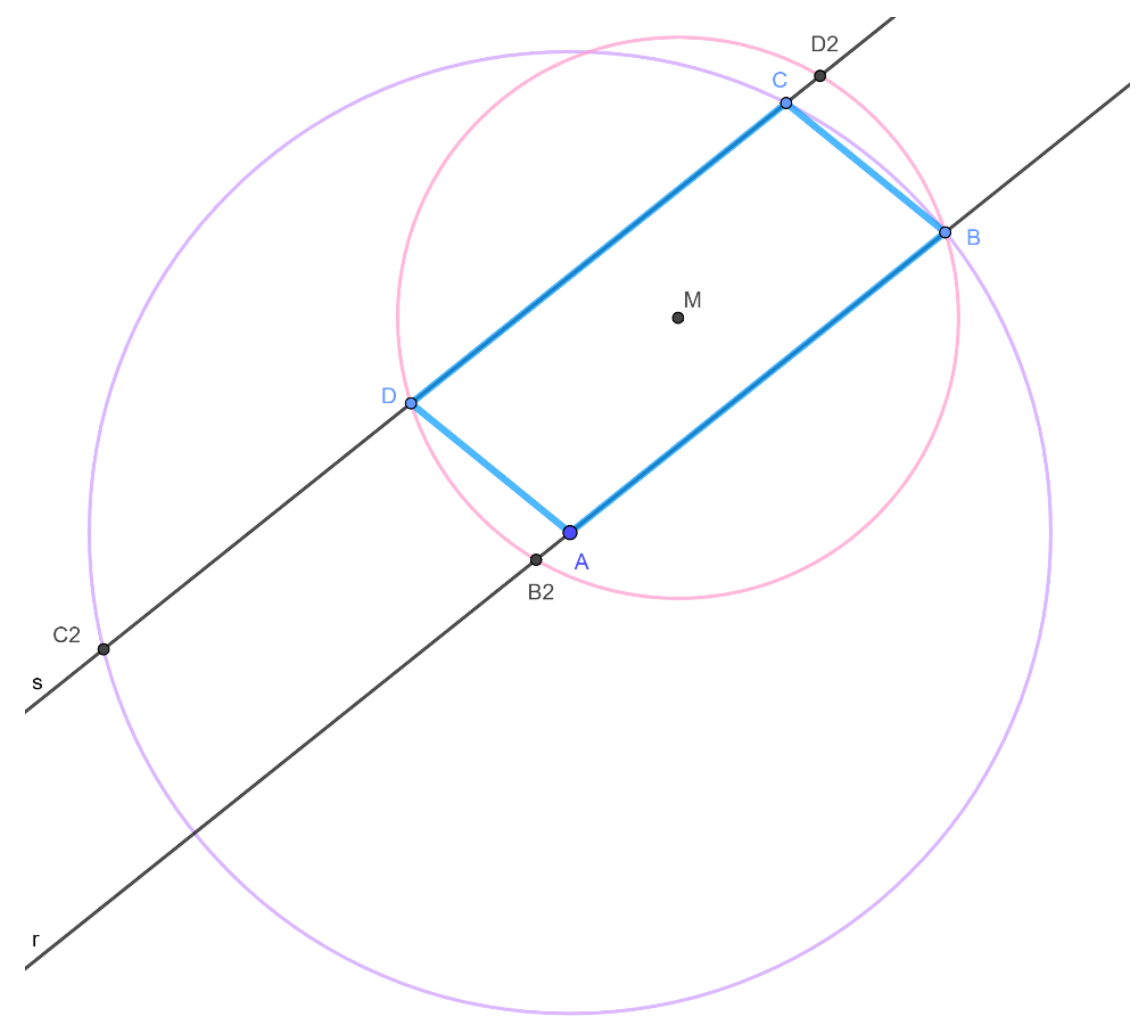

Resolución 2

Considerar el punto $\mathrm{C} 2$ y a partir de AC2, determinar M2 punto medio de AC2 y la intersección de la circunferencia de centro $\mathrm{M} 2$ y radio 3,5 $\mathrm{cm}$ (mitad de la medida de BD), con las rectas $\mathrm{r}$ y s, se obtienen B3 y D3 respectivamente. 


\section{ANEXO C. TABLAS SÍNTESIS POR ACTIVIDAD}

\section{Actividad C}

Tabla 1. Componentes del sentido espacial en Actividad C

\begin{tabular}{|c|c|c|}
\hline \multicolumn{2}{|c|}{ Componentes del sentido espacial } & Actividad C \\
\hline \multirow{8}{*}{$\begin{array}{l}\text { Manejo de } \\
\text { conceptos } \\
\text { geométricos }\end{array}$} & Conceptos de las figuras & $\begin{array}{l}\text { Concepto de rectángulo, paralelogramo, } \\
\text { ángulos rectos, medida y distancia. }\end{array}$ \\
\hline & Propiedades de las formas & $\begin{array}{l}\text { Perímetro de figuras en el plano. } \\
\text { Pares de lados paralelos. }\end{array}$ \\
\hline & Relaciones geométricas & $\begin{array}{l}\text { Descomposición de distancias en } \\
\text { distancias menores cuya suma es igual a } \\
\text { la dada. }\end{array}$ \\
\hline & & $\begin{array}{l}\text { Longitudes de trozos de lados paralelos } \\
\text { son iguales. }\end{array}$ \\
\hline & & $\begin{array}{l}\text { Longitud de hipotenusa es mayor que } \\
\text { longitud de catetos. }\end{array}$ \\
\hline & & $\begin{array}{l}\text { Disposición de las medidas, reduce y } \\
\text { aumenta a la vez. }\end{array}$ \\
\hline & Ubicación y movimientos & -- \\
\hline & Orientación & -- \\
\hline \multirow{10}{*}{$\begin{array}{l}\text { Habilidades } \\
\text { de visualización }\end{array}$} & Coordinación ojo-motor & -- \\
\hline & Percepción figura-contexto & $\begin{array}{l}\text { Considerar las figuras A y C insertas en } \\
\text { un rectángulo, y apreciar la igualdad de } \\
\text { trozos escalonados con sus paralelos en } \\
\text { el "contexto"/rectángulo. }\end{array}$ \\
\hline & Conservación de la percepción & $\begin{array}{l}\text { Aunque varíe la forma se conservan las } \\
\text { medidas. }\end{array}$ \\
\hline & $\begin{array}{l}\text { Percepción de la posición en } \\
\text { el espacio }\end{array}$ & -- \\
\hline & $\begin{array}{l}\text { Percepción de las relaciones } \\
\text { espaciales }\end{array}$ & $\begin{array}{l}\text { Se conserva el perímetro en las diferentes } \\
\text { figuras. }\end{array}$ \\
\hline & & $\begin{array}{l}\text { Identificación de los segmentos que } \\
\text { forman la "escalera" con los } \\
\text { correspondientes del rectángulo en que } \\
\text { se inscriben las figuras A y C. }\end{array}$ \\
\hline & Discriminación visual & $\begin{array}{l}\text { Tres figuras conservan el perímetro: A, C } \\
\text { y D y una cuarta figura no: } \mathrm{B} \text {. }\end{array}$ \\
\hline & & Especialmente, apreciación de que la \\
\hline & & $\begin{array}{l}\text { longitud del lado oblicuo es mayor que el } \\
\text { vertical. }\end{array}$ \\
\hline & Memoria visual & -- \\
\hline
\end{tabular}

Tabla 2. Características en Actividad C 


\begin{tabular}{ll}
\hline Contexto & $\begin{array}{l}\text { Un carpintero que hace un borde para una jardinera corresponde a } \\
\text { una situación real, laboral. }\end{array}$ \\
Datos del enunciado & $\begin{array}{l}\text { Brinda información relevante en el texto breve y en los diseños, } \\
\text { presentación esquemática de la información. La gráfica que se } \\
\text { aporta presenta figuras semejantes a las buscadas, están en } \\
\text { proporción dada, es decir, cada } 10 \text { de ancho hace } 6 \text { de alto. }\end{array}$ \\
& Exige examinar procedimientos conocidos para resolver, el \\
perímetro de una figura y a la vez probar otros no conocidos que & \\
Tipología de tarea & se plantea para cada forma del borde. \\
Complejidad & Ya se presentan las formas geométricas de la jardinera. \\
& Se necesita vincular el dato del borde de la jardinera con el \\
& perímetro de una figura geométrica. \\
& Saber cómo se calcula el perímetro de una figura, \\
& Asociar la medida de la altura de las figuras con la medida de los \\
& lados correspondientes. Establecer conexiones entre la \\
información brindada, la que se necesita y utilizarla de forma \\
adecuada.
\end{tabular}

\section{Actividad E}

Tabla 3. Componentes del sentido espacial en Actividad E

\begin{tabular}{|c|c|c|}
\hline \multicolumn{2}{|c|}{ Componentes del sentido espacial } & Actividad E \\
\hline \multirow{9}{*}{$\begin{array}{l}\text { Manejo de } \\
\text { conceptos } \\
\text { geométricos }\end{array}$} & Conceptos de las figuras & Concepto de altura, medida y distancia. \\
\hline & Propiedades de las formas & $\begin{array}{l}\text { Escalones paralelos al plano del piso, la } \\
\text { altura perpendicular al plano del piso. }\end{array}$ \\
\hline & Relaciones geométricas & $\begin{array}{l}\text { La altura de la escalera se descompone } \\
\text { en la suma de la altura de los } 14 \\
\text { escalones. }\end{array}$ \\
\hline & & Altura del escalón es paralelo a \\
\hline & & segmento que muestra la altura de la \\
\hline & & $\begin{array}{l}\text { l1gura. } \\
\text { Identificación de los segmentos que }\end{array}$ \\
\hline & & $\begin{array}{l}\text { forman la altura de los escalones con } \\
\text { trozos de la altura del polígono. }\end{array}$ \\
\hline & Ubicación y movimientos & -- \\
\hline & Orientación & $\begin{array}{l}\text { Disposición de la altura de cada } \\
\text { escalón, de manera perpendicular a la } \\
\text { "huella". }\end{array}$ \\
\hline \multirow{7}{*}{$\begin{array}{l}\text { Habilidades de } \\
\text { visualización }\end{array}$} & Coordinación ojo-motor & -- \\
\hline & Percepción figura-contexto & -- \\
\hline & Conservación de la percepción & $\begin{array}{l}\text { Se conserva la medida, varía la forma } \\
\text { en la que se dispone. }\end{array}$ \\
\hline & $\begin{array}{l}\text { Percepción de la posición en el } \\
\text { espacio }\end{array}$ & $\begin{array}{l}\text { Identificación de los elementos de los } \\
\text { que depende la altura. }\end{array}$ \\
\hline & $\begin{array}{l}\text { Percepción de las relaciones } \\
\text { espaciales }\end{array}$ & $\begin{array}{l}\text { Ver la relación entre la altura de los } \\
\text { escalones y la altura de la escalera } \\
\text { (apreciar que sólo los escalones tienen } \\
\text { que salvar la altura de la figura). }\end{array}$ \\
\hline & Discriminación visual & -- \\
\hline & Memoria visual & -- \\
\hline
\end{tabular}




\begin{tabular}{ll}
\hline \multicolumn{1}{c}{ Características } & \multicolumn{1}{c}{ Actividad E } \\
\hline Contexto & Una escalera y el alto de los escalones corresponde a una situación \\
real de nivel ocupacional o laboral. & La gráfica no es semejante, se da una figura en la \\
que la altura no está en proporción 27/40 con el ancho, como & aparece en el enunciado. El ancho no es importante, pero esto es \\
& un dato concreto. Hay información relevante en el texto breve que \\
& se reitera en la representación gráfica, en ella aparece información \\
& innecesaria que puede llevar a la confusión. Presentación \\
& esquemática de la información. \\
Tipología de tarea & Tienen todos los datos a la vista y deben realizar una operación \\
& para encontrar la solución. Ejercitan un procedimiento muy \\
& conocido como es la división. \\
Complejidad & Se presentan todos los datos en el texto breve. \\
& Exige reconocer la operación a realizar y reproducir el \\
& procedimiento de reparto, de división.
\end{tabular}

\section{Actividad D}

Tabla 5. Componentes del sentido espacial en Actividad D

\begin{tabular}{|c|c|c|}
\hline Compo & entes del sentido espacial & Actividad D \\
\hline \multirow{11}{*}{$\begin{array}{l}\text { Manejo de } \\
\text { conceptos } \\
\text { geométricos }\end{array}$} & Conceptos de las figuras & $\begin{array}{l}\text { Concepto de cubo, desarrollo plano del cubo. } \\
\text { Caras contiguas. Caras opuestas. }\end{array}$ \\
\hline & \multirow[t]{2}{*}{ Propiedades de las formas } & Caras paralelas dos a dos. \\
\hline & & Tres caras determinan cada vértice. \\
\hline & \multirow[t]{5}{*}{ Relaciones geométricas } & $\begin{array}{l}\text { Cada cara tiene contacto con otras cuatro, sólo } \\
\text { no tiene contacto con su opuesta. }\end{array}$ \\
\hline & & $\begin{array}{l}\text { Vínculo entre el cubo y su desarrollo plano. } \\
\text { Caras no consecutivas de un dado suman } 7 \text {. }\end{array}$ \\
\hline & & Caras contiguas en desarrollo son adyacentes \\
\hline & & en cuerpo. \\
\hline & & $\begin{array}{l}\text { Caras opuestas en cuerpo no pueden tener } \\
\text { arista común en desarrollo. }\end{array}$ \\
\hline & Ubicación y movimientos & $\begin{array}{l}\text { Ubicación del cubo en el espacio y su correlato } \\
\text { con su desarrollo plano. }\end{array}$ \\
\hline & \multirow[t]{2}{*}{ Orientación } & Disposición de las caras del dado. \\
\hline & & $\begin{array}{l}\text { Disposición de los números en el desarrollo. } \\
\text { La capacidad de girar la imagen visual del } \\
\text { cubo, o de las caras del desarrollo para apreciar } \\
\text { dónde se colocan. }\end{array}$ \\
\hline & Coordinación ojo-motor & -- \\
\hline & Percepción figura-contexto & -- \\
\hline & Conservación de la percepción & $\begin{array}{l}\text { Se conserva el tamaño y la forma de las caras } \\
\text { en los desarrollos planos. }\end{array}$ \\
\hline & $\begin{array}{l}\text { Percepción de la posición en el } \\
\text { espacio }\end{array}$ & $\begin{array}{l}\text { Se conserva la posición de las caras en los } \\
\text { desarrollos planos. }\end{array}$ \\
\hline & & $\begin{array}{l}\text { Identificación de la relación que existe entre } \\
\text { las caras de desarrollo y las caras en el cubo. }\end{array}$ \\
\hline $\begin{array}{l}\text { Habilidades de } \\
\text { visualización }\end{array}$ & $\begin{array}{l}\text { Percepción de las relaciones } \\
\text { espaciales }\end{array}$ & Caras paralelas dos a dos suman 7 . \\
\hline
\end{tabular}


Dos caras contiguas en desarrollo que sumen 7 no son opuestas en cubo.

Discriminación visual Diferenciar los desarrollos presentados. Dos desarrollos planos conservan que caras paralelas suman 7: II y III y dos no conservan: I y IV.

Identificar el cubo que resulta de los

Memoria visual desarrollos II y III, pese a que son diferentes. $--$

Tabla 6. Características en la Actividad D

\begin{tabular}{|c|c|}
\hline Características & Actividad D \\
\hline Contexto & $\begin{array}{l}\text { Los dados se consideran elementos integrantes de los juegos del } \\
\text { estudiante, corresponde a una situación real a nivel personal. }\end{array}$ \\
\hline Datos del enunciado & $\begin{array}{l}\text { Texto largo del que deben extraer datos relevantes, como la suma } \\
\text { de caras opuestas suma } 7 \text {. La representación gráfica del dado en } \\
\text { dos dimensiones brinda la información para poder seleccionar la } \\
\text { respuesta correcta. Presentación de texto y esquemática de la } \\
\text { información. }\end{array}$ \\
\hline Tipología de tarea & $\begin{array}{l}\text { Exige asociar las representaciones en dos y tres dimensiones del } \\
\text { dado. Para aplicar la regla establecida de las caras opuestas suman } \\
7 \text { no hay un camino establecido y previamente conocido por el } \\
\text { estudiante. Resulta ser un problema a resolver. }\end{array}$ \\
\hline Complejidad & $\begin{array}{l}\text { Asociar las dos representaciones del dado en dos y tres } \\
\text { dimensiones. Exige habilidades de visualización para discriminar } \\
\text { los desarrollos que cumplan la consigna establecida. Se establecen } \\
\text { conexiones. }\end{array}$ \\
\hline
\end{tabular}

\section{Actividad G1}

Tabla 7. Componentes del sentido espacial en Actividad G1

\begin{tabular}{lll}
\hline \multicolumn{2}{c}{ Componentes del sentido espacial } & \multicolumn{1}{c}{ Actividad G1 } \\
\hline & Conceptos de las figuras & $\begin{array}{l}\text { Concepto de prisma, rectángulo y } \\
\text { paralelogramo. }\end{array}$ \\
$\begin{array}{l}\text { Manejo de } \\
\text { conceptos } \\
\text { geométricos }\end{array}$ & Propiedades de las formas & $\begin{array}{l}\text { Pentágonos, trapecios isósceles (casi } \\
\text { rectángulos) y paralelogramos, para } \\
\text { representar en perspectiva pentágono y } \\
\text { rectángulos de paredes y tejado. }\end{array}$ \\
& Paralelismo entre caras laterales, dos a \\
& Res. & \\
& & $\begin{array}{l}\text { Perpendicularidad entre caras } \\
\text { consecutivas laterales. }\end{array}$ \\
& Posición relativa entre puerta y ventana, \\
& cercanía a cara de puerta, lateralidad (se \\
& ve a su izquierda). \\
& Cambio de posición del garaje en las \\
& respuestas.
\end{tabular}


La capacidad de simetrizar la imagen visual del garaje, en las posiciones B y $\mathrm{D}$ y de girarlo a las posiciones $\mathrm{A}$ y $\mathrm{C}$.

Coordinación ojo-motor Percepción figura-contexto

Habilidades de visualización

--

Identificación de posición de figura tridimensional por la posición respecto al fondo negro, pese a tratarse de una representación plana (en perspectiva, captación de la perspectiva).

Conservación de la percepción

Percepción de la posición en el espacio

Percepción de las relaciones espaciales

Discriminación visual
Identificación de las relaciones de lateralidad y cercanía entre ventana y cara de la puerta.

Identificación de la posición relativa con los otros elementos (fondo, cara opuesta a ventana).

Cercanía de la ventana con la puerta y lejanía de la ventana con la pared del fondo.

Diferenciar figuras por los elementos que suministra (puerta, ventana, posición)

Memoria visual $--$

Tabla 8. Características en la Actividad Gl

\begin{tabular}{ll}
\hline \multicolumn{1}{c}{ Características } & \multicolumn{1}{c}{ Actividad G1 } \\
\hline Contexto & Un fabricante de garaje corresponde a una situación real a nivel \\
ocupacional o laboral. & Las gráficas del enunciado están dadas en \\
perspectiva cónica, con dos puntos de fuga, que diferencia el & frontal, que es más grande. Texto breve que contextualiza la \\
& situación y orienta en la búsqueda de la solución, "solo una". La \\
& representación gráfica del garaje en tres dimensiones con vista \\
& frontal presenta los datos de ubicación de ventana y puerta. \\
& Presentación esquemática de toda la situación. \\
& Exige asociar las representaciones en tres dimensiones del garaje \\
& del frente con el fondo, habiendo cambiado de posición. Para \\
& determinar la vista del fondo adecuada no hay un único camino, \\
Tipología de tarea & tampoco son conocidas las estrategias. Se puede vincular con la \\
& rotación de objetos. Resulta ser un problema. \\
& Asociar las dos representaciones en tres dimensiones del garaje, la \\
& frontal y la de fondo. \\
& Exige habilidades de visualización para lograr la rotación \\
& adecuada del garaje. Establecer vínculos entre la ubicación de la \\
puerta y la ventana dadas como referencia y ver en qué lugar \\
Complejidad \\
quedan en la vista del fondo. Exige una interpretación visual de la \\
información para establecer conexiones.
\end{tabular}

\section{Actividad G2}

Tabla 9. Componentes del sentido espacial en Actividad G2 


\begin{tabular}{|c|c|c|}
\hline Component & del sentido espacial & Actividad G2 \\
\hline \multirow{12}{*}{$\begin{array}{l}\text { Manejo de } \\
\text { conceptos } \\
\text { geométricos }\end{array}$} & $\begin{array}{l}\text { Conceptos de las } \\
\text { figuras }\end{array}$ & $\begin{array}{l}\text { Triángulos rectángulos, rectángulos y altura (del } \\
\text { techo). }\end{array}$ \\
\hline & $\begin{array}{l}\text { Propiedades de las } \\
\text { formas }\end{array}$ & Teorema de Pitágoras, área del rectángulo. \\
\hline & Relaciones & Lados opuestos de un rectángulo son paralelos. \\
\hline & geométricas & $\begin{array}{l}\text { Lados consecutivos de un rectángulo son } \\
\text { perpendiculares. La altura es perpendicular a la } \\
\text { horizontal. El lado del rectángulo del tejado es la } \\
\text { hipotenusa de un triángulo rectángulo }\end{array}$ \\
\hline & & determinado por dos medidas que no \\
\hline & & corresponden a ningún objeto físico (la mitad de \\
\hline & & la anchura del tejado y la altura del mismo) \\
\hline & Ubicación y & -- \\
\hline & $\begin{array}{l}\text { movimientos } \\
\text { Orientación }\end{array}$ & unerior de la vista \\
\hline & & lateral no representa el techo. \\
\hline & & $\begin{array}{l}\text { Considerar la vista frontal y la lateral como parte } \\
\text { de un todo. }\end{array}$ \\
\hline & & $\begin{array}{l}\text { Sintetizar la información en un nuevo rectángulo } \\
\text { que se corresponde con el techo. }\end{array}$ \\
\hline \multirow{10}{*}{$\begin{array}{l}\text { Habilidades de } \\
\text { visualización }\end{array}$} & $\begin{array}{l}\text { Coordinación ojo- } \\
\text { motor }\end{array}$ & -- \\
\hline & $\begin{array}{l}\text { Percepción figura- } \\
\text { contexto }\end{array}$ & $\begin{array}{l}\text { Identificación de medidas que corresponden a } \\
\text { objetos, como el largo del garaje se corresponde } \\
\text { con el largo del techo. }\end{array}$ \\
\hline & & Identificación de distancias entre objetos, como \\
\hline & & $\begin{array}{l}\text { los que determinan el triángulo rectángulo que } \\
\text { tiene por hipotenusa al lado del tejado. }\end{array}$ \\
\hline & $\begin{array}{l}\text { Conservación de la } \\
\text { percepción }\end{array}$ & Reconocer el ancho y el largo del techo. \\
\hline & $\begin{array}{l}\text { Percepción de la } \\
\text { posición en el espacio }\end{array}$ & $\begin{array}{l}\text { Vincular la posición del ancho del techo en la } \\
\text { vista frontal con un segmento perpendicular al } \\
\text { largo de la vista lateral. }\end{array}$ \\
\hline & $\begin{array}{l}\text { Percepción de las } \\
\text { relaciones espaciales }\end{array}$ & $\begin{array}{l}\text { Identificar el largo del techo con el largo de la } \\
\text { vista lateral. }\end{array}$ \\
\hline & & $\begin{array}{l}\text { Identificar el ancho del techo como la hipotenusa } \\
\text { de un triángulo rectángulo. }\end{array}$ \\
\hline & & Determinar un nuevo rectángulo para el techo. \\
\hline & Discriminación visual & Diferenciar la altura del ancho techo. \\
\hline
\end{tabular}

Tabla 10. Características en la Actividad G2

\begin{tabular}{|c|c|}
\hline Características & Actividad G2 \\
\hline Contexto & $\begin{array}{l}\text { Un fabricante de garaje corresponde a una situación real a nivel } \\
\text { ocupacional o laboral. }\end{array}$ \\
\hline Datos del enunciado & $\begin{array}{l}\text { Texto breve que contextualiza la situación La representación } \\
\text { gráfica del garaje en dos dimensiones con vista frontal y lateral. } \\
\text { La multiplicidad de datos, relevantes e irrelevantes ofrecen } \\
\text { dificultad. Presentación esquemática de toda la situación. }\end{array}$ \\
\hline
\end{tabular}


Tipología de tarea

Complejidad
Exige asociar las representaciones en dos dimensiones del garaje del frente y la lateral. Para realizar el cálculo solicitado debe hacer cálculos previos a través de algoritmos conocidos. El camino de resolución del problema demanda creatividad y conocimientos previos.

Asociar las dos representaciones en dos dimensiones del garaje, la frontal y la de fondo.

Asociar las dimensiones que se corresponden entre las dos vistas.

Discriminar datos necesarios de los que no.

Determinar que dato le falta.

Recurrir a una estrategia conocida para determinar el dato desconocido, el ancho del techo.

Considerar el nuevo rectángulo y sus dimensiones para poder calcular el área y luego duplicar esa área.

Exige una reflexión para poder trazar el camino de resolución, elaborar la estrategia de resolución.

\section{Actividad PG1}

Tabla 11. Componentes del sentido espacial en Actividad PG1

\begin{tabular}{|c|c|c|}
\hline \multicolumn{2}{|c|}{ Componentes del sentido espacial } & Actividad PG1 \\
\hline \multirow{5}{*}{$\begin{array}{l}\text { Manejo de } \\
\text { conceptos } \\
\text { geométricos }\end{array}$} & Conceptos de las figuras & Ángulos \\
\hline & Propiedades de las formas & $\begin{array}{l}\text { Las tres puertas, de a dos forman ángulos } \\
\text { iguales. }\end{array}$ \\
\hline & Relaciones geométricas & $\begin{array}{l}\text { Ángulos consecutivos, obtusos y ángulo } \\
\text { completo. }\end{array}$ \\
\hline & Ubicación y movimientos & $\begin{array}{l}\text { En las tres posiciones que se muestran, se } \\
\text { conserva la amplitud de los sectores. }\end{array}$ \\
\hline & Orientación & -- \\
\hline \multirow{7}{*}{$\begin{array}{l}\text { Habilidades } \\
\text { de } \\
\text { visualización }\end{array}$} & Coordinación ojo-motor & -- \\
\hline & Percepción figura-contexto & -- \\
\hline & Conservación de la percepción & $\begin{array}{l}\text { Se conserva la amplitud de los sectores } \\
\text { formados por las puertas. }\end{array}$ \\
\hline & $\begin{array}{l}\text { Percepción de la posición en el } \\
\text { espacio }\end{array}$ & $\begin{array}{l}\text { Las tres posiciones responden a una única } \\
\text { puerta giratoria. }\end{array}$ \\
\hline & $\begin{array}{l}\text { Percepción de las relaciones } \\
\text { espaciales }\end{array}$ & -- \\
\hline & Discriminación visual & $\begin{array}{l}\text { Identificar las puertas representadas por } \\
\text { una visión desde arriba. }\end{array}$ \\
\hline & Memoria visual & -- \\
\hline
\end{tabular}

Tabla 12. Características en la Actividad PG1

\begin{tabular}{ll}
\hline \multicolumn{1}{c}{ Características } & \multicolumn{1}{c}{ Actividad PG1 } \\
\hline Contexto & $\begin{array}{l}\text { Una puerta giratoria de la que se brinda la imagen vista desde } \\
\text { arriba y se solicita el ángulo formado entre dos de las hojas } \\
\text { corresponde a una situación real a nivel científico. } \\
\text { Datos del enunciado } \\
\text { Texto breve que contextualiza la situación y brinda un dato que no } \\
\text { relevante. La representación gráfica de la puerta giratoria vista }\end{array}$
\end{tabular}


Tipología de tarea

Complejidad desde arriba permite deducir que los ángulos entre las hojas son iguales. Presentación esquemática de toda la situación.

Requiere de conocimientos previos específicos, acerca de la medida del ángulo completo, teniendo ese dato se arriba a la solución a través de un algoritmo sencillo. Resulta ser un problema.

Exige deducir de la representación gráfica que los ángulos entre las hojas de la puerta son iguales.

Exige un conocimiento preciso, saber que el ángulo completo mide $360^{\circ}$. El camino de resolución es la aplicación de un algoritmo sencillo.

Para acceder a la solución se necesita emplear conocimiento matemático y analizar por tal necesita proceso de reflexión.

\section{Actividad PG2}

Tabla 13. Componentes del sentido espacial en Actividad PG2

\begin{tabular}{|c|c|c|}
\hline Componentes & el sentido espacial & Actividad PG2 \\
\hline \multirow{5}{*}{$\begin{array}{l}\text { Manejo de } \\
\text { conceptos } \\
\text { geométricos }\end{array}$} & $\begin{array}{l}\text { Conceptos de las } \\
\text { figuras }\end{array}$ & $\begin{array}{l}\text { Angulo completo, circunferencia, arcos de } \\
\text { circunferencia, amplitud de un arco. }\end{array}$ \\
\hline & $\begin{array}{l}\text { Propiedades de las } \\
\text { formas }\end{array}$ & $\begin{array}{l}\text { Longitud de la circunferencia, radio, relación entre } \\
\text { ángulo central y arco. }\end{array}$ \\
\hline & $\begin{array}{l}\text { Relaciones } \\
\text { geométricas }\end{array}$ & $\begin{array}{l}\text { Amplitud del sector formado por dos puertas es igual } \\
\text { a una parte cerrada de la puerta giratoria. Las dos } \\
\text { partes abiertas suman lo que una cerrada. }\end{array}$ \\
\hline & $\begin{array}{l}\text { Ubicación y } \\
\text { movimientos }\end{array}$ & $\begin{array}{l}\text { Identificar posiciones en que se puede producir } \\
\text { circulación de aire. }\end{array}$ \\
\hline & Orientación & $\begin{array}{l}\text { Asociar los tres sectores que forman las puestas con } \\
\text { las partes abiertas y cerradas de la puerta giratoria. } \\
\text { Capacidad para analizar el vínculo entre los sectores } \\
\text { y las partes abiertas y cerradas. }\end{array}$ \\
\hline \multirow{7}{*}{$\begin{array}{l}\text { Habilidades } \\
\text { de } \\
\text { visualización }\end{array}$} & $\begin{array}{l}\text { Coordinación ojo- } \\
\text { motor }\end{array}$ & -- \\
\hline & $\begin{array}{l}\text { Percepción figura- } \\
\text { contexto }\end{array}$ & -- \\
\hline & $\begin{array}{l}\text { Conservación de la } \\
\text { percepción }\end{array}$ & -- \\
\hline & $\begin{array}{l}\text { Percepción de la } \\
\text { posición en el espacio }\end{array}$ & $\begin{array}{l}\text { La parte cerrada de la puerta giratoria es igual al } \\
\text { sector formado por dos puertas. }\end{array}$ \\
\hline & $\begin{array}{l}\text { Percepción de las } \\
\text { relaciones espaciales }\end{array}$ & $\begin{array}{l}\text { Determinar la relación entre los sectores y las partes } \\
\text { cerradas y abiertas. }\end{array}$ \\
\hline & Discriminación visual & -- \\
\hline & Memoria visual & -- \\
\hline
\end{tabular}

Tabla 14. Características en la Actividad PG2 


\begin{tabular}{ll}
\hline Contexto & Una puerta giratoria de la que se brinda la imagen vista desde \\
arriba y se solicita la longitud de un arco corresponde a una \\
situación real a nivel científico. \\
Texto largo que contextualiza la situación, pero no brinda datos \\
relevantes. La representación gráfica de la puerta giratoria vista \\
desde arriba permite deducir que las partes cerradas de la puerta \\
tienen igual amplitud que entre dos hojas. Presentación \\
esquemática de la información relevante. \\
Requiere de conocimientos previos específicos, acerca de la \\
longitud de la circunferencia, presenta un desafío, podrían \\
encontrar distintos caminos para establecer la parte abierta de la \\
puesta. Resulta ser un problema. \\
Exige asociar la longitud de los arcos a la longitud de la \\
circunferencia y por tanto recordar la fórmula del perímetro. \\
Deducir de la representación gráfica que la longitud de la parte \\
cerrada de la puerta se corresponde a la distancia entre dos de las \\
hojas. Asociar que la distancia entre las hojas es igual. \\
Ver que la parte abierta por tanto se corresponde a una parte \\
cerrada, para luego partir en dos. \\
Para acceder a la solución se necesita emplear conocimiento \\
matemático y analizar por tal necesita proceso de reflexión. \\
\hline
\end{tabular}

\section{Actividad A1}

Tabla 15. Componentes del sentido espacial en Actividad Al

\begin{tabular}{lll}
\hline Componentes del sentido espacial & \multicolumn{1}{c}{ Actividad A1 } \\
\hline Conceptos de las & Concepto de circunferencia, círculo y bisectriz de \\
figuras & un ángulo como lugar geométrico y de distancia. \\
fropiedades de las & Todos los puntos de la circunferencia distan "r" del \\
& centro. \\
& Todos los puntos del círculo están a una distancia \\
& menor o igual al radio del centro. \\
& Todos los puntos de la bisectriz de un ángulo están \\
& a igual distancia de los lados del ángulo. \\
& Relaciones & Las bisectrices de ángulos opuestos por el vértice \\
geométricas & están incluidas en la misma recta. \\
& Las bisectrices de ángulos suplementarios son \\
& perpendiculares. \\
conceptos de & La distancia entre A y las bisectrices es menor que \\
geométricos & 4,5cm (radio). \\
& Los puntos de la circunferencia están a 4,5cm de A \\
& por tanto no van a formar parte de la solución. \\
& Los segmentos de bisectrices que se encuentren \\
& dentro de la circunferencia cumplen las condiciones \\
& solicitadas. \\
& La intersección de las bisectrices con los puntos \\
& interiores del círculo cumple las condiciones \\
& solicitadas. \\
& Posición relativa de los segmentos de las bisectrices \\
& con relación al círculo y/o circunferencia. \\
& --
\end{tabular}




\begin{tabular}{|c|c|c|}
\hline \multirow{7}{*}{$\begin{array}{l}\text { Habilidades de } \\
\text { visualización }\end{array}$} & $\begin{array}{l}\text { Coordinación ojo- } \\
\text { motor }\end{array}$ & $\begin{array}{l}\text { Conocer y lograr el trazado del procedimiento de } \\
\text { construcción de la circunferencia y de las dos } \\
\text { bisectrices. }\end{array}$ \\
\hline & $\begin{array}{l}\text { Percepción figura- } \\
\text { contexto }\end{array}$ & $\begin{array}{l}\text { Considerar los segmentos de bisectrices incluidos } \\
\text { en el círculo. }\end{array}$ \\
\hline & $\begin{array}{l}\text { Conservación de la } \\
\text { percepción }\end{array}$ & -- \\
\hline & $\begin{array}{l}\text { Percepción de la } \\
\text { posición en el } \\
\text { espacio }\end{array}$ & -- \\
\hline & $\begin{array}{l}\text { Percepción de las } \\
\text { relaciones } \\
\text { espaciales }\end{array}$ & $\begin{array}{l}\text { Determinación de todos los puntos que cumplen } \\
\text { con estar a menos de } 4,5 \mathrm{~cm} \text { y equidistantes de las } \\
\text { rectas } \mathrm{AB} \text { y EF. }\end{array}$ \\
\hline & $\begin{array}{l}\text { Discriminación } \\
\text { visual }\end{array}$ & -- \\
\hline & Memoria visual & -- \\
\hline
\end{tabular}

Tabla 16. Características en la Actividad Al

\begin{tabular}{ll}
\hline \multicolumn{1}{c}{ Características } & \multicolumn{1}{c}{ Actividad A1 } \\
\hline Contexto & Indicar los puntos del plano, es una situación específicamente \\
& matemática, perteneciente al ámbito académico, situación \\
& científica. \\
Datos del enunciado & Texto breve con los datos relevantes, con elementos geométricos. \\
& La representación gráfica muestra la situación dos rectas que se \\
& cortan, y sitúa en ellas los puntos indicados en el enunciado, \\
& dando distancias diferentes a los segmentos AB y EF. La única \\
& alusión métrica en el dibujo es el ángulo que forman las rectas, no \\
& hay distancias. La representación gráfica completa la información \\
& relevante de los datos geométricos. \\
& Requiere de conocimientos previos específicos, acerca de los \\
& lugares geométricos vistos en el curso, presenta un desafío, cuál o \\
& cuáles resuelven la situación. Resulta ser un problema. \\
& Exige conocer todos los lugares geométricos vistos en el curso. \\
& Exige interpretar la representación gráfica brindada porque se \\
Tipología de tarea & trabajará en ella. \\
& Es necesario saber trazar bisectriz y circunferencia con lápiz y \\
& papel. \\
& Determinar los puntos equidistantes de los lados de un ángulo y \\
& asociar a la bisectriz del ángulo \\
& Descubrir que hay cuatro ángulos y no sólo quedarse con el \\
& agudo. \\
& Descifrar los elementos de una circunferencia. Determinar el \\
& círculo a través de la expresión “a menos de 4,5cm". \\
& Interceptar las figuras y seleccionar los puntos que cumplen las \\
& dos condiciones a la vez, con la precisión de excluir los puntos del \\
& borde. \\
& Para acceder a la solución se necesita emplear conocimiento \\
& matemático, analizar y armar un plan, por tal necesita proceso de \\
& conexión. \\
& \\
\hline &
\end{tabular}


Tabla 17. Componentes del sentido espacial en Actividad A2

\begin{tabular}{|c|c|c|}
\hline Componentes d & I sentido espacial & Actividad A2 \\
\hline \multirow{14}{*}{$\begin{array}{l}\text { Manejo de } \\
\text { conceptos } \\
\text { geométricos }\end{array}$} & $\begin{array}{l}\text { Conceptos de } \\
\text { las figuras }\end{array}$ & $\begin{array}{l}\text { Concepto de distancia, medida, mediana, punto medio, } \\
\text { vértices, ángulo y triángulo. }\end{array}$ \\
\hline & & $\begin{array}{l}\text { Circunferencia, mediatriz, arco capaz como lugar } \\
\text { geométrico. }\end{array}$ \\
\hline & $\begin{array}{l}\text { Propiedades de } \\
\text { las formas }\end{array}$ & $\begin{array}{l}\text { Los puntos de la mediatriz equidistan de los extremos } \\
\text { del segmento. }\end{array}$ \\
\hline & & $\begin{array}{l}\text { Los puntos del arco capaz ven a un segmento bajo el } \\
\text { mismo ángulo. }\end{array}$ \\
\hline & & $\begin{array}{l}\text { Los puntos de la circunferencia distan una distancia fija } \\
\text { del centro. }\end{array}$ \\
\hline & & Tres lados determinan un triángulo. \\
\hline & $\begin{array}{l}\text { Relaciones } \\
\text { geométricas }\end{array}$ & $\begin{array}{l}\text { El punto } \mathrm{C} \text { pertenece a una circunferencia cuyo radio } \\
\text { es } 8 \mathrm{~cm} \text {. }\end{array}$ \\
\hline & & $\begin{array}{l}\text { El punto } B \text { pertenece a una circunferencia de centro el } \\
\text { punto medio del segmento AC y radio la medida de la } \\
\text { mediana }\left(\mathrm{m}_{\mathrm{B}}\right) \text {. }\end{array}$ \\
\hline & & $\begin{array}{l}\text { El punto B pertenece al Arco Capaz que ve al } \\
\text { segmento AC bajo un ángulo de } 70^{\circ} .\end{array}$ \\
\hline & $\begin{array}{l}\text { Ubicación y } \\
\text { movimientos }\end{array}$ & $\begin{array}{l}\text { La medida de la mediana como radio de una } \\
\text { circunferencia y el punto medio del segmento como su } \\
\text { centro. }\end{array}$ \\
\hline & & $\begin{array}{l}\text { Asociar la amplitud del ángulo ABC, al segmento AC } \\
\text { y Arco Capaz que determinan. }\end{array}$ \\
\hline & & La posición del punto B como la intersección de dos \\
\hline & & $\begin{array}{l}\text { lugares geométricos anteriores: circunferencia y arco } \\
\text { capaz. }\end{array}$ \\
\hline & Orientación & $\begin{array}{l}\text { Identificar que en iguales condiciones que el punto B } \\
\text { están E, G y H. }\end{array}$ \\
\hline \multirow{10}{*}{$\begin{array}{l}\text { Habilidades de } \\
\text { visualización }\end{array}$} & $\begin{array}{l}\text { Coordinación } \\
\text { ojo-motor }\end{array}$ & $\begin{array}{l}\text { Conocer y lograr el trazado del procedimiento de } \\
\text { construcción de la mediatriz, circunferencia y arco } \\
\text { capaz. }\end{array}$ \\
\hline & & Uso del trasportador y trazado del ángulo de $70^{\circ}$. \\
\hline & Percepción & Considerar los puntos que son solución como \\
\hline & figura-contexto & intersección de la circunferencia y el arco capaz. \\
\hline & Conservación de & -- \\
\hline & la percepción & \\
\hline & $\begin{array}{l}\text { Percepción de la } \\
\text { posición en el } \\
\text { espacio }\end{array}$ & -- \\
\hline & $\begin{array}{l}\text { Percepción de } \\
\text { las relaciones } \\
\text { espaciales }\end{array}$ & $\begin{array}{l}\text { Determinación de todos los puntos que cumplen con } \\
\text { estar en la mediana de } 5 \mathrm{~cm} \text { y ser vértice del ángulo } \\
\mathrm{ABC} \text { de } 70^{\circ} \text {. }\end{array}$ \\
\hline & $\begin{array}{l}\text { Discriminación } \\
\text { visual }\end{array}$ & -- \\
\hline & Memoria visual & -- \\
\hline
\end{tabular}

Tabla 18. Características en la Actividad A2 


\begin{tabular}{ll}
\hline Contexto & $\begin{array}{l}\text { Construir un triángulo ABC, es una situación específicamente } \\
\text { matemática, perteneciente al ámbito académico, situación } \\
\text { científica. } \\
\text { Datos del enunciado }\end{array}$ \\
Texto breve con los datos relevantes, específicamente \\
geométricos. \\
Requiere de conocimientos previos específicos, acerca de los \\
lugares geométricos vistos en el curso, presenta un desafío, cuál o \\
cuáles se deben combinar para determinar el triángulo. Resulta ser \\
un problema. \\
Exige conocer todos los lugares geométricos vistos en el curso. \\
Exige interpretar el dato de la mediana y asociar al punto medio \\
como centro de la circunferencia de radio la medida de la \\
mediana. \\
Con el dato del nombre del ángulo y la amplitud, es necesario \\
asociarlo al segmento AC dado antes y toda la información unirla \\
en un arco capaz \\
Es necesario saber trazar arco capaz y circunferencia con lápiz y \\
papel. \\
Interceptar las figuras, seleccionar los puntos que cumplen las dos \\
condiciones a la vez y trazar el triángulo. \\
Identificar los pasos realizados, ordenarlos y buscar la expresión \\
más precisa para comunicar cada paso. \\
Para acceder a la solución se necesita emplear conocimiento \\
matemático, analizar y armar un plan, por tal necesita proceso de \\
conexión.
\end{tabular}

\section{Actividad A3}

Tabla 19. Componentes del sentido espacial en Actividad 3

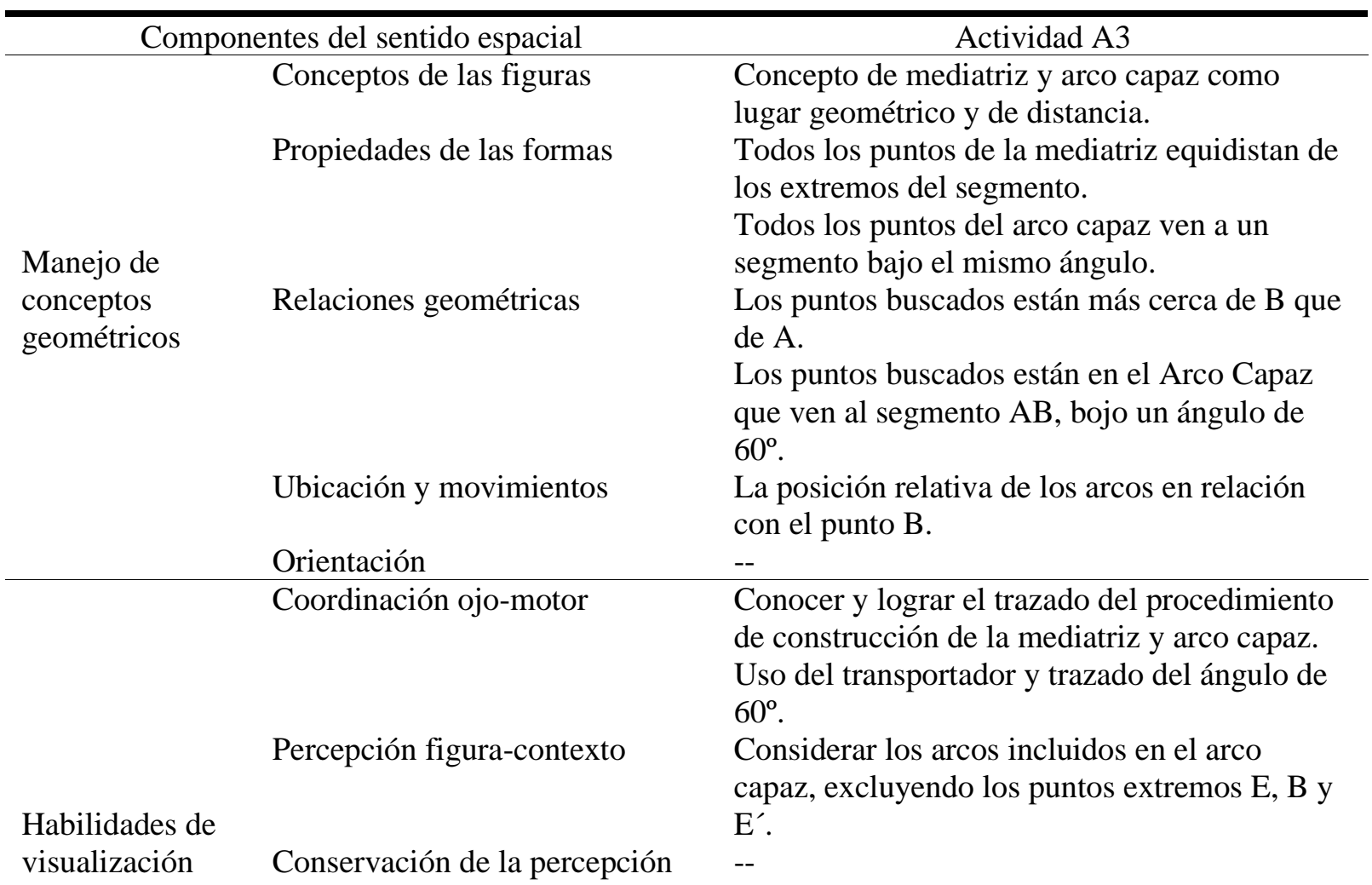


Percepción de la posición en el -

espacio

Percepción de las relaciones Determinación de todos los puntos que

espaciales

cumplen con estar más cerca de $\mathrm{B}$ que de $\mathrm{A}$, al semiplano que contiene a $\mathrm{B}$ y ven al segmento $\mathrm{AB}$ bajo un ángulo de $60^{\circ}$. Excluyendo $\mathrm{E}, \mathrm{B}$ y $\mathrm{E}^{\prime}$.

Discriminación visual

$--$

Memoria visual

Tabla 20. Características en la Actividad A3

\begin{tabular}{|c|c|}
\hline Características & Actividad A3 \\
\hline Contexto & $\begin{array}{l}\text { Indicar los puntos del plano, es una situación específicamente } \\
\text { matemática, perteneciente al ámbito académico, situación } \\
\text { científica. }\end{array}$ \\
\hline Datos del enunciado & $\begin{array}{l}\text { Texto breve con los datos relevantes, con elementos geométricos. } \\
\text { Se da un segmento que no es paralelo a los bordes del folio La } \\
\text { representación gráfica completa la información relevante de los } \\
\text { datos geométricos. }\end{array}$ \\
\hline Tipología de tarea & $\begin{array}{l}\text { Requiere de conocimientos previos específicos, acerca de los } \\
\text { lugares geométricos vistos en el curso, presenta un desafío, cuál o } \\
\text { cuáles resuelven la situación. Resulta ser un problema. }\end{array}$ \\
\hline Complejidad & $\begin{array}{l}\text { Exige conocer todos los lugares geométricos vistos en el curso. } \\
\text { Exige transportar el segmento AB dado o trazar desde él. } \\
\text { Segmento AB no paralelo a los bordes del folio, genera } \\
\text { razonamiento que no tenga en cuenta las direcciones vertical y } \\
\text { horizontal. } \\
\text { Es necesario saber trazar arco capaz y mediatriz con lápiz y papel. } \\
\text { Determinar los puntos que están equidistantes de A y B y luego } \\
\text { determinar los que están "más cerca de B que da A". } \\
\text { Descifrar los elementos necesarios para construir un arco capaz, } \\
\text { segmento y un ángulo que lo "ve". } \\
\text { Interceptar las figuras y seleccionar los puntos que cumplen las } \\
\text { dos condiciones a la vez, con la precisión de excluir } 3 \text { puntos en } \\
\text { particular por motivos diferentes, B porque no "ve" al segmento } \\
\text { con un ángulo de } 60^{\circ} \text { y los que están en la mediatriz no cumplen } \\
\text { con "estar más cerca de B". } \\
\text { Para acceder a la solución se necesita emplear conocimiento } \\
\text { matemático, analizar y armar un plan, por tal necesita proceso de } \\
\text { conexión. }\end{array}$ \\
\hline
\end{tabular}

\section{Actividad A4}

Tabla 21. Componentes del sentido espacial en Actividad A4

\begin{tabular}{cl}
\hline Componentes del sentido espacial & \multicolumn{1}{c}{ Actividad A4 } \\
\hline Conceptos de las figuras & $\begin{array}{l}\text { Concepto de circunferencia y unión de } \\
\text { paralelas como lugar geométrico y de } \\
\text { mediatriz y distancia. }\end{array}$
\end{tabular}


Propiedades de las formas

Relaciones geométricas

Manejo de

conceptos

geométricos
Ubicación y movimientos

Orientación

Coordinación ojo-motor

Percepción figura-contexto

Habilidades de visualización
Conservación de la percepción

Percepción de la posición en el espacio

Percepción de las relaciones

espaciales

Discriminación visual Memoria visual
Todos los puntos de la circunferencia distan una distancia constante del centro.

Todos los puntos de la unión de paralelas están a una distancia constante de una recta dada. El punto $Q$ pertenece a una circunferencia cuyo radio es $8 \mathrm{~cm}$.

El punto $\mathrm{R}$ pertenece a una circunferencia de centro el punto medio del segmento $\mathrm{PQ}$ y radio la medida de la mediana $\left(\mathrm{m}_{\mathrm{R}}\right)$.

El punto $\mathrm{R}$ pertenece a la unión de paralelas que distan la altura $\left(\mathrm{h}_{\mathrm{R}}\right)$ respecto de $\mathrm{AB}$.

La medida de la mediana como radio de una circunferencia y el punto medio del segmento como su centro.

Asociar la altura dada del triángulo, a la distancia entre la recta $\mathrm{AB}$ y sus paralelas. La posición del punto $\mathrm{R}$ como la intersección de dos lugares geométricos anteriores: circunferencia y unión de paralelas. Identificar que en iguales condiciones que el punto R están C, E y F.

Conocer y lograr el trazado del procedimiento de construcción de la mediatriz, circunferencia y unión de paralelas.

Considerar los puntos que son solución como intersección de la circunferencia y la unión de paralelas.

$--$

$-$

Identificar que los puntos solución cumplen con estar en las paralelas respecto de PQ a $4 \mathrm{~cm}$ y en la circunferencia con centro un punto que no es dado y medida $7 \mathrm{~cm}$ igual a la mediana.

Tabla 22. Características en la Actividad A4

\begin{tabular}{ll}
\hline \multicolumn{1}{c}{ Características } & \multicolumn{1}{c}{ Actividad A4 } \\
\hline Contexto & $\begin{array}{l}\text { Construir un triángulo PQR, es una situación específicamente } \\
\text { matemática, perteneciente al ámbito académico, situación } \\
\text { científica. }\end{array}$ \\
Texto breve con los datos relevantes, específicamente \\
geométricos.
\end{tabular}


Exige conocer todos los lugares geométricos vistos en el curso.

Exige interpretar el dato de la mediana y asociar al punto medio como centro de la circunferencia de radio la medida de la mediana.

Con el dato de la altura significa tener una medida constante y asociarlo a los puntos de las paralelas.

Es necesario saber trazar circunferencia y paralelas a una distancia dada con lápiz y papel.

Interceptar las figuras, seleccionar los puntos que cumplen las dos condiciones a la vez y trazar el triángulo.

Identificar los pasos realizados, ordenarlos y buscar la expresión más precisa para comunicar cada paso.

Para acceder a la solución se necesita emplear conocimiento matemático, analizar y armar un plan, por tal necesita proceso de conexión.

\section{Actividad A5}

Tabla 23. Componentes del sentido espacial en Actividad A5

Componentes del sentido espacial

Conceptos de las figuras

Propiedades de las formas

Manejo de conceptos geométricos

Relaciones geométricas
Actividad A5

Concepto de paralela media y arco capaz como lugar geométrico, y de ángulo, distancia y trapecio.

Todos los puntos de la paralela media están a igual distancia de dos paralelas.

Todos los puntos del arco capaz ven a un segmento bajo el mismo ángulo.

Los puntos buscados se encuentran a igual distancia de las rectas $A B$ y $C D$.

Los puntos buscados están en el Arco Capaz que ven al segmento $\mathrm{BC}$, bajo un ángulo de $30^{\circ}$.

Ubicación y movimientos

Orientación

Coordinación ojo-motor

Habilidades de Percepción figura-contexto visualización

Conservación de la percepción

Percepción de la posición en el espacio

Percepción de las relaciones espaciales

Discriminación visual Memoria visual
$--$

$-$

Conocer y lograr el trazado del procedimiento de construcción de la mediatriz, la paralela media y el arco capaz.

Uso de transportador y trazado de ángulo de $30^{\circ}$.

Considerar los puntos que son solución como intersección del arco capaz y la paralela media.

$--$

$-$

Determinar los puntos que cumplen con estar a igual distancia de las rectas $\mathrm{AB}$ y $\mathrm{CD}$, en la paralela media, y ven al segmento $\mathrm{BC}$ bajo un ángulo de $30^{\circ}$, en el arco capaz.

$--$ 


\begin{tabular}{ll}
\hline \multicolumn{1}{c}{ Características } & \multicolumn{1}{c}{ Actividad A5 } \\
\hline Contexto & Encontrar todos los puntos del plano, es una situación \\
& específicamente matemática, perteneciente al ámbito académico, \\
& situación científica. \\
Datos del enunciado & Texto breve con los datos relevantes de elementos geométricos. \\
& La representación gráfica completa la información relevante de \\
& los datos geométricos. Algunos datos no se utilizan, el segmento \\
& AD. El punto P que se va a determinar, forma parte de los datos. \\
Tipología de tarea & Requiere de conocimientos previos específicos, acerca de los \\
& lugares geométricos vistos en el curso, presenta un desafío, cuál o \\
& cuáles resuelven la situación. Resulta ser un problema. \\
& Exige conocer todos los lugares geométricos vistos en el curso. \\
& Exige trazar desde el trapecio ABCD. \\
& Es necesario saber trazar arco capaz y la paralela media con lápiz \\
& y papel. \\
& Exige asociar que el punto P no está determinado, es el que se va a \\
& determinar y aparece utilizado en los datos. \\
& Determinar los puntos que están equidistantes de las dos rectas \\
& AB y CD. \\
& Descifrar los elementos necesarios para construir un arco capaz, \\
& segmento BC y el ángulo BPC. \\
& Interceptar la paralela media y el arco capaz, seleccionar los \\
puntos que cumplen las dos condiciones a la vez. & Para acceder a la solución se necesita emplear conocimiento \\
& matemático, analizar y armar un plan, por tal necesita proceso de \\
conexión.
\end{tabular}

\section{Actividad A6}

Tabla 25. Componentes del sentido espacial en actividad A6

\begin{tabular}{ll}
\hline \multicolumn{1}{c}{ Componentes del sentido espacial } & \multicolumn{1}{c}{ Actividad A6 } \\
\hline Conceptos de las figuras & $\begin{array}{l}\text { Concepto de circunferencia, mediatriz, } \\
\text { circuncentro, distancia, ángulo, semirrecta y } \\
\text { triángulo. }\end{array}$ \\
& Todos los puntos de la circunferencia distan \\
& una distancia constante del centro. \\
& Una semirrecta secante a una circunferencia, \\
& con el origen perteneciente a la circunferencia, \\
& la intercepta en otro punto. \\
Manejo de & Los puntos de la mediatriz equidistan de los \\
conceptos & extremos del segmento. \\
geométricos & La distancia del circuncentro a los vértices de \\
& un triángulo es constante. \\
& El punto B pertenece a una circunferencia cuyo \\
& radio es 4cm. \\
& El circuncentro O se encuentra en la mediatriz \\
& del segmento AB y en la Circunferencia de \\
& centro A y radio 3cm (distancia del \\
& circuncentro a A)
\end{tabular}


Ubicación y movimientos

Orientación

Coordinación ojo-motor

Habilidades de visualización

Percepción figura-contexto

Conservación de la percepción Percepción de la posición en el espacio

Percepción de las relaciones espaciales

Discriminación visual Memoria visual
El punto $\mathrm{C}$ pertenece a una circunferencia de centro el circuncentro $\mathrm{O}$ y radio 3 .

El punto $\mathrm{C}$ pertenece a la semirrecta que forma $60^{\circ}$ con $\mathrm{AB}$.

Asociar la distancia del circuncentro al vértice $\mathrm{A}$, como el radio de dos circunferencias una con centro en A para determinar $\mathrm{O}$ y la circunferencia donde se va a encontrar $\mathrm{C}$ con centro en $\mathrm{O}$.

La posición del punto $\mathrm{C}$ como la intersección de la circunferencia de centro $\mathrm{O}$ y la semirrecta que forma $60^{\circ}$ antihorario con $\mathrm{AB}$.

$--$

Conocer y lograr el trazado del procedimiento de construcción de la mediatriz y circunferencia.

Uso de transportador y trazado de ángulo de $60^{\circ}$.

Considerar el punto solución como intersección de la circunferencia de centro el circuncentro y el lado del ángulo.

$-$

$-$

Identificar que el punto solución es la intersección de la circunferencia de centro el circuncentro y el lado del ángulo de $60^{\circ}$ con $\mathrm{AB}$.

$--$

Tabla 26. Características en la Actividad A6

\begin{tabular}{ll}
\hline \multicolumn{1}{c}{ Características } & \multicolumn{1}{c}{ Actividad A6 } \\
\hline Contexto & $\begin{array}{l}\text { Construir un triángulo } \mathrm{ABC} \text {, es una situación específicamente } \\
\text { matemática, perteneciente al ámbito académico, situación } \\
\text { científica. }\end{array}$ \\
Texto breve con los datos relevantes, específicamente \\
geométricos.
\end{tabular}


Exige conocer todos los lugares geométricos vistos en el curso.

Saber qué es el circuncentro de un triángulo.

Aislar la propiedad del circuncentro sin tener un triángulo

determinado.

Invertir desde donde se mira la propiedad, no desde el

circuncentro sino desde el vértice y ubicarlo como perteneciente a una circunferencia.

Con el dato del nombre del ángulo $\mathrm{ACB}$ y el segmento $\mathrm{AB}$ asociar a los elementos para determinar un arco capaz.

Es necesario saber trazar circunferencia y arco capaz con lápiz y papel.

Interceptar las figuras, seleccionar los puntos que cumplen las dos condiciones a la vez y trazar el triángulo.

Identificar los pasos realizados, ordenarlos y buscar la expresión más precisa para comunicar cada paso.

Para acceder a la solución se necesita emplear conocimiento matemático, analizar y armar un plan, por tal necesita proceso de conexión.

\section{Actividad A7}

Tabla 27. Componentes del sentido espacial en Actividad A7

\begin{tabular}{lll}
\hline Componentes del sentido espacial & \multicolumn{1}{c}{ Actividad A7 } \\
\hline Conceptos de & Concepto de distancia, equidistancia, medida, \\
las figuras & mediatriz, punto medio, vértices, ángulo y trapecio. \\
& Unión de paralelas, mediatriz, arco capaz como lugar \\
& geométrico (lugar de Thales). \\
Propiedades de & Los puntos de la mediatriz equidistan de los extremos \\
las formas & del segmento. \\
& Los puntos del arco capaz ven a un segmento bajo el \\
& mismo ángulo. \\
& Los puntos de la unión de paralelas distan una distancia \\
& fija de una recta dada. \\
& Los trapecios tienen un par de lados paralelos. \\
Relaciones & El punto B pertenece a una circunferencia cuyo radio \\
& es 7cm. \\
& El punto D pertenece a una recta paralela a AB que \\
& dista 3cm de la misma. \\
& El punto D pertenece al arco capaz que ve al segmento \\
Manejo de & AB bajo un ángulo de 90. \\
gonceptos & El punto C pertenece a la recta paralela a AB, a \\
& distancia 3cm. \\
& El punto C pertenece a la mediatriz del segmento DB \\
& por equidistar de los extremos. \\
& Asociar la medida de la altura del trapecio como la \\
& distancia a la recta AB, para determinar la recta \\
& paralela. \\
& Asociar la amplitud del ángulo ADB, al segmento AB \\
& y al arco capaz que determinan. \\
& La posición del punto D como la intersección de dos \\
& lugares geométricos anteriores: la paralela y arco \\
& capaz.
\end{tabular}


Identificar que $\mathrm{C}$ pertenece a la mediatriz del segmento $\mathrm{DB}$, porque equidista de ellos.

También $\mathrm{C}$ debe pertenecer a la recta a la que pertenece $\mathrm{D}$ por ser paralela $\mathrm{aB}$

La posición del punto $\mathrm{C}$ como intersección de la mediatriz y la paralela antes dichas.

Orientación Identificar que en igual condición que el punto D están D4. Los otros se descartan por ordenación consecutiva de vértices D2, D3.

Identificar que el punto $\mathrm{C} 2$ se descarta por no cumplir con ordenación consecutiva de vértices.

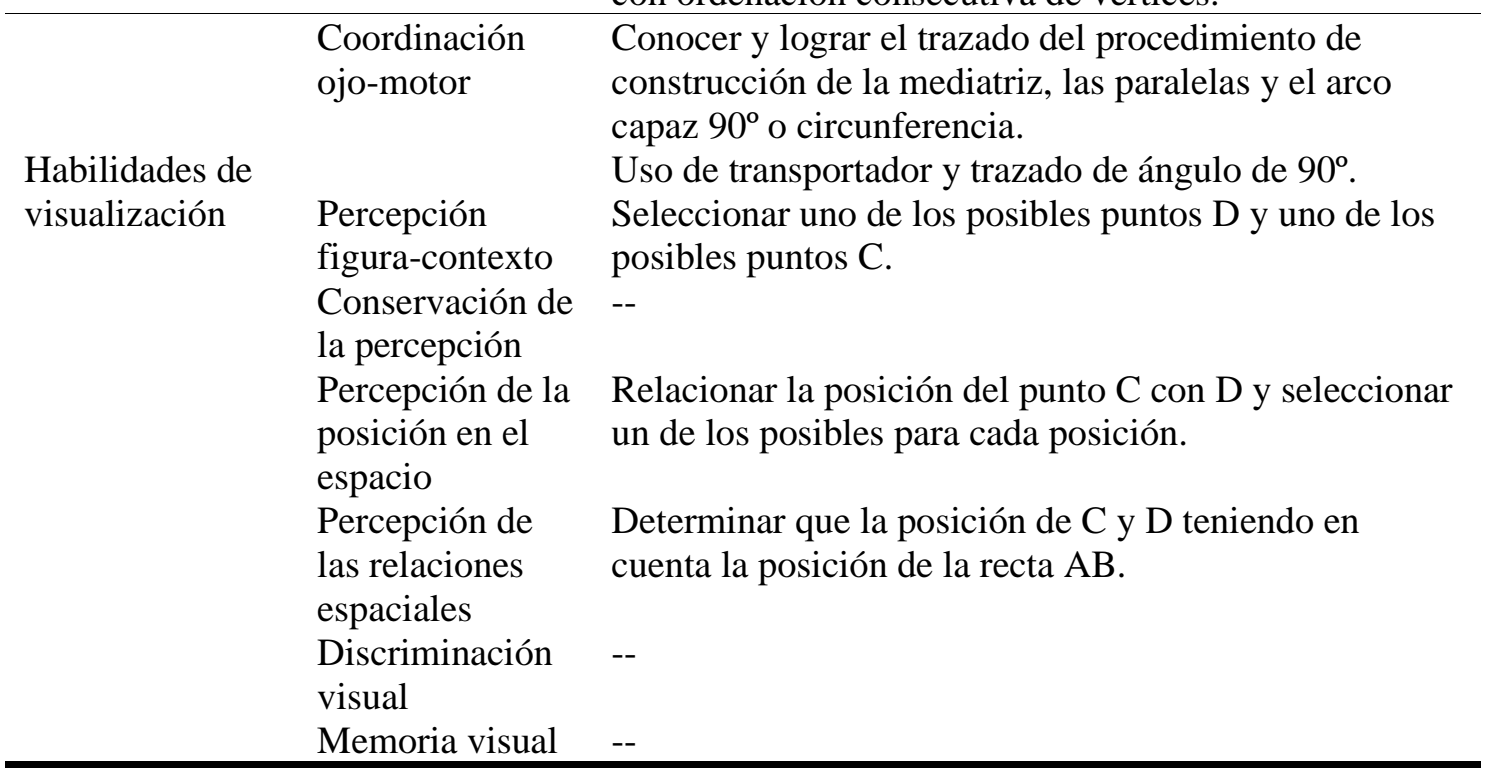

Tabla 28. Características en la Actividad A7

\begin{tabular}{ll}
\hline \multicolumn{1}{c}{ Características } & \multicolumn{1}{c}{ Actividad A7 } \\
\hline Contexto & $\begin{array}{l}\text { Construir un trapecio ABCD, es una situación específicamente } \\
\text { matemática, perteneciente al ámbito académico, situación } \\
\text { científica. }\end{array}$ \\
Tatos del enunciado & $\begin{array}{l}\text { Texto breve con los datos relevantes, específicamente } \\
\text { geométricos. }\end{array}$ \\
Tipología de tarea & Requiere de conocimientos previos específicos, acerca de los \\
& lugares geométricos vistos en el curso, presenta un desafío, cuál o \\
& cuáles se deben combinar para determinar el trapecio. Resulta ser \\
& un problema. \\
& Saber qué es un trapecio. \\
& Exige conocer todos los lugares geométricos vistos en el curso. \\
& Asociar el dato de la altura a una distancia constante y por tanto a \\
paralelas. & \\
& Asociar que el vértice C y D se van a encontrar en esas paralelas. \\
& Unir los datos del segmento AB y el ángulo ADB como elementos \\
& que determinan un arco capaz. \\
& Una vez determinado y seleccionado el D, considerando que los \\
& vértices se nombran en forma consecutiva, se puede avanzar para \\
& determinar el C.
\end{tabular}


Identificar que $\mathrm{C}$ se encuentra en la mediatriz de $\mathrm{B}$ y $\mathrm{D}$, por el dato "equidista de B y D".

Interceptar las figuras diferentes para ir encontrando los vértices que faltan.

Saber trazar paralelas a una distancia dada, mediatriz y arco capaz de $90^{\circ}$ con lápiz y papel.

Para acceder a la solución se necesita emplear conocimiento matemático, analizar y armar un plan, por tal necesita proceso de conexión.

\section{Actividad 8}

Tabla 29. Componentes del sentido espacial en actividad A8

\begin{tabular}{|c|c|c|}
\hline Componente & sentido espacial & Actividad A8 \\
\hline \multirow{18}{*}{$\begin{array}{l}\text { Manejo de } \\
\text { conceptos } \\
\text { geométricos }\end{array}$} & $\begin{array}{l}\text { Conceptos de } \\
\text { las figuras }\end{array}$ & $\begin{array}{l}\text { Concepto de paralelismo, distancia, medida, mediatriz, } \\
\text { punto medio, vértices, diagonal, ángulo y trapecio. } \\
\text { Unión de paralelas, circunferencia, arco capaz como } \\
\text { lugar geométrico (lugar de Thales). }\end{array}$ \\
\hline & \multirow[t]{4}{*}{$\begin{array}{l}\text { Propiedades de } \\
\text { las formas }\end{array}$} & $\begin{array}{l}\text { Los puntos de la circunferencia están a una distancia } \\
\text { fija del centro. }\end{array}$ \\
\hline & & $\begin{array}{l}\text { Los puntos del arco capaz ven a un segmento bajo el } \\
\text { mismo ángulo. }\end{array}$ \\
\hline & & $\begin{array}{l}\text { Los puntos de la unión de paralelas distan una distancia } \\
\text { fija de una recta dada. }\end{array}$ \\
\hline & & Los trapecios tienen un par de lados paralelos. \\
\hline & \multirow[t]{5}{*}{$\begin{array}{l}\text { Relaciones } \\
\text { geométricas }\end{array}$} & $\begin{array}{l}\text { El punto B pertenece a una circunferencia cuyo radio } \\
\text { es } 7 \mathrm{~cm} \text {. }\end{array}$ \\
\hline & & $\begin{array}{l}\text { El punto } \mathrm{D} \text { pertenece a una recta paralela a } \mathrm{AB} \text { que } \\
\text { dista } 2 \mathrm{~cm} \text { de la misma. }\end{array}$ \\
\hline & & $\begin{array}{l}\text { El punto D pertenece al arco capaz que ve al segmento } \\
\mathrm{AB} \text { bajo un ángulo de } 90^{\circ} \text {. }\end{array}$ \\
\hline & & $\begin{array}{l}\text { El punto } \mathrm{C} \text { pertenece a la recta paralela a } \mathrm{AB}, \mathrm{a} \\
\text { distancia } 2 \mathrm{~cm} .\end{array}$ \\
\hline & & $\begin{array}{l}\text { El punto } \mathrm{C} \text { pertenece a la circunferencia de centro B y } \\
\text { radio } 4 \mathrm{~cm} \text {. }\end{array}$ \\
\hline & \multirow[t]{6}{*}{$\begin{array}{l}\text { Ubicación y } \\
\text { movimientos }\end{array}$} & $\begin{array}{l}\text { Asociar la distancia en las rectas paralelas } \mathrm{AB} \text { y } \mathrm{CD} \\
\text { como la medida de la altura del trapecio. }\end{array}$ \\
\hline & & $\begin{array}{l}\text { Asociar la medida del segmento BC como el radio de } \\
\text { una circunferencia. }\end{array}$ \\
\hline & & $\begin{array}{l}\text { Identificar que } C \text { pertenece a la paralela a } A B \text { y a la } \\
\text { circunferencia de centro } B \text { y radio } 4 \mathrm{~cm} \text {. }\end{array}$ \\
\hline & & $\begin{array}{l}\text { Identificar el ángulo formado por la diagonal BD y el } \\
\text { lado AD como el ángulo ADB. }\end{array}$ \\
\hline & & $\begin{array}{l}\text { Asociar que el vértice } D \text { pertenece al arco capaz de } 90^{\circ} \\
\text { que ve al segmento } A B \text {. }\end{array}$ \\
\hline & & $\begin{array}{l}\text { La posición del punto D como la intersección de dos } \\
\text { lugares geométricos anteriores: la paralela y arco } \\
\text { capaz. }\end{array}$ \\
\hline & \multirow[t]{2}{*}{ Orientación } & $\begin{array}{l}\text { Identificar que en iguales condiciones que el punto C } \\
\text { está } \mathrm{C} 2, \mathrm{C} 3 \text { y } \mathrm{C} 4 \text {. }\end{array}$ \\
\hline & & $\begin{array}{l}\text { Identificar que en iguales condiciones que el punto D } \\
\text { están D2, D3 y D4. }\end{array}$ \\
\hline
\end{tabular}


Identificar que se conservan las duplas C2D2, C3D3, C4D4.

\begin{tabular}{|c|c|c|}
\hline \multirow{8}{*}{$\begin{array}{l}\text { Habilidades de } \\
\text { visualización }\end{array}$} & $\begin{array}{l}\text { Coordinación } \\
\text { ojo-motor }\end{array}$ & $\begin{array}{l}\text { Conocer y lograr el trazado del procedimiento de } \\
\text { construcción de la mediatriz, las paralelas y } \\
\text { circunferencia. }\end{array}$ \\
\hline & $\begin{array}{l}\text { Percepción } \\
\text { figura-contexto }\end{array}$ & $\begin{array}{l}\text { Seleccionar uno de los posibles puntos } \mathrm{C} \text { y uno de los } \\
\text { posibles puntos } \mathrm{D} \text {. }\end{array}$ \\
\hline & Conservación de & -- \\
\hline & la percepción & \\
\hline & $\begin{array}{l}\text { Percepción de la } \\
\text { posición en el } \\
\text { espacio }\end{array}$ & $\begin{array}{l}\text { Relacionar la posición del punto C con D y seleccionar } \\
\text { un de los posibles para cada posición. }\end{array}$ \\
\hline & $\begin{array}{l}\text { Percepción de } \\
\text { las relaciones } \\
\text { espaciales }\end{array}$ & $\begin{array}{l}\text { Determinar que la posición de } \mathrm{C} \text { y } \mathrm{D} \text { teniendo en } \\
\text { cuenta la posición de la recta } \mathrm{AB} \text {. }\end{array}$ \\
\hline & $\begin{array}{l}\text { Discriminación } \\
\text { visual }\end{array}$ & -- \\
\hline & Memoria visual & -- \\
\hline
\end{tabular}

Tabla 30. Características en la Actividad A8

\begin{tabular}{ll}
\hline \multicolumn{1}{c}{ Características } & \multicolumn{1}{c}{ Actividad A8 } \\
\hline Contexto & Construir un trapecio ABCD, es una situación específicamente \\
& matemática, perteneciente al ámbito académico, situación \\
& científica. \\
Datos del enunciado & Texto breve con los datos relevantes, específicamente \\
& geométricos. \\
Tipología de tarea & Requiere de conocimientos previos específicos, acerca de los \\
& lugares geométricos vistos en el curso, presenta un desafío, cuál o \\
& cuáles se deben combinar para determinar el trapecio. Resulta ser \\
& un problema. \\
& Saber qué es un trapecio. \\
& Exige conocer todos los lugares geométricos vistos en el curso. \\
& Asociar el dato de la distancia entre paralelas como la altura del \\
& trapecio y la ubicación de esa distancia en un segmento \\
& perpendicular a uno de los lados AB o CD. \\
& Identificar que conviene comenzar a construir por el segmento \\
& AB, en tanto que es uno de los lados paralelos y se tiene la \\
& medida. \\
& Asociar la medida del lado BC y el punto B como elementos de \\
& una circunferencia. \\
& Formar el ángulo ADB de $90^{\circ}$ con los datos dados y asociarlo al \\
& segmento AB para construir el arco capaz. \\
& Asociar que el vértice C y D se van a encontrar la paralela a AB. \\
& Interceptar paralela y arco capaz de $90^{\circ}$ para encontrar D \\
& Interceptar paralela y circunferencia de centro B para encontrar C. \\
& Saber trazar paralelas a una distancia dada, mediatriz, \\
& circunferencia y arco capaz de $90^{\circ}$ con lápiz y papel. \\
& Para acceder a la solución se necesita emplear conocimiento \\
& matemático, analizar y armar un plan, por tal necesita proceso de \\
& conexión. \\
\hline
\end{tabular}




\section{Actividad A9}

Tabla 31. Componentes del sentido espacial en actividad A9

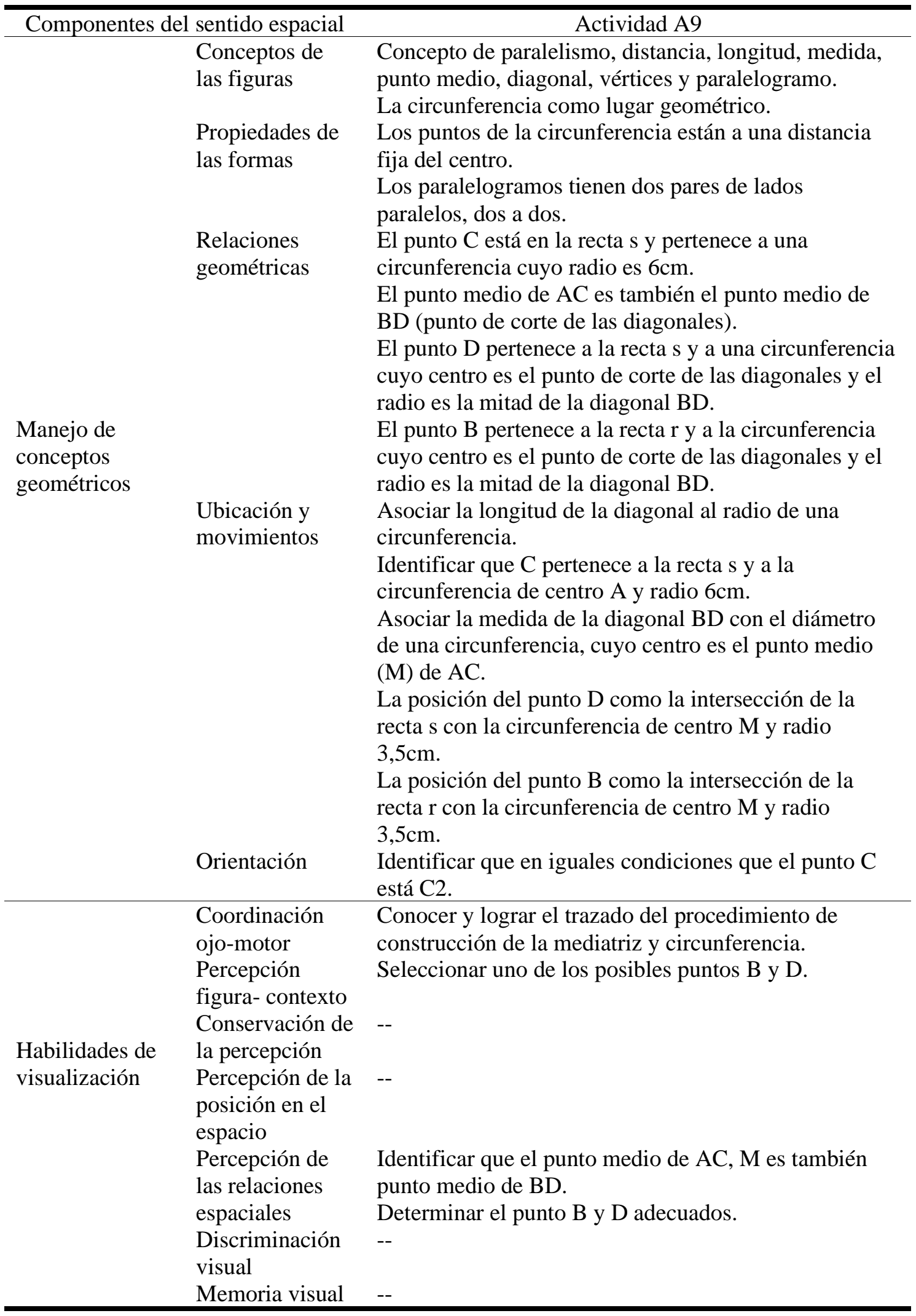




\begin{tabular}{|c|c|}
\hline Características & Actividad A9 \\
\hline Contexto & $\begin{array}{l}\text { Construir un paralelogramo ABCD, es una situación } \\
\text { específicamente matemática, perteneciente al ámbito académico, } \\
\text { situación científica. }\end{array}$ \\
\hline Datos del enunciado & $\begin{array}{l}\text { Texto breve con los datos relevantes, específicamente } \\
\text { geométricos. Representación gráfica que complementa la } \\
\text { información. Es relevante por la ubicación. }\end{array}$ \\
\hline Tipología de tarea & $\begin{array}{l}\text { Requiere de conocimientos previos específicos, acerca de los } \\
\text { lugares geométricos vistos en el curso, presenta un desafío, cuál o } \\
\text { cuáles se deben combinar para determinar el trapecio. Resulta ser } \\
\text { un problema. }\end{array}$ \\
\hline Complejidad & $\begin{array}{l}\text { Saber qué es un paralelogramo. } \\
\text { Exige ubicar la disposición de la representación gráfica dada e } \\
\text { incorporar a esa representación los datos que se van apareciendo. } \\
\text { Asociar la longitud de la diagonal AC como el radio de una } \\
\text { circunferencia de centro A. } \\
\text { Identificar que C se encuentra la intersección de la circunferencia } \\
\text { de centro A y radio } 6 \mathrm{~cm} \text {, y la recta s. } \\
\text { Asociar que BD por ser diagonal comparte el punto medio con } \\
\text { AC, un punto medio que no forma parte de los datos. } \\
\text { Determinar los elementos de una circunferencia, con el punto } \\
\text { medio y la mitad de la medida de BD como radio. } \\
\text { Exige conocer todos los lugares geométricos vistos en el curso. } \\
\text { Identificar qué permite comenzar a determinar los vértices } \\
\text { buscados. } \\
\text { Saber trazar circunferencia y mediatriz con lápiz y papel. } \\
\text { Para acceder a la solución se necesita emplear conocimiento } \\
\text { matemático, analizar y armar un plan, por tal necesita proceso de } \\
\text { conexión. }\end{array}$ \\
\hline
\end{tabular}




\section{ANEXO D. TABLAS SÍNTESIS AGRUPADAS}

\section{Actividades C, E y D}

Tabla 1. Componentes del sentido espacial en actividades: C, E y D

\begin{tabular}{|c|c|c|c|}
\hline Componentes del sentido espacial & Actividad C & Actividad E & Actividad D \\
\hline \multirow{9}{*}{$\begin{array}{l}\text { Manejo de } \\
\text { conceptos } \\
\text { geométricos }\end{array}$} & $\begin{array}{l}\text { Concepto de rectángulo, } \\
\text { paralelogramo, ángulos rectos, } \\
\text { medida y distancia. }\end{array}$ & $\begin{array}{l}\text { Concepto de altura, medida y } \\
\text { distancia. }\end{array}$ & $\begin{array}{l}\text { Concepto de cubo, desarrollo plano del } \\
\text { cubo. } \\
\text { Caras contiguas. Caras opuestas. }\end{array}$ \\
\hline & $\begin{array}{l}\text { Perímetro de figuras en el plano. } \\
\text { Pares de lados paralelos. }\end{array}$ & $\begin{array}{l}\text { Escalones paralelos al plano del piso, } \\
\text { la altura perpendicular al plano del } \\
\text { piso. }\end{array}$ & $\begin{array}{l}\text { Caras paralelas dos a dos. } \\
\text { Tres caras determinan cada vértice. }\end{array}$ \\
\hline & $\begin{array}{l}\text { Descomposición de distancias en } \\
\text { distancias menores cuya suma es } \\
\text { igual a la dada. }\end{array}$ & $\begin{array}{l}\text { La altura de la escalera se descompone } \\
\text { en la suma de la altura de los } 14 \\
\text { escalones. }\end{array}$ & $\begin{array}{l}\text { Cada cara tiene contacto con otras } \\
\text { cuatro, sólo no tiene contacto con su } \\
\text { opuesta. }\end{array}$ \\
\hline & $\begin{array}{l}\text { Longitudes de trozos de lados } \\
\text { paralelos son iguales. }\end{array}$ & $\begin{array}{l}\text { Altura del escalón es paralelo a } \\
\text { segmento que muestra la altura de la }\end{array}$ & $\begin{array}{l}\text { Vínculo entre el cubo y su desarrollo } \\
\text { plano. Caras no consecutivas de un dado }\end{array}$ \\
\hline & Longitud de hipotenusa es mayor & figura. & suman 7. \\
\hline & que longitud de catetos. & Identificación de los segmentos que & Caras contiguas en desarrollo son \\
\hline & $\begin{array}{l}\text { Disposición de las medidas, } \\
\text { reduce y aumenta a la vez. }\end{array}$ & $\begin{array}{l}\text { forman la altura de los escalones con } \\
\text { trozos de la altura del polígono. }\end{array}$ & $\begin{array}{l}\text { adyacentes en cuerpo. } \\
\text { Caras opuestas en cuerpo no pueden } \\
\text { tener arista común en desarrollo. }\end{array}$ \\
\hline & -- & -- & $\begin{array}{l}\text { Ubicación del cubo en el espacio y su } \\
\text { correlato con su desarrollo plano. }\end{array}$ \\
\hline & -- & $\begin{array}{l}\text { Disposición de la altura de cada } \\
\text { escalón, de manera perpendicular a la } \\
\text { "huella". }\end{array}$ & $\begin{array}{l}\text { Disposición de las caras del dado. } \\
\text { Disposición de los números en el } \\
\text { desarrollo. }\end{array}$ \\
\hline
\end{tabular}


La capacidad de girar la imagen visual del cubo, o de las caras del desarrollo para apreciar dónde se colocan.

Coordinación

ojo-motor

Percepción

figura-contexto

Habilidades de visualización

Conservación de

la percepción

Percepción de la

posición en el

espacio

Percepción de las relaciones

espaciales

Se conserva el perímetro en las diferentes figuras.

Identificación de los segmentos que forman la "escalera" con los correspondientes del rectángulo en que se inscriben las figuras $\mathrm{A} y$ C.

Discriminación Tres figuras conservan el

visual

perímetro: A, C y D y una cuarta figura no: $\mathrm{B}$.

Especialmente, apreciación de que la longitud del lado oblicuo es mayor que el vertical.

$-$

$-$

e conserva la medida, varía la forma en la que se dispone.

Identificación de los elementos de los que depende la altura.

Ver la relación entre la altura de los escalones y la altura de la escalera (apreciar que sólo los escalones tienen que salvar la altura de la figura).
Se conserva el tamaño y la forma de las caras en los desarrollos planos.

Se conserva la posición de las caras en los desarrollos planos.

Identificación de la relación que existe entre las caras de desarrollo y las caras en el cubo.

Caras paralelas dos a dos suman 7 .

Dos caras contiguas en desarrollo que sumen 7 no son opuestas en cubo.

Diferenciar los desarrollos presentados. Dos desarrollos planos conservan que caras paralelas suman 7: II y III y dos no conservan: I y IV.

Identificar el cubo que resulta de los desarrollos II y III, pese a que son diferentes. 
Tabla 2. Características en actividades: $C, E$ y $D$

\begin{tabular}{|c|c|c|c|}
\hline Características & Actividad C & Actividad E & Actividad D \\
\hline Contexto & $\begin{array}{l}\text { Un carpintero que hace un borde para una } \\
\text { jardinera corresponde a una situación real, } \\
\text { laboral. }\end{array}$ & $\begin{array}{l}\text { Una escalera y el alto de los escalones } \\
\text { corresponde a una situación real de } \\
\text { nivel ocupacional o laboral. }\end{array}$ & $\begin{array}{l}\text { Los dados se consideran elementos } \\
\text { integrantes de los juegos del } \\
\text { estudiante, corresponde a una } \\
\text { situación real a nivel personal. }\end{array}$ \\
\hline $\begin{array}{l}\text { Datos del } \\
\text { enunciado }\end{array}$ & $\begin{array}{l}\text { Brinda información relevante en el texto breve y } \\
\text { en los diseños, presentación esquemática de la } \\
\text { información. La gráfica que se aporta presenta } \\
\text { figuras semejantes a las buscadas, están en } \\
\text { proporción dada, es decir, cada } 10 \text { de ancho hace } \\
6 \text { de alto. }\end{array}$ & $\begin{array}{l}\text { La gráfica no es semejante, se da una } \\
\text { figura en la } \\
\text { que la altura no está en proporción } \\
27 / 40 \text { con el ancho, como aparece en el } \\
\text { enunciado. El ancho no es importante, } \\
\text { pero esto es un dato concreto. Hay } \\
\text { información relevante en el texto breve } \\
\text { que se reitera en la representación } \\
\text { gráfica, en ella aparece información } \\
\text { innecesaria que puede llevar a la } \\
\text { confusión. Presentación esquemática de } \\
\text { la información. }\end{array}$ & $\begin{array}{l}\text { Texto largo del que deben extraer } \\
\text { datos relevantes, como la suma de } \\
\text { caras opuestas suma } 7 \text {. La } \\
\text { representación gráfica del dado en dos } \\
\text { dimensiones brinda la información } \\
\text { para poder seleccionar la respuesta } \\
\text { correcta. Presentación de texto y } \\
\text { esquemática de la información. }\end{array}$ \\
\hline Tipología de tarea & $\begin{array}{l}\text { Exige examinar procedimientos conocidos para } \\
\text { resolver, el perímetro de una figura y a la vez } \\
\text { probar otros no conocidos que se le plantea para } \\
\text { cada forma del borde. }\end{array}$ & $\begin{array}{l}\text { Tienen todos los datos a la vista y deben } \\
\text { realizar una operación para encontrar la } \\
\text { solución. Ejercitan un procedimiento } \\
\text { muy conocido como es la división. }\end{array}$ & $\begin{array}{l}\text { Exige asociar las representaciones en } \\
\text { dos y tres dimensiones del dado. Para } \\
\text { aplicar la regla establecida de las caras } \\
\text { opuestas suman } 7 \text { no hay un camino } \\
\text { establecido y previamente conocido } \\
\text { por el estudiante. Resulta ser un } \\
\text { problema a resolver. }\end{array}$ \\
\hline Complejidad & $\begin{array}{l}\text { Ya se presentan las formas geométricas de la } \\
\text { jardinera. }\end{array}$ & $\begin{array}{l}\text { Se presentan todos los datos en el texto } \\
\text { breve. }\end{array}$ & $\begin{array}{l}\text { Asociar las dos representaciones del } \\
\text { dado en dos y tres dimensiones. Exige } \\
\text { habilidades de visualización para } \\
\text { discriminar los desarrollos que }\end{array}$ \\
\hline
\end{tabular}


Se necesita vincular el dato del borde de la jardinera con el perímetro de una figura geométrica.

Saber cómo se calcula el perímetro de una figura,

Asociar la medida de la altura de las figuras con

la medida de los lados correspondientes.

Establecer conexiones entre la información

brindada, la que se necesita y utilizarla de forma

adecuada.
Exige reconocer la operación a realizar y reproducir el procedimiento de reparto, de división. cumplan la consigna establecida. Se establecen conexiones.

\section{Actividades G1, G2, PG1, PG2}

Tabla 3. Componentes del sentido espacial en actividades: G1, G2 PG1 y PG2

\begin{tabular}{|c|c|c|c|c|c|}
\hline Compone & $\begin{array}{l}\text { tes del sentido } \\
\text { pacial }\end{array}$ & Actividad G1 & Actividad G2 & Actividad PG1 & Actividad PG2 \\
\hline \multirow[t]{3}{*}{$\begin{array}{l}\text { Manejo de } \\
\text { conceptos } \\
\text { geométricos }\end{array}$} & $\begin{array}{l}\text { Conceptos de } \\
\text { las figuras }\end{array}$ & $\begin{array}{l}\text { Concepto de prisma, } \\
\text { rectángulo y paralelogramo. }\end{array}$ & $\begin{array}{l}\text { Triángulos rectángulos, } \\
\text { rectángulos y altura (del techo). }\end{array}$ & Ángulos & $\begin{array}{l}\text { Ángulo completo, circunferencia, } \\
\text { arcos de circunferencia, amplitud } \\
\text { de un arco. }\end{array}$ \\
\hline & $\begin{array}{l}\text { Propiedades de } \\
\text { las formas }\end{array}$ & $\begin{array}{l}\text { Pentágonos, trapecios } \\
\text { isósceles (casi rectángulos) y } \\
\text { paralelogramos, para } \\
\text { representar en perspectiva } \\
\text { pentágono y rectángulos de } \\
\text { paredes y tejado. }\end{array}$ & $\begin{array}{l}\text { Teorema de Pitágoras, área del } \\
\text { rectángulo. }\end{array}$ & $\begin{array}{l}\text { Las tres puertas, de a } \\
\text { dos forman ángulos } \\
\text { iguales. }\end{array}$ & $\begin{array}{l}\text { Longitud de la circunferencia, } \\
\text { radio, relación entre ángulo central } \\
\text { y arco. }\end{array}$ \\
\hline & $\begin{array}{l}\text { Relaciones } \\
\text { geométricas }\end{array}$ & $\begin{array}{l}\text { Paralelismo entre caras } \\
\text { laterales, dos a dos. } \\
\text { Perpendicularidad entre caras } \\
\text { consecutivas laterales. }\end{array}$ & $\begin{array}{l}\text { Lados opuestos de un rectángulo } \\
\text { son paralelos. } \\
\text { Lados consecutivos de un } \\
\text { rectángulo son perpendiculares. } \\
\text { La altura es perpendicular a la } \\
\text { horizontal. El lado del rectángulo }\end{array}$ & $\begin{array}{l}\text { Ángulos consecutivos, } \\
\text { obtusos y ángulo } \\
\text { completo. }\end{array}$ & $\begin{array}{l}\text { Amplitud del sector formado por } \\
\text { dos puertas es igual a una parte } \\
\text { cerrada de la puerta giratoria. Las } \\
\text { dos partes abiertas suman lo que } \\
\text { una cerrada. }\end{array}$ \\
\hline
\end{tabular}




\begin{tabular}{|c|c|c|}
\hline & $\begin{array}{l}\text { Ubicación y } \\
\text { movimientos }\end{array}$ & $\begin{array}{l}\text { Posición relativa entre puerta } \\
\text { y ventana, cercanía a cara de } \\
\text { puerta, lateralidad (se ve a su } \\
\text { izquierda). } \\
\text { Cambio de posición del } \\
\text { garaje en las respuestas. }\end{array}$ \\
\hline \multirow{4}{*}{$\begin{array}{l}\text { Habilidades } \\
\text { de } \\
\text { visualización }\end{array}$} & & $\begin{array}{l}\text { La capacidad de simetrizar la } \\
\text { imagen visual del garaje, en } \\
\text { las posiciones B y D y de } \\
\text { girarlo a las posiciones A y } \\
\text { C. }\end{array}$ \\
\hline & $\begin{array}{l}\text { Coordinación } \\
\text { ojo-motor }\end{array}$ & -- \\
\hline & $\begin{array}{l}\text { Percepción } \\
\text { figura-contexto }\end{array}$ & $\begin{array}{l}\text { Identificación de posición de } \\
\text { figura tridimensional por la } \\
\text { posición respecto al fondo } \\
\text { negro, pese a tratarse de una } \\
\text { representación plana (en } \\
\text { perspectiva, captación de la } \\
\text { perspectiva). }\end{array}$ \\
\hline & $\begin{array}{l}\text { Conservación } \\
\text { de la percepción }\end{array}$ & $\begin{array}{l}\text { Identificación de las } \\
\text { relaciones de lateralidad y } \\
\text { cercanía entre ventana y cara } \\
\text { de la puerta. }\end{array}$ \\
\hline
\end{tabular}

del tejado es la hipotenusa de un triángulo rectángulo determinado por dos medidas que no

corresponden a ningún objeto

físico (la mitad de la anchura del

tejado y la altura del mismo)

$-$

Identificar que el rectángulo superior de la vista lateral no representa el techo.

Considerar la vista frontal y la lateral como parte de un todo. Sintetizar la información en un nuevo rectángulo que se corresponde con el techo.
En las tres posiciones que se muestran, se conserva la amplitud de los sectores.

--

$--$

$-$

Asociar los tres sectores que forman las puestas con las partes abiertas y cerradas de la puerta giratoria.

Capacidad para analizar el vínculo entre los sectores y las partes abiertas y cerradas.
Identificar posiciones en que se

puede producir circulación de aire. 
Percepción de la Identificación de la posición posición en el espacio relativa con los otros elementos (fondo, cara opuesta a ventana).

Percepción de las relaciones espaciales

Cercanía de la ventana con la puerta y lejanía de la ventana con la pared del fondo.

Discriminación

visual

Diferenciar figuras por los

elementos que suministra

(puerta, ventana, posición)
La parte cerrada de la puerta giratoria es igual al sector

formado por dos puertas.

Cada parte abierta es la mitad de

la parte cerrada.

Determinar la relación entre los

sectores y las partes cerradas y abiertas.

Memoria visual $--$
Las tres posiciones responden a una única puerta giratoria.

$--$

Identificar las puertas representadas por una visión desde arriba.
La parte cerrada de la puerta giratoria es igual al sector formado por dos puertas.

Cada parte abierta es la mitad de la parte cerrada.

Determinar la relación entre los sectores y las partes cerradas y abiertas. $--$

Tabla 4. Características en actividades: G1, G2, PG1 y PG2

\section{Características}

Contexto

Un fabricante de garaje

corresponde a una situación real a

nivel ocupacional o laboral.

Datos del

enunciado
Las gráficas del enunciado están dadas en perspectiva cónica, con dos puntos de fuga, que diferencia el frontal, que es más grande. Texto breve que contextualiza la situación y orienta en la búsqueda de la solución, "solo una". La

Actividad G2

Un fabricante de garaje corresponde una situación real a nivel ocupaciona o laboral.

Texto breve que contextualiza la situación La representación gráfica del garaje en dos dimensiones con vista frontal y lateral. La multiplicidad de datos, relevantes e irrelevantes ofrecen dificultad. Presentación esquemática de toda la situación.

Actividad PG1

Una puerta giratoria de la que se brinda la imagen vista desde arriba y se solicita el ángulo formado entre dos de las hojas corresponde a una situación real a nivel científico.

Texto breve que contextualiza la situación y brinda un dato no relevante. La

representación gráfica de la puerta giratoria vista desde arriba permite deducir que los ángulos entre las hojas son iguales. Presentación Actividad PG2

Una puerta giratoria de la que se brinda la imagen vista desde arriba y se solicita la longitud de un arco corresponde a una situación real a nivel científico.

Texto largo que contextualiza la situación, pero no brinda datos relevantes. La representación gráfica de la puerta giratoria vista desde arriba permite deducir que las partes cerradas de la puerta tienen igual amplitud que entre dos hojas. 
representación gráfica del garaje en tres dimensiones con vista

frontal presenta los datos de ubicación de ventana y puerta.

Presentación esquemática de toda la situación.

Tipología de Exige asociar las representaciones tarea

Complejidad en tres dimensiones del garaje del frente con el fondo, habiendo cambiado de posición. Para determinar la vista del fondo adecuada no hay un único camino, tampoco son conocidas las estrategias. Se puede vincular con la rotación de objetos. Resulta ser un problema.

Asociar las dos representaciones en tres dimensiones del garaje, la frontal y la de fondo.

Exige habilidades de visualización para lograr la rotación adecuada del garaje.

Establecer vínculos entre la ubicación de la puerta y la ventana dadas como referencia y ver en qué lugar quedan en la vista del fondo. Exige una interpretación visual de la información para establecer conexiones. esquemática de toda la situación.

Exige asociar las representaciones en dos dimensiones del garaje del frente y la lateral. Para realizar el cálculo solicitado debe hacer cálculos previos a través de algoritmos conocidos. E

camino de resolución del problema demanda creatividad y conocimientos previos.

Asociar las dos representaciones en dos dimensiones del garaje, la frontal y la de fondo.

Asociar las dimensiones que se corresponden entre las dos vistas.

Discriminar datos necesarios de los que no.

Determinar que dato le falta.

Recurrir a una estrategia conocida para determinar el dato desconocido, el ancho del techo.

Considerar el nuevo rectángulo y sus dimensiones para poder calcular el área y luego duplicar esa área.

Exige una reflexión para poder trazar el camino de resolución, elaborar la estrategia de resolución.

Presentación esquemática de la información relevante.

Requiere de conocimientos previos específicos, acerca de la medida del ángulo completo, teniendo ese dato se arriba a la solución a través de un algoritmo sencillo. Resulta ser un problema.

Exige deducir de la representación gráfica que los ángulos entre las hojas de la puerta son iguales.

Exige un conocimiento preciso, saber que el ángulo completo mide $360^{\circ}$. E camino de resolución es la aplicación de un algoritmo sencillo.

Para acceder a la solución se necesita emplear conocimiento matemático y analizar por tal necesita proceso de reflexión.
Requiere de conocimientos previos específicos, acerca de la longitud de la circunferencia, presenta un desafío, podrían encontrar distintos caminos para establecer la parte abierta de la puesta. Resulta ser un problema.

Exige asociar la longitud de los arcos a la longitud de la circunferencia y por tanto recordar la fórmula del perímetro.

Deducir de la representación gráfica que la longitud de la parte cerrada de la puerta se corresponde a la distancia entre dos de las hojas. Asociar que la distancia entre las hojas es igual.

Ver que la parte abierta por tanto se corresponde a una parte cerrada para luego partir en dos.

Para acceder a la solución se necesita emplear conocimiento matemático y analizar por tal necesita proceso de reflexión. 


\section{Actividad A1, A3, A5}

Tabla 5. Componentes del sentido espacial en actividades de aula: $A 1, A 3, A 5$

\begin{tabular}{|c|c|}
\hline Componentes del sentido espacial & Actividad A1 \\
\hline $\begin{array}{l}\text { Conceptos de } \\
\text { las figuras } \\
\text { Propiedades de } \\
\text { las formas }\end{array}$ & $\begin{array}{l}\text { Concepto de circunferencia, círculo y } \\
\text { bisectriz de un ángulo como lugar } \\
\text { geométrico y de distancia. } \\
\text { Todos los puntos de la circunferencia } \\
\text { distan "r" del centro. } \\
\text { Todos los puntos del círculo están a } \\
\text { una distancia menor o igual al radio } \\
\text { del centro. } \\
\text { Todos los puntos de la bisectriz de un } \\
\text { ángulo están a igual distancia de los } \\
\text { lados del ángulo. } \\
\text { Las bisectrices de ángulos opuestos } \\
\text { por el vértice están incluidas en la } \\
\text { misma recta. } \\
\text { Las bisectrices de ángulos } \\
\text { suplementarios son perpendiculares. } \\
\text { La distancia entre A y las bisectrices } \\
\text { es menor que } 4,5 c m \text { (radio). } \\
\text { Los puntos de la circunferencia están } \\
\text { a } 4,5 \text { cm de A por tanto no van a } \\
\text { formar parte de la solución. } \\
\text { Los segmentos de bisectrices que se } \\
\text { encuentren dentro de la } \\
\text { circunferencia cumplen las } \\
\text { condiciones solicitadas. }\end{array}$ \\
\hline
\end{tabular}


La intersección de las bisectrices con

los puntos interiores del círculo

cumple las condiciones solicitadas.

Ubicación y

movimientos

Posición relativa de los segmentos de

las bisectrices con relación al círculo y/o circunferencia.

Orientación

Coordinación

ojo-motor

\section{Conocer y lograr el trazado del} procedimiento de construcción de la circunferencia y de las dos bisectrices.

\section{Habilidades de visualización}

\section{Percepción} figura-contexto

Considerar los segmentos de

Conservación de

la percepción

Percepción de la

posición en el

espacio

Percepción de

las relaciones

espaciales

Determinación de todos los puntos que cumplen con estar a menos de $4,5 \mathrm{~cm}$ y equidistantes de las rectas $\mathrm{AB}$ y $\mathrm{EF}$.

Discriminación

visual

Memoria visual

La posición relativa de los arcos en relación con el punto $B$.

Conocer y lograr el trazado del

procedimiento de construcción de la mediatriz y arco capaz.

Uso del transportador y trazado del ángulo de $60^{\circ}$.

Considerar los arcos incluidos en el arco capaz, excluyendo los puntos extremos E, B y E'.

Determinación de todos los puntos que cumplen con estar más cerca de $\mathrm{B}$ que de A, al semiplano que contiene a B y ven al segmento $A B$ bajo un ángulo de $60^{\circ}$. Excluyendo E, B y E'.
Conocer y lograr el trazado del

procedimiento de construcción de la mediatriz, la paralela media y el arco capaz.

Uso de transportador y trazado de ángulo de $30^{\circ}$.

Considerar los puntos que son solución como intersección del arco capaz y la paralela media.

Determinar los puntos que cumplen con estar a igual distancia de las rectas $A B$ y $\mathrm{CD}$, en la paralela media, y ven al segmento $\mathrm{BC}$ bajo un ángulo de $30^{\circ}$, en el arco capaz. 
Tabla 6. Características en actividades de aula: A1, A3, A5

\begin{tabular}{|c|c|c|c|}
\hline Características & Actividad A1 & Actividad A3 & Actividad A5 \\
\hline Contexto & $\begin{array}{l}\text { Indicar los puntos del plano, es una } \\
\text { situación específicamente matemática, } \\
\text { perteneciente al ámbito académico, } \\
\text { situación científica. }\end{array}$ & $\begin{array}{l}\text { Indicar los puntos del plano, es una situación } \\
\text { específicamente matemática, perteneciente al } \\
\text { ámbito académico, situación científica. }\end{array}$ & $\begin{array}{l}\text { Encontrar todos los puntos del plano, es } \\
\text { una situación específicamente matemática, } \\
\text { perteneciente al ámbito académico, } \\
\text { situación científica. }\end{array}$ \\
\hline $\begin{array}{l}\text { Datos del } \\
\text { enunciado }\end{array}$ & $\begin{array}{l}\text { Texto breve con los datos relevantes, con } \\
\text { elementos geométricos. La representación } \\
\text { gráfica muestra la situación dos rectas que } \\
\text { se cortan, y sitúa en ellas los puntos } \\
\text { indicados en el enunciado, dando } \\
\text { distancias diferentes a los segmentos AB } \\
\text { y EF. La única alusión métrica en el } \\
\text { dibujo es el ángulo que forman las rectas, } \\
\text { no hay distancias. La representación } \\
\text { gráfica completa la información relevante } \\
\text { de los datos geométricos. }\end{array}$ & $\begin{array}{l}\text { Texto breve con los datos relevantes, con } \\
\text { elementos geométricos. Se da un segmento que } \\
\text { no es paralelo a los bordes del folio La } \\
\text { representación gráfica completa la información } \\
\text { relevante de los datos geométricos. }\end{array}$ & $\begin{array}{l}\text { Texto breve con los datos relevantes de } \\
\text { elementos geométricos. La representación } \\
\text { gráfica completa la información relevante } \\
\text { de los datos geométricos. Algunos datos no } \\
\text { se utilizan, el segmento AD. El punto P que } \\
\text { se va a determinar, forma parte de los } \\
\text { datos. }\end{array}$ \\
\hline Tipología de tarea & $\begin{array}{l}\text { Requiere de conocimientos previos } \\
\text { específicos, acerca de los lugares } \\
\text { geométricos vistos en el curso, presenta } \\
\text { un desafío, cuál o cuáles resuelven la } \\
\text { situación. Resulta ser un problema. }\end{array}$ & $\begin{array}{l}\text { Requiere de conocimientos previos específicos, } \\
\text { acerca de los lugares geométricos vistos en el } \\
\text { curso, presenta un desafío, cuál o cuáles } \\
\text { resuelven la situación. Resulta ser un problema. }\end{array}$ & $\begin{array}{l}\text { Requiere de conocimientos previos } \\
\text { específicos, acerca de los lugares } \\
\text { geométricos vistos en el curso, presenta un } \\
\text { desafío, cuál o cuáles resuelven la } \\
\text { situación. Resulta ser un problema. }\end{array}$ \\
\hline Complejidad & $\begin{array}{l}\text { Exige conocer todos los lugares } \\
\text { geométricos vistos en el curso. } \\
\text { Exige interpretar la representación gráfica } \\
\text { brindada porque se trabajará en ella. } \\
\text { Es necesario saber trazar bisectriz y } \\
\text { circunferencia con lápiz y papel. } \\
\text { Determinar los puntos equidistantes de los } \\
\text { lados de un ángulo y asociar a la bisectriz } \\
\text { del ángulo }\end{array}$ & $\begin{array}{l}\text { Exige conocer todos los lugares geométricos } \\
\text { vistos en el curso. } \\
\text { Exige transportar el segmento AB dado o trazar } \\
\text { desde él. } \\
\text { Segmento AB no paralelo a los bordes del folio, } \\
\text { genera razonamiento que no tenga en cuenta las } \\
\text { direcciones vertical y horizontal. } \\
\text { Es necesario saber trazar arco capaz y mediatriz } \\
\text { con lápiz y papel. }\end{array}$ & $\begin{array}{l}\text { Exige conocer todos los lugares } \\
\text { geométricos vistos en el curso. } \\
\text { Exige trazar desde el trapecio ABCD. } \\
\text { Es necesario saber trazar arco capaz y la } \\
\text { paralela media con lápiz y papel. } \\
\text { Exige asociar que el punto P no está } \\
\text { determinado, es el que se va a determinar y } \\
\text { aparece utilizado en los datos. } \\
\text { Determinar los puntos que están } \\
\text { equidistantes de las dos rectas AB y CD. }\end{array}$ \\
\hline
\end{tabular}


Descubrir que hay cuatro ángulos y no sólo quedarse con el agudo.

Descifrar los elementos de una circunferencia. Determinar el círculo a través de la expresión "a menos de $4,5 \mathrm{~cm} "$.

Interceptar las figuras y seleccionar los puntos que cumplen las dos condiciones a la vez, con la precisión de excluir los puntos del borde.

Para acceder a la solución se necesita emplear conocimiento matemático, analizar y armar un plan, por tal necesita proceso de conexión.
Determinar los puntos que están equidistantes de A y B y luego determinar los que están "más cerca de B que da A".

Descifrar los elementos necesarios para construir un arco capaz, segmento y un ángulo que lo "ve". Interceptar las figuras y seleccionar los puntos que cumplen las dos condiciones a la vez, con la precisión de excluir 3 puntos en particular por motivos diferentes, B porque no "ve" al segmento con un ángulo de $60^{\circ}$ y los que están en la mediatriz no cumplen con "estar más cerca de B". Para acceder a la solución se necesita emplear conocimiento matemático, analizar y armar un plan, por tal necesita proceso de conexión.
Descifrar los elementos necesarios para construir un arco capaz, segmento BC y el ángulo BPC.

Interceptar la paralela media y el arco capaz, seleccionar los puntos que cumplen las dos condiciones a la vez.

Para acceder a la solución se necesita emplear conocimiento matemático, analizar y armar un plan, por tal necesita proceso de conexión.

\section{Actividad A2, A4, A6}

Tabla 7. Componentes del sentido espacial en actividades de aula: A2, A4, A6

\begin{tabular}{clll}
\hline Componentes del sentido espacial & \multicolumn{1}{c}{ Actividad A2 } & \multicolumn{1}{c}{ Actividad A4 } & \multicolumn{1}{c}{ Actividad A6 } \\
\hline $\begin{array}{l}\text { Conceptos de las } \\
\text { figuras }\end{array}$ & $\begin{array}{l}\text { Concepto de distancia, medida, } \\
\text { mediana, punto medio, vértices, } \\
\text { ángulo y triángulo. Circunferencia, } \\
\text { mediatriz, arco capaz como l. g. }\end{array}$ & $\begin{array}{l}\text { Concepto de circunferencia y unión de } \\
\text { paralelas como lugar geométrico y de } \\
\text { mediatriz y distancia. }\end{array}$ & $\begin{array}{l}\text { Concepto de circunferencia, mediatriz, } \\
\text { circuncentro, distancia, ángulo, } \\
\text { semirrecta y triángulo. }\end{array}$ \\
$\begin{array}{l}\text { Propiedades de } \\
\text { las formas }\end{array}$ & $\begin{array}{l}\text { Los puntos de la mediatriz equidistan } \\
\text { de lostremos del segmento. } \\
\text { Los puntos del arco capaz ven a un } \\
\text { segmento bajo el mismo ángulo. }\end{array}$ & $\begin{array}{l}\text { Todos los puntos de la circunferencia } \\
\text { distan una distancia constante del }\end{array}$ & $\begin{array}{l}\text { Todos los puntos de la circunferencia } \\
\text { distan una distancia constante del centro. }\end{array}$ \\
& & $\begin{array}{l}\text { Una semirrecta secante a una } \\
\text { circunferencia, con el origen }\end{array}$
\end{tabular}


Manejo de conceptos geométricos

Relaciones geométricas

Ubicación y movimientos

Orientación

ojo-motor
Los puntos de la circunferencia distan una distancia fija del centro.

Tres lados determinan un triángulo.

Todos los puntos de la unión de paralelas están a una distancia constante de una recta dada.

El punto $\mathrm{C}$ pertenece a una circunferencia cuyo radio es $8 \mathrm{~cm}$. El punto $\mathrm{B}$ pertenece a una circunferencia de centro el punto medio del segmento AC y radio la medida de la mediana $\left(\mathrm{m}_{\mathrm{B}}\right)$. El punto B pertenece al Arco Capaz que ve al segmento $\mathrm{AC}$ bajo un ángulo de $70^{\circ}$.

La medida de la mediana como radio de una circunferencia y el punto medio del segmento como su centro. Asociar la amplitud del ángulo ABC, al segmento AC y Arco Capaz que determinan.

La posición del punto B como la intersección de dos lugares geométricos anteriores: circunferencia y arco capaz. Identificar que en iguales condiciones que el punto B están $\mathrm{E}$, $\mathrm{G}$ y $\mathrm{H}$.

Conocer y lograr el trazado del
procedimiento de construcción de la mediatriz, circunferencia y arco capaz.
El punto $\mathrm{Q}$ pertenece a una circunferencia cuyo radio es $8 \mathrm{~cm}$. El punto R pertenece a una circunferencia de centro el punto medio del segmento PQ y radio la medida de la mediana $\left(\mathrm{m}_{\mathrm{R}}\right)$.

El punto $\mathrm{R}$ pertenece a la unión de paralelas que distan la altura $\left(\mathrm{h}_{\mathrm{R}}\right)$ respecto de $\mathrm{AB}$.

La medida de la mediana como radio de una circunferencia y el punto medio

Asociar la altura dada del triángulo, a la distancia entre la recta $\mathrm{AB}$ y sus paralelas.

La posición del punto $\mathrm{R}$ como la intersección de dos lugares geométricos anteriores: circunferencia y unión de paralelas.

Identificar que en iguales condiciones que el punto $\mathrm{R}$ están $\mathrm{C}, \mathrm{E}$ y $\mathrm{F}$.

\section{Conocer y lograr el trazado del}

procedimiento de construcción de la mediatriz, circunferencia y unión de paralelas. del segmento como su centro. perteneciente a la circunferencia, la intercepta en otro punto.

Los puntos de la mz equidistan de los extremos del segmento.

La distancia del circuncentro a los vértices de un triángulo es constante. El punto B pertenece a una

circunferencia cuyo radio es $4 \mathrm{~cm}$

$\mathrm{El}$ circuncentro $\mathrm{O}$ se encuentra en la

mediatriz del segmento $\mathrm{AB}$ y en la

Circunferencia de centro A y radio $3 \mathrm{~cm}$

(distancia del circuncentro a A)

$\mathrm{El}$ punto $\mathrm{C}$ pertenece a una

circunferencia de centro el circuncentro $\mathrm{O}$ y radio 3 y a la semirrecta que forma $60^{\circ}$ con $\mathrm{AB}$.

La distancia del circuncentro al vértice

A, como el radio de dos circunferencias una con centro en A para determinar $\mathrm{O} y$ la circunferencia donde se va a encontrar $\mathrm{C}$ con centro en $\mathrm{O}$.

La posición del punto $\mathrm{C}$ como la intersección de la circunferencia de centro $\mathrm{O}$ y la semirrecta que forma $60^{\circ}$ antihorario con $\mathrm{AB}$.

Conocer y lograr el trazado del

procedimiento de construcción de la mediatriz y circunferencia. 


\begin{tabular}{|c|c|c|c|c|}
\hline & & $\begin{array}{l}\text { Uso del trasportador y trazado del } \\
\text { ángulo de } 70^{\circ} \text {. }\end{array}$ & & $\begin{array}{l}\text { Uso de transportador y trazado de } \\
\text { ángulo de } 60^{\circ} \text {. }\end{array}$ \\
\hline \multirow[t]{6}{*}{$\begin{array}{l}\text { Habilidades de } \\
\text { visualización }\end{array}$} & $\begin{array}{l}\text { Percepción } \\
\text { figura-contexto }\end{array}$ & $\begin{array}{l}\text { Considerar los puntos que son } \\
\text { solución como intersección de la } \\
\text { circunferencia y el arco capaz. }\end{array}$ & $\begin{array}{l}\text { Considerar los puntos que son solución } \\
\text { como intersección de la circunferencia } \\
\text { y la unión de paralelas. }\end{array}$ & $\begin{array}{l}\text { Considerar el punto solución como } \\
\text { intersección de la circunferencia de } \\
\text { centro el circuncentro y el lado del } \\
\text { ángulo. }\end{array}$ \\
\hline & $\begin{array}{l}\text { Conservación de } \\
\text { la percepción }\end{array}$ & -- & -- & -- \\
\hline & $\begin{array}{l}\text { Percepción de la } \\
\text { posición en el } \\
\text { espacio }\end{array}$ & -- & -- & -- \\
\hline & $\begin{array}{l}\text { Percepción de } \\
\text { las relaciones } \\
\text { espaciales }\end{array}$ & $\begin{array}{l}\text { Determinación de todos los puntos } \\
\text { que cumplen con estar en la mediana } \\
\text { de } 5 \mathrm{~cm} \text { y ser vértice del ángulo } \mathrm{ABC} \\
\text { de } 70^{\circ} \text {. }\end{array}$ & $\begin{array}{l}\text { Identificar que los puntos solución } \\
\text { cumplen con estar en las paralelas } \\
\text { respecto de PQ a } 4 \mathrm{~cm} \text { y en la } \\
\text { circunferencia con centro un punto que } \\
\text { no es dado y medida } 7 \mathrm{~cm} \text { igual a la } \\
\text { mediana. }\end{array}$ & $\begin{array}{l}\text { Identificar que el punto solución es la } \\
\text { intersección de la circunferencia de } \\
\text { centro el circuncentro y el lado del } \\
\text { ángulo de } 60^{\circ} \text { con } A B \text {. }\end{array}$ \\
\hline & $\begin{array}{l}\text { Discriminación } \\
\text { visual }\end{array}$ & -- & -- & -- \\
\hline & Memoria visual & -- & -- & -- \\
\hline
\end{tabular}

Tabla 8. Características en actividades de aula: A2, A4, A6

\begin{tabular}{llll}
\hline Características & Actividad A2 & \multicolumn{1}{c}{ Actividad A4 } & Actividad A6 \\
\hline Contexto & Construir un triángulo ABC, es una & Construir un triángulo PQR, es una & Construir un triángulo ABC, es una \\
& situación específicamente matemática, & situación específicamente matemática, & situación específicamente matemática, \\
perteneciente al ámbito académico, & perteneciente al ámbito académico, & situación científica. & situación científica. \\
situación científica. & Texto breve con los datos relevantes, & Texto breve con los datos relevantes, \\
Tatos del & expecíficamente geométricos. & específicamente geométricos. & específicamente geométricos.
\end{tabular}


Tipología de tarea Requiere de conocimientos previos específicos, acerca de los lugares geométricos vistos en el curso, presenta un desafío, cuál o cuáles se deben combinar para determinar el triángulo. Resulta ser un problema.

Complejidad

Exige conocer todos los lugares geométricos vistos en el curso. Exige interpretar el dato de la mediana y asociar al punto medio como centro de la circunferencia de radio la medida de la mediana.

Con el dato del nombre del ángulo y la amplitud, es necesario asociarlo al segmento AC dado antes y toda la información unirla en un arco capaz Es necesario saber trazar arco capaz y circunferencia con lápiz y papel. Interceptar las figuras, seleccionar los puntos que cumplen las dos condiciones a la vez y trazar el triángulo.

Identificar los pasos realizados, ordenarlos y buscar la expresión más precisa para comunicar cada paso.

Para acceder a la solución se necesita emplear conocimiento matemático,

analizar y armar un plan, por tal necesita proceso de conexión.
Requiere de conocimientos previos específicos, acerca de los lugares

geométricos vistos en el curso, presenta un desafío, cuál o cuáles se deben combinar para determinar el triángulo. Resulta ser un problema.

Exige conocer todos los lugares geométricos vistos en el curso.

Exige interpretar el dato de la mediana y asociar al punto medio como centro de la circunferencia de radio la medida de la mediana.

Con el dato de la altura significa tener una medida constante y asociarlo a los puntos de las paralelas.

Es necesario saber trazar circunferencia y paralelas a una distancia dada con lápiz y papel.

Interceptar las figuras, seleccionar los

puntos que cumplen las dos condiciones a la vez y trazar el triángulo.

Identificar los pasos realizados, ordenarlos y buscar la expresión más precisa para comunicar cada paso.

Para acceder a la solución se necesita emplear conocimiento matemático, analizar y armar un plan, por tal necesita proceso de conexión.
Requiere de conocimientos previos específicos, acerca de los lugares geométricos vistos en el curso, presenta un desafío, cuál o cuáles se deben combinar para determinar el triángulo. Resulta ser un problema.

Exige conocer todos los lugares geométricos vistos en el curso.

Saber qué es el circuncentro de un triángulo.

Aislar la propiedad del circuncentro sin tener un triángulo determinado.

Invertir desde donde se mira la propiedad,

no desde el circuncentro sino desde el vértice y ubicarlo como perteneciente a una circunferencia.

Con el dato del nombre del ángulo ACB y

el segmento $\mathrm{AB}$ asociar a los elementos

para determinar un arco capaz.

Es necesario saber trazar circunferencia y arco capaz con lápiz y papel.

Interceptar las figuras, seleccionar los puntos que cumplen las dos condiciones a la vez y trazar el triángulo.

Identificar los pasos realizados, ordenarlos y buscar la expresión más precisa para comunicar cada paso.

Para acceder a la solución se necesita emplear conocimiento matemático, analizar y armar un plan, por tal necesita proceso de conexión. 


\section{Actividades A7, A8, A9}

Tabla 9. Componentes del sentido espacial en actividades de aula: $A 7, A 8, A 9$

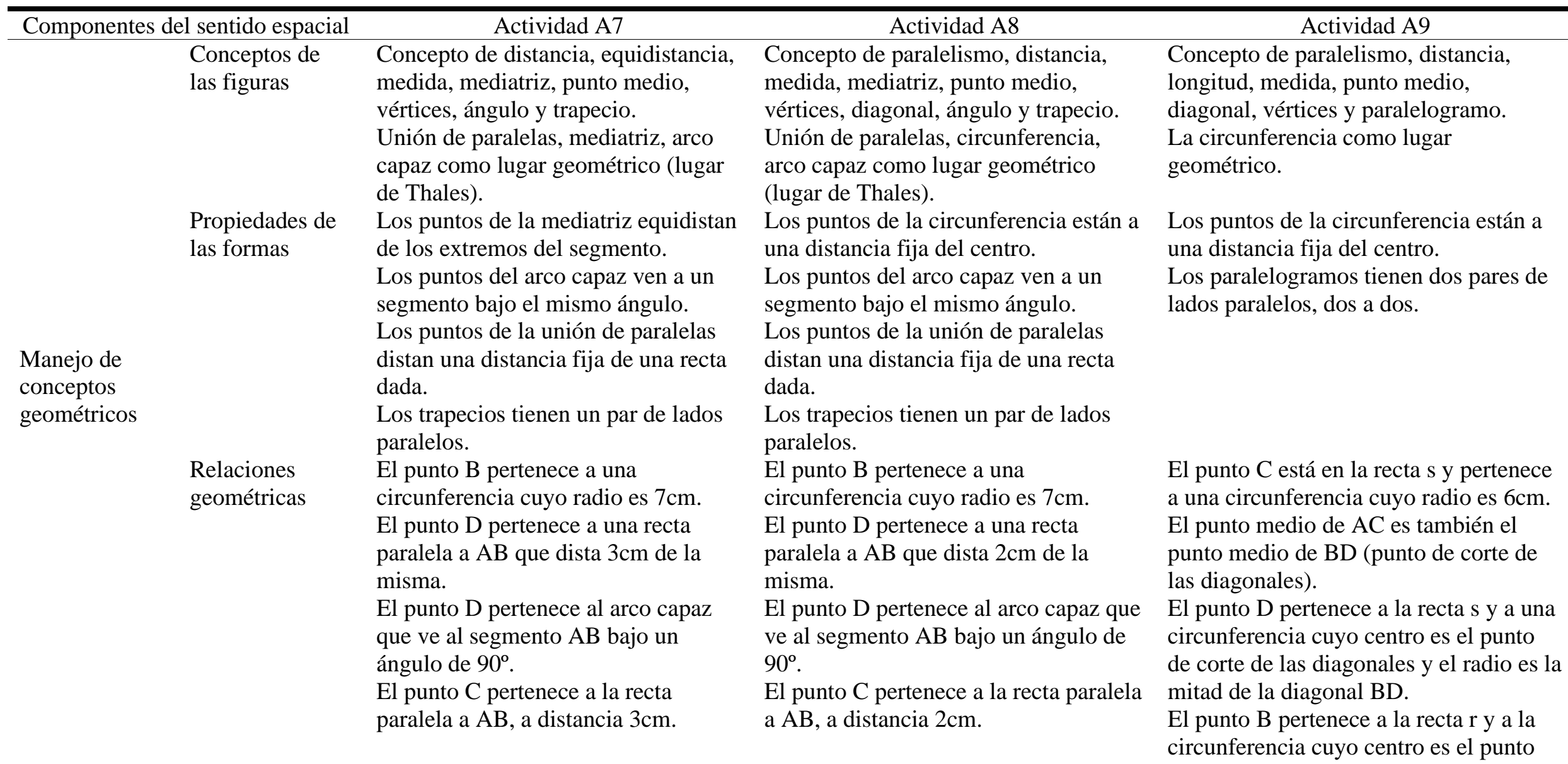


El punto $\mathrm{C}$ pertenece a la mediatriz del segmento DB por equidistar de los extremos.

Ubicación y movimientos

Asociar la medida de la altura del trapecio como la distancia a la recta $\mathrm{AB}$, para determinar la recta paralela. Asociar la amplitud del ángulo ADB, al segmento $\mathrm{AB}$ y al arco capaz que determinan.

La posición del punto D como la intersección de dos lugares geométricos anteriores: la paralela y arco capaz.

Identificar que $\mathrm{C}$ pertenece a la mediatriz del segmento $\mathrm{DB}$, porque equidista de ellos.

También $\mathrm{C}$ debe pertenecer a la recta a la que pertenece $\mathrm{D}$ por ser paralela a $\mathrm{AB}$

La posición del punto $\mathrm{C}$ como intersección de la mediatriz y la paralela antes dichas.

Orientación Identificar que en igual condición que el punto D están D4. Los otros se descartan por ordenación consecutiva de vértices D2, D3.

Identificar que el punto $\mathrm{C} 2 \mathrm{se}$ descarta por no cumplir con ordenación consecutiva de vértices.

Coordinación Conocer y lograr el trazado del ojo-motor

procedimiento de construcción de la
El punto $\mathrm{C}$ pertenece a la circunferencia de centro $\mathrm{B}$ y radio $4 \mathrm{~cm}$.

Asociar la distancia en las rectas paralelas $\mathrm{AB}$ y $\mathrm{CD}$ como la medida de la altura del trapecio.

Asociar la medida del segmento BC como el radio de una circunferencia. Identificar que $\mathrm{C}$ pertenece a la paralela a $\mathrm{AB}$ y a la circunferencia de centro $B$ y radio $4 \mathrm{~cm}$.

Identificar el ángulo formado por la diagonal $\mathrm{BD}$ y el lado $\mathrm{AD}$ como el ángulo $\mathrm{ADB}$.

Asociar que el vértice $\mathrm{D}$ pertenece al arco capaz de $90^{\circ}$ que ve al segmento $\mathrm{AB}$.

La posición del punto D como la intersección de dos lugares geométricos anteriores: la paralela y arco capaz.

Identificar que en iguales condiciones que el punto $\mathrm{C}$ está $\mathrm{C} 2, \mathrm{C} 3$ y $\mathrm{C} 4$.

Identificar que en iguales condiciones que el punto D están D2, D3 y D4.

Identificar que se conservan las duplas C2D2, C3D3, C4D4 mediatriz, las paralelas y el arco capaz $90^{\circ}$ o circunferencia.

\section{Conocer y lograr el trazado del} mediatriz, las paralelas y circunferencia. procedimiento de construcción de la de corte de las diagonales y el radio es la mitad de la diagonal BD.

Asociar la longitud de la diagonal al radio de una circunferencia.

Identificar que $\mathrm{C}$ pertenece a la recta s $\mathrm{y}$ a la circunferencia de centro A y radio $6 \mathrm{~cm}$.

Asociar la medida de la diagonal BD con el diámetro de una circunferencia, cuyo centro es el punto medio (M) de AC.

La posición del punto D como la intersección de la recta s con la circunferencia de centro $\mathrm{M}$ y radio $3,5 \mathrm{~cm}$.

La posición del punto B como la intersección de la recta $\mathrm{r}$ con la circunferencia de centro $\mathrm{M}$ y radio $3,5 \mathrm{~cm}$.

Identificar que en iguales condiciones que el punto $\mathrm{C}$ está $\mathrm{C} 2$.

\section{Conocer y lograr el trazado del} procedimiento de construcción de la mediatriz y circunferencia. 


\begin{tabular}{|c|c|c|c|c|}
\hline \multirow[t]{6}{*}{$\begin{array}{l}\text { Habilidades de } \\
\text { visualización }\end{array}$} & $\begin{array}{l}\text { Percepción } \\
\text { figura-contexto }\end{array}$ & $\begin{array}{l}\text { Seleccionar uno de los posibles } \\
\text { puntos D y uno de los posibles } \\
\text { puntos C. }\end{array}$ & $\begin{array}{l}\text { Seleccionar uno de los posibles puntos } \\
\text { C y uno de los posibles puntos D. }\end{array}$ & $\begin{array}{l}\text { Seleccionar uno de los posibles puntos B } \\
\text { y D. }\end{array}$ \\
\hline & $\begin{array}{l}\text { Conservación de } \\
\text { la percepción }\end{array}$ & -- & -- & -- \\
\hline & $\begin{array}{l}\text { Percepción de la } \\
\text { posición en el } \\
\text { espacio }\end{array}$ & $\begin{array}{l}\text { Relacionar la posición del punto C } \\
\text { con D y seleccionar un de los } \\
\text { posibles para cada posición. }\end{array}$ & $\begin{array}{l}\text { Relacionar la posición del punto C con } \\
\text { D y seleccionar un de los posibles para } \\
\text { cada posición. }\end{array}$ & -- \\
\hline & $\begin{array}{l}\text { Percepción de } \\
\text { las relaciones } \\
\text { espaciales }\end{array}$ & $\begin{array}{l}\text { Determinar que la posición de } \mathrm{C} \text { y } \mathrm{D} \\
\text { teniendo en cuenta la posición de la } \\
\text { recta } \mathrm{AB} \text {. }\end{array}$ & $\begin{array}{l}\text { Determinar que la posición de C y D } \\
\text { teniendo en cuenta la posición de la } \\
\text { recta } A B \text {. }\end{array}$ & $\begin{array}{l}\text { Identificar que el punto medio de AC, M } \\
\text { es también punto medio de BD. } \\
\text { Determinar el punto B y D adecuados. }\end{array}$ \\
\hline & $\begin{array}{l}\text { Discriminación } \\
\text { visual }\end{array}$ & -- & -- & -- \\
\hline & Memoria visual & -- & -- & -- \\
\hline
\end{tabular}

Tabla 10. Características en actividades de aula: A7, A8, A9

\begin{tabular}{|c|c|c|c|}
\hline Características & Actividad A7 & Actividad A8 & Actividad A9 \\
\hline Contexto & $\begin{array}{l}\text { Construir un trapecio ABCD, es una } \\
\text { situación específicamente matemática, } \\
\text { perteneciente al ámbito académico, } \\
\text { situación científica. }\end{array}$ & $\begin{array}{l}\text { Construir un trapecio ABCD, es una } \\
\text { situación específicamente matemática, } \\
\text { perteneciente al ámbito académico, } \\
\text { situación científica. }\end{array}$ & $\begin{array}{l}\text { Construir un paralelogramo } \mathrm{ABCD} \text {, es una } \\
\text { situación específicamente matemática, } \\
\text { perteneciente al ámbito académico, situación } \\
\text { científica. }\end{array}$ \\
\hline $\begin{array}{l}\text { Datos del } \\
\text { enunciado }\end{array}$ & $\begin{array}{l}\text { Texto breve con los datos relevantes, } \\
\text { específicamente geométricos. }\end{array}$ & $\begin{array}{l}\text { Texto breve con los datos relevantes, } \\
\text { específicamente geométricos. }\end{array}$ & $\begin{array}{l}\text { Texto breve con los datos relevantes, } \\
\text { específicamente geométricos. } \\
\text { Representación gráfica que complementa la } \\
\text { información. Es relevante por la ubicación. }\end{array}$ \\
\hline Tipología de tarea & $\begin{array}{l}\text { Requiere de conocimientos previos } \\
\text { específicos, acerca de los lugares }\end{array}$ & $\begin{array}{l}\text { Requiere de conocimientos previos } \\
\text { específicos, acerca de los lugares }\end{array}$ & $\begin{array}{l}\text { Requiere de conocimientos previos } \\
\text { específicos, acerca de los lugares }\end{array}$ \\
\hline
\end{tabular}


geométricos vistos en el curso, presenta un desafío, cuál o cuáles se deben combinar para determinar el trapecio. Resulta ser un problema.

Complejidad

Saber qué es un trapecio.
Exige conocer todos los lugares

geométricos vistos en el curso.

Asociar el dato de la altura a una distancia constante y por tanto a paralelas.

Asociar que el vértice $\mathrm{C}$ y $\mathrm{D}$ se van a encontrar en esas paralelas.

Unir los datos del segmento AB y el ángulo ADB como elementos que determinan un arco capaz.

Una vez determinado y seleccionado el D, considerando que los vértices se nombran en forma consecutiva, se puede avanzar para determinar el $\mathrm{C}$.

Identificar que $\mathrm{C}$ se encuentra en la mediatriz de $\mathrm{B}$ y D, por el dato "equidista de B y D".

Interceptar las figuras diferentes para ir encontrando los vértices que faltan.

Saber trazar paralelas a una distancia dada, mediatriz y arco capaz de $90^{\circ}$ con lápiz y papel.

Para acceder a la solución se necesita emplear conocimiento matemático, analizar y armar un plan, por tal necesita proceso de conexión. geométricos vistos en el curso, presenta un desafío, cuál o cuáles se deben combinar para determinar el trapecio. Resulta ser un problema.

Saber qué es un trapecio.

Exige conocer todos los lugares

geométricos vistos en el curso.

Asociar el dato de la distancia entre

paralelas como la altura del trapecio y la

ubicación de esa distancia en un segmento

perpendicular a uno de los lados $\mathrm{AB}$ o $\mathrm{CD}$.

Identificar que conviene comenzar a

construir por el segmento $\mathrm{AB}$, en tanto que

es uno de los lados paralelos y se tiene la medida.

Asociar la medida del lado BC y el punto B como elementos de una circunferencia.

Formar el ángulo $\mathrm{ADB}$ de $90^{\circ}$ con los dato dados y asociarlo al segmento AB para construir el arco capaz.

Asociar que el vértice $\mathrm{C}$ y $\mathrm{D}$ se van a encontrar la paralela a AB.

Interceptar paralela y arco capaz de $90^{\circ}$ para encontrar D

Interceptar paralela y circunferencia de centro B para encontrar C.

Saber trazar paralelas a una distancia dada, mediatriz, circunferencia y arco capaz de

$90^{\circ}$ con lápiz y papel.

Para acceder a la solución se necesita

emplear conocimiento matemático, analizar y armar un plan, por tal necesita proceso de geométricos vistos en el curso, presenta un desafío, cuál o cuáles se deben combinar para determinar el trapecio. Resulta ser un problema.

Saber qué es un paralelogramo.

Exige ubicar la disposición de la

representación gráfica dada e incorporar a

esa representación los datos que se van

apareciendo.

Asociar la longitud de la diagonal AC como el radio de una circunferencia de centro $\mathrm{A}$.

Identificar que $\mathrm{C}$ se encuentra la intersección de la circunferencia de centro A y radio $6 \mathrm{~cm}$. y la recta $s$.

Asociar que BD por ser diagonal comparte el punto medio con $\mathrm{AC}$, un punto medio que no forma parte de los datos.

Determinar los elementos de una

circunferencia, con el punto medio y la mitad de la medida de BD como radio.

Exige conocer todos los lugares geométricos vistos en el curso.

Identificar qué permite comenzar a determinar los vértices buscados.

Saber trazar circunferencia y mediatriz con lápiz y papel.

Para acceder a la solución se necesita emplear conocimiento matemático, analizar y armar un plan, por tal necesita proceso de conexión. 
